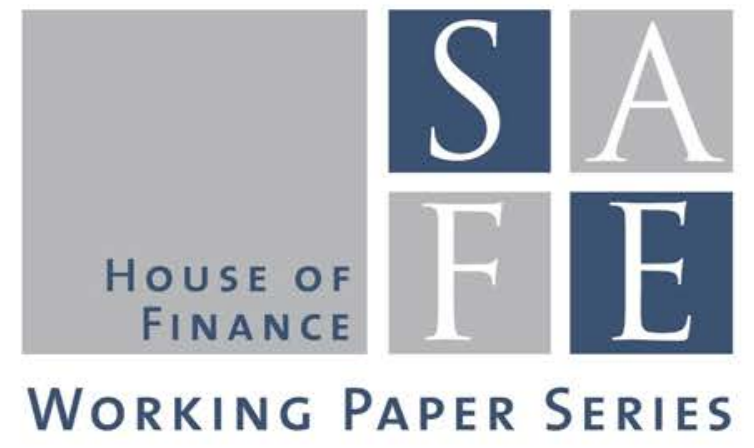

Loriana Pelizzon - Marti G. Subrahmanyam - Davide Tomio - Jun Uno

\title{
Sovereign Credit Risk, Liquidity, and ECB Intervention: Deus ex Machina?
}

SAFE Working Paper No. 95

SAFE I Sustainable Architecture for Finance in Europe A cooperation of the Center for Financial Studies and Goethe University Frankfurt 


\section{Non-Technical Summary}

European Sovereign Debt Crisis reached its apogee in summer 2011 with the downgrade of two of the major European economies, Spain and Italy. Due to the high interconnectedness between the public and private financial sectors in Europe, the risk of jeopardizing the whole EU economy and also economies beyond was concrete and high. The crisis was approached by many policy makers through fiscal action and monetary policy. In our paper, we examine the dynamic relationship between credit risk and liquidity in the sovereign bond market in the context of the ECB intervention (LTRO and OMT) arguing that monetary policy interventions are the most effective to calm the sovereign debt crisis down due to the strong relationship between credit risk and market liquidity.

We base our specific econometric approach on the Italian sovereign bond market utilizing a unique tick-by-tick dataset provided by Mercato dei Titoli di Stato (MTS) and selecting a window of 18 months around the EU sovereign debt crisis. We formulate and empirically test 3 hypotheses: i) the relationship between the credit risk of a sovereign bond and its liquidity is statistically significant, non-linear and credit risk driven, ii) the monetary policy interventions of the ECB affect the dynamics of the relationship between credit risk and market liquidity, iii) global systemic risk factors, approximated by a set of state variables, may affect market liquidity.

Our main findings are that, prior to the ECB interventions, the relationship between credit risk and market liquidity was strong and dependent not simply on the dynamics of credit risk but also on its level. In fact, empirical evidence confirms our hypothesis that Italy's creditworthiness significantly determined market liquidity of sovereign bonds in a non-linear way with a break point set at $500 \mathrm{bp}$ of the CDS spread. Moreover, we demonstrate the effectiveness of the LTRO program by showing that, after the quantitative ease provided by the $E C B$, no significant change in the relationship between credit risk and market liquidity was observable despite the CDS spread breached the 500 bp threshold. Finally, we find that, among the tested global systemic risk factors, the only state variable affecting market liquidity after the ECB intervention is the global funding liquidity CCBSS. Thus, ECB action not only improved the liquidity of the market but substantially loosened the link between credit risk and market liquidity.

Concluding, our paper provides a relevant indication for policy makers and regulators: the LTRO program, with the objective of providing short-term liquidity to banks, has shown that the channel from bank bailout to sovereign risk can also be reversed. Offering liquidity to banks may improve market liquidity of sovereign bonds and, indirectly, reduce sovereign risk. 


\title{
Sovereign Credit Risk, Liquidity, and ECB Intervention: Deus ex Machina? *
}

\author{
Loriana Pelizzon Marti G Subrahmanyam Davide Tomio Jun Uno \\ First draft: September 2013. This draft: March 2015
}

\begin{abstract}
This paper examines the dynamic relationship between credit risk and liquidity in the sovereign bond market in the context of the European Central Bank (ECB) interventions. Using a comprehensive set of liquidity measures obtained from a detailed, quote-level dataset of the largest interdealer market for Italian government bonds, we show that changes in credit risk, as measured by the Italian sovereign credit default swap (CDS) spread, generally drive the liquidity of the market: a 10\% change in the CDS spread leads a $11 \%$ change in the bid-ask spread. This relationship is stronger, and the transmission is faster, when the CDS spread is above the 500 basis point threshold, estimated endogenously, and can be ascribed to changes in margins and collateral, as well as clientele effects. Moreover, we show that the Long-Term Refinancing Operations (LTRO) intervention by the ECB weakened the sensitivity of the liquidity provision by the market makers to changes in the Italian government's credit risk. We also document the importance of market-wide and dealer-specific funding liquidity measures in determining the market liquidity for Italian government bonds.
\end{abstract}

Keywords: Liquidity, Credit Risk, Euro-zone Government Bonds, Financial Crisis, MTS Bond Market

JEL Classification: G01, G12, G14.

\footnotetext{
${ }^{*}$ Ca' Foscari University of Venice and Goethe University Frankfurt, Stern School of Business at New York University, Copenhagen Business School, and Waseda University, respectively. We thank Einaudi Institute of Economics and Finance, the NYU Stern Center for Global Economy and Business, and the NYU-Salomon Center, the project SYRTO of the European Union under the 7th Framework Programme (FP7-SSH/2007-2013 - Grant Agreement n 320270), the project MISURA, funded by the Italian MIUR, and the SAFE Center, funded by the State of Hessen initiative for research, LOEWE, for their financial support. We thank Antje Berndt, Monica Billio, Rohit Deo, Rama Cont, Clara Vega, Eric Ghysels, Kenneth Singleton, and participants at the CREDIT 2013 Conference, Venice, the American Finance Association 2014 meetings, Philadelphia, the NYU-Stern Volatility 2014 Conference, the Financial Management Association conference in Tokyo, the 2nd Conference on Global Financial Stability and Prosperity (Sydney), the European Finance Association 2014 Conference, the First International Conference on Sovereign Bond Markets, the Multinational Finance Society Conference, and seminars at the NY Fed, Federal Reserve Board, ECB, Bank of England, Bank of Italy, Italian Department of Treasury, Goethe University, University of Mannheim, Frankfurt School, EIEF Institute, and Vienna University of Economics and Business Administration, for their insightful comments. We thank Stefano Bellani, Mitja Blazincic, Alberto Campari, Alfonso Dufour, Carlo Draghi, Peter Eggleston, Sven Gerhardt, and Davide Menini for sharing their thorough understanding of market practice with us. We also thank the MTS group for providing us with access to their datasets. The views expressed in the paper are solely those of the authors. We are responsible for all remaining errors. Corresponding author: Loriana Pelizzon, loriana.pelizzon@unive.it.
} 


\section{Introduction}

The challenges facing the governments of the GIIPS countries (Greece, Ireland, Italy, Portugal and Spain) in refinancing their debt marked the genesis of the Euro-zone sovereign debt crisis. Following a series of credit rating downgrades of three countries on the Euro-zone periphery, Greece, Ireland and Portugal, in the spring of 2010, the crisis spread throughout the Euro-zone. The instability in the Euro-zone sovereign bond market reached its apogee during the summer of 2011, when the credit ratings of two of the larger countries in the Euro-zone periphery, Italy and Spain, were also downgraded. This culminated in serious hurdles being faced by several Euro-zone countries, causing their bond yields to spike to unsustainable levels. The crisis has abated to some extent, due in part to fiscal measures by the European Union (EU) and the International Monetary Fund (IMF) but mostly thanks to the intervention by the European Central Bank (ECB) through a series of policy actions, including the Long-Term Refinancing Operations (LTRO) program, starting in December 2011.

The discussion in the academic and policy-making literatures on the Euro-zone crisis has mainly focused on market aggregates such as bond yields, relative spreads, and credit default swap (CDS) spreads and the reaction of the market to intervention by the Troika of the ECB, the EU and the IMF. Although the analysis of yields and spreads is useful, it is equally relevant for policy makers and market participants to understand the dynamics of market liquidity in the European sovereign debt markets, i.e., the drivers of market liquidity, particularly given the impact market liquidity has on bond yields, as documented in the previous literature on asset prices.

In this paper, we address the latter issue and analyze the inter-relationship between market liquidity and credit risk, as well as the effect of the funding liquidity of the market makers, and how this interrelationship has changed thanks to the ECB interventions. Why is the linkage between credit risk and market liquidity of considerable interest to monetary economists and policy makers, such as central bankers and public debt managers? First, market liquidity has an important influence on interest rates, the key economic aggregates that monetary policy actions, such as quantitative easing, attempt to control. Second, the major central banks of the world, including the Federal Reserve System, the Bank of England, the Bank of Japan, and the ECB, have employed unusually strong quantitative easing measures, which will ultimately have to be unwound, and a sound knowledge of the mechanisms affecting market liquidity in the sovereign bond market will be of paramount importance when this occurs. Third, monetary policy has a direct impact, not only on the level of short-term (and perhaps long-term) interest rates, but also on market liquidity and liquidity risk, as we demonstrate in this paper. Fourth, again as we show in this paper, monetary policy has an impact on the interplay between credit risk and market liquidity.

The Euro-zone sovereign crisis provides us with an unusual laboratory in which to study how the interaction between credit risk and illiquidity played out, in a more comprehensive framework than has been used in previous studies of corporate or other sovereign bond markets. In contrast to research on corporate bonds, which are generally traded over-the-counter (OTC), we have the advantage of investigating an exchange-traded market, using a unique, tick-by-tick dataset obtained from the Mercato dei Titoli di Stato (MTS), the world's largest electronic trading platform for sovereign bonds. With respect to the US Treasury and other sovereign bond markets, the presence of a common 
currency for sovereign issuers means that Italy's central bank, the ECB, is completely independent of its government. Hence, the central bank's monetary policy has a qualitatively different impact on its sovereign credit risk, as well as on the market liquidity of its sovereign bonds, compared to countries whose central banks are somewhat within the control of the sovereign. We are then able to investigate the dynamic relationship between credit risk and market liquidity, measured by proxies constructed from intra-day data, on a daily basis, and analyze the effects of other risk factors, such as those measuring global systemic risk, the counterparty risk of the primary dealers, and funding liquidity. On top of this, we investigate how the ECB programs affected the relationship between credit risk and market liquidity. It is difficult to imagine another setting in which the confluence of these issues could be studied with such detailed data as are available in the context of the Euro-zone crisis.

To our knowledge, ours is the first paper to empirically investigate the dynamic relationship between market liquidity and credit risk in the sovereign bond market, particularly during a period of crisis. The existing literature has highlighted the theoretical relationship between bond yields and market liquidity, as well as that between funding liquidity and market liquidity (see Brunnermeier and Pedersen (2009)). We focus here on such an analysis in the Italian sovereign bond market, particularly since the inception of the Euro-zone crisis in July 2011. Italy has the largest sovereign bond market in the Euro-zone (and the third largest in the world after the US and Japan) in terms of amount outstanding, and is also a market that experienced substantial stress during the recent crisis. Hence, the Italian sovereign bond market is best suited to an in-depth analysis of the liquidity effects of the Euro-zone crisis, both in terms of the inter-linkages between sovereign credit risk and liquidity, and in terms of the effects on the credit risk and funding constraints of the market makers. It is important to emphasize that such an analysis cannot be performed in other large sovereign bond markets, such as those of Germany or France, since they were not as affected by the sovereign credit risk concerns. In fact, Germany actually attracted investors in a flight to quality, while the credit standing of France was affected only marginally. Thus, during this period, neither of these two "core" countries experienced the sharp decline in credit quality that makes the analysis of Italian sovereign bonds particularly interesting for our analysis. Moreover, the relative size of the Italian bond market compared to those of other "periphery" countries, e.g., Spain and Portugal, made it the primary market in which to acquire or short the credit risk of peripheral Europe.

The other consideration that leads us to choose the Italian sovereign bond market for our analysis is the availability of detailed market data. Italy remains the only large sovereign bond market with tick-by-tick data that are publicly available from a central market place, rather than being dispersed in an OTC market. Such granular data are simply not available in other countries with large amounts of sovereign bonds outstanding, such as Germany and France, and, certainly not, for the other countries in the Euro-zone periphery, such as Portugal and Spain. Our dataset, obtained from the MTS Global Market bond trading system, is unique for several reasons. This market is the largest interdealer trading system for Euro-zone government bonds, largely based on electronic transactions, and is, hence, one of the most important financial markets in the world, and liquid, with participation by a large number of active market makers 11 Moreover, Italy has the largest number of sovereign bonds

\footnotetext{
${ }^{1}$ While it is difficult to precisely quantify the market share of the MTS in terms of trading in Italian sovereign bonds, estimates provided to us by leading market participants range between $80 \%$ and $85 \%$ of interdealer transactions. For
} 
outstanding and the largest trading volumes on the MTS trading platform.

The main focus of our research in this paper is to determine the dynamic relationship between market liquidity and credit risk, as well as other risk factors such as global systemic risk, market volatility, and the funding liquidity risk of market makers. We study the effects of the ECB measures in the context of this dynamic relationship. We employ the time-series of a range of liquidity metrics, as well as CDS spreads, a measure of credit quality, to analyze the liquidity of Italian sovereign bonds during the period from June 1, 2011 to December 31, 2012. We allow the data to help us uncover how the relationship between credit risk and liquidity depends on the endogenous level of the CDS spread. In addition, we examine how these relationships were influenced by the interventions of the ECB.

First, we test the hypothesis that the relationship between the credit risk of a sovereign bond and its liquidity is statistically significant and, specifically, that the credit risk, as measured by the CDS spread, leads the liquidity, and not the other way around. We find that a $10 \%$ change in credit risk is followed by a $11 \%$ change in market liquidity. Further, we find that the coefficients of both contemporaneous and lagged changes in the CDS spread are statistically and economically significant in explaining the market liquidity of sovereign bonds, even after controlling for the lagged liquidity variable and the contemporaneous changes in other factors. In particular, we test whether global systemic risk and funding liquidity factors also affect market liquidity.

Second, we examine whether the relationship between credit risk and market liquidity is non-linear, and specifically whether it is significantly altered when the CDS spread crosses a certain threshold. We let the data identify the presence of such a CDS threshold effect, and find that the relationship between market liquidity and credit liquidity is different, depending on whether the Italian CDS spread is below or above $500 \mathrm{bp}$. We find not only that a change in the CDS spread has a larger impact on market liquidity when the CDS spread is above $500 \mathrm{bp}$, but that this relationship is instantaneous, while the lead-lag relationship is stronger for lower levels of the CDS spread. We interpret this finding, together with a change in the margins for bonds, in light of the predictions by Brunnermeier and Pedersen (2009).

Third, we analyze the impact of ECB intervention on the relationship between credit risk and liquidity. The threshold effect in CDS levels is present only until December 21, 2011. In fact, our test for an endogenous structural break indicates that, on December 21, 2011 (when the ECB allotted the funds of the LTRO program), the relationship between the two variables changes significantly. Thereafter, during 2012, after the large funding liquidity from the LTRO program became available to the market makers, changes in market liquidity still respond to changes in credit risk, but with a lagged effect, and with a significantly lower intensity while the only contemporaneous variable that affects market liquidity significantly is the global funding liquidity variable proxied by the Euro-US

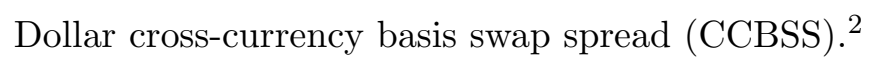

In Section III of the paper, we survey the literature on sovereign bonds, particularly the papers relating to liquidity issues. In Section III, we discuss the hypotheses to be tested in the paper and their economic motivation. In Section IV, we provide a description of the MTS market architecture,

\footnotetext{
Germany, France, Spain, and Portugal MTS market share ranges between 1\% and 10\% during the sovereign bond crisis.

${ }^{2}$ This spread represents the additional premium paid per period for a cross-currency swap between Euribor and US Dollar Libor. Market participants view it as a measure of the macro-liquidity imbalances in currency flows between the Euro and the US Dollar, the global reserve currency.
} 
the features of our database, our data filtering procedures and our liquidity measures. In Section $\mathrm{V}$, we present our descriptive statistics. Our analysis and results are presented in Section VI, and Section VII presents several robustness checks. Section VIII concludes.

\section{Literature Survey}

The dynamic relationship between credit risk and the market liquidity of sovereign bond markets has received limited attention in the literature, thus far. The extant literature on bond market liquidity seldom focuses on sovereign bond markets, with the exception of the US Treasury bond market; yet, even in this case, most papers cover periods before the current financial crisis and address limited issues related to the pricing of liquidity in the bond yields $3^{3}$ It is, therefore, fair to say that the relation between sovereign credit risk and market liquidity has not yet been investigated in the US Treasury market, possibly because US sovereign risk was not an issue until the recent credit downgrade by Standard \& Poor's. Similarly, there is a handful of papers on the European sovereign bond markets, and again, these papers generally examine a limited time period, mostly prior to the global financial crisis, and largely focus on the impact of market liquidity on bond yields. Hence, it is valid to conclude that the existing literature on the sovereign bond markets is fairly limited in depth and scope in the context of what we study in this paper: the relationship between credit risk and liquidity in the Euro-zone sovereign bond markets during the depths of the recent Euro-zone crisis. Nevertheless, we provide below a short summary of the existing literature so as to put our research in context.

We begin with a brief review of the papers on liquidity in the US Treasury bond market. Fleming and Remolona (1999) study the price and volume responses of the US Treasury markets to unanticipated macro-economic news announcements. Chakravarty and Sarkar (1999) study the determinants of the bid-ask spread in the corporate, municipal, and government bond markets in the US during 1995-1997, using data from the National Association of Insurance Commissioners. Fleming (2003) studies the realized bid-ask spread using GovPX data from 1996-2000, and finds that it is a better measure of liquidity than the quote size, trade size, on-the-run/off-the-run spread, and other competing metrics. Pasquariello and Vega (2006) analyze the announcement effects of macro-economic news using daily data from GovPX on the US Treasury bond market. In a related paper, Pasquariello, Roush and Vega (2011) study the impact of outright (i.e., permanent) open-market operations (POMOs) by the Federal Reserve Bank of New York (FRBNY) on the microstructure of the secondary US Treasury market. Goyenko, Subrahmanyam and Ukhov (2011) use quoted bid and ask prices for Treasury bonds with standard maturities, obtained from the Center for Research in Security Prices (CRSP) database, for the period from November 1967 to December 2005, to study the determinants of liquidity in the US Treasury bond market. They document that order flow surprises are linked to macro-economic news announcements.

There are a few papers in the literature analyzing data from the electronic trading platform similar to MTS known as BrokerTec, which was introduced in 2000. Fleming and Mizrach (2009) provide

\footnotetext{
${ }^{3}$ Specifically, the existing literature documents the direct impact of liquidity (e.g., Dick-Nielsen, Feldhütter and Lando (2012) among others) on bond yields and prices, but not the impact of credit risk on liquidity, or how credit risk affects the bond yields through bond liquidity. In this spirit, we need to establish the relation between credit risk and liquidity in order to then, in turn, quantify its effect on bond yields.
} 
a detailed description of this market and an analysis of its liquidity, showing the latter to be much greater than has been reported in prior studies using less detailed data from GovPX. Using more recent data from BrokerTec, Engle, Fleming, Ghysels and Nguyen (2011) propose a new class of dynamic order book models based on prior work by Engle (2002). They show that liquidity decreases with price volatility, but increases with liquidity volatility.

There is a vast literature on liquidity effects in the US corporate bond market, examining data from the Trade Reporting and Compliance Engine (TRACE) database maintained by the Financial Industry Regulatory Authority (FINRA) and using liquidity measures for different time periods, including the global financial crisis. This literature is relevant to our research both because it analyzes a variety of liquidity measures and because it deals with a relatively illiquid market with a vast array of securities. For example, Friewald, Jankowitsch and Subrahmanyam (2012a) show that liquidity effects are more pronounced in periods of financial crisis, especially for bonds with high credit risk, based on a sample of over 20,000 bonds, and employing several measures including the Amihud measure, the price dispersion measure, and the Roll measure, as well as bond characteristics and transaction measures such as the bid-ask spread. Similar results have been obtained by Dick-Nielsen, Feldhütter and Lando (2012), who investigate the effect of credit risk (credit ratings) on the market liquidity of corporate bonds $4^{4}$

In the context of European sovereign bond markets, Coluzzi, Ginebri and Turco (2008) use various liquidity measures to analyze Italian Treasury bonds, using data from the MTS market during the period 2004-2006. Dufour and Nguyen (2011) analyze data from 2003-2007 for the Euro-zone sovereign bond market to estimate the permanent price response to trades. Beber, Brandt and Kavajecz (2009) analyze the Euro-zone sovereign markets using MTS data for the period between April 2003 and December 2004. They show that most of the yield spread differences are accounted for by differences in credit quality, although liquidity plays some role for the bonds of higher-rated countries. Similar results have been reported for a more recent time period by Favero, Pagano and Von Thadden (2010). More recently, Bai, Julliard and Yuan (2012) have studied how liquidity and credit risks have evolved in the Euro-zone sovereign bond markets since 2006. They conclude that bond yield spread variations prior to the recent global financial crisis were mostly due to liquidity concerns but since late 2009 have been more attributable to credit risk concerns, exacerbated by contagion effects.

He and Milbradt (2014) provide an important theoretical framework for the analysis of corporate bonds traded in OTC markets. Building on the search cost literature pioneered by Duffie, Garleânu and Pedersen (2007), they show that, in a combined dealer-to-dealer and dealer-to-customer OTC market where bond holders are hit by liquidity shocks, the liquidity of defaultable bonds is increasing in the distance-to-default of the company that issued them. Moreover, they show that, in their model, a thinner market liquidity, following a cash flow decline, feeds back into the shareholders' decision to default, making the company more likely to default.

The paper whose analysis is most closely related to ours is that of Darbha and Dufour (2012), who use a range of liquidity proxies to analyze the liquidity component of Euro-area sovereign bond yield spreads prior to the global financial crisis (2004-2007), and during the crisis period (2007-2010). They

\footnotetext{
${ }^{4}$ Other recent papers quantifying liquidity in this market provide related evidence. See, for example, Edwards, Harris and Piwowar (2007), Mahanti, Nashikkar, Subrahmanyam, Chacko and Mallik (2008), Ronen and Zhou (2009), Jankowitsch, Nashikkar and Subrahmanyam (2011), Bao, Pan and Wang (2011), Nashikkar, Subrahmanyam and Mahanti (2011), Lin, Wang and Wu (2011), Feldhütter (2012), and Jankowitsch, Nagler and Subrahmanyam (2014).
} 
find that liquidity, particularly as measured by the bid-ask spread of non-AAA bonds, explains the dynamics of corresponding yield spreads better during the crisis than prior to the crisis.

More recent work has highlighted the effects of ECB interventions on bond yields, market liquidity, and arbitrage relationships between fixed income securities. Ghysels, Idier, Manganelli and Vergote (2013) study the effect of the Security Markets Programme (SMP) intervention on the first and second moments of bond returns, using high-frequency data on ECB government bond purchases, and show that it was successful in reducing both bond yields and volatility. Corradin and Rodriguez-Moreno (2014) document the existence of unexploited arbitrage opportunities between European sovereign bonds denominated in Euros and in Dollars, as a consequence of the SMP. Eser and Schwaab (2014) and Mesters, Schwaab, and Koopman (2014) show long- and short-term effects of the ECB interventions on European bond yields. Finally, Corradin and Maddaloni (2015) and Boissel, Derrien, Örs and Thesmar (2014) investigate the relationship between sovereign risk and repo market rates during the European sovereign crisis.

There are several important differences between the prior literature and the evidence we present in this paper. First, we are among the first to focus on the relationship between liquidity (rather than yield spreads) in the cash bond market and credit risk, especially in the context of sovereign credit risk. Second, while most of the previous literature spans past, and thus more normal, time periods in the US and Euro-zone markets, the sample period we consider includes the most relevant period of the Euro-zone sovereign crisis, that since mid-2011, when both Italy and Spain experienced a series of rating downgrades that spread instability both to other European countries (including France, and later on even Germany) and to many European banks. Third, our focus is on the interaction between credit risk and liquidity, i.e., how credit risk affects illiquidity and vice versa, which has been of particular interest since the onset of the Euro-zone crisis. In particular, we examine the dynamics of the interaction between credit and liquidity, tracing these effects over time. This is in contrast to the prior literature on both corporate bonds and, to a lesser extent, sovereign bonds, which focuses only on the static cross-sectional relationship between credit quality and liquidity rather than its time-series property. Fourth, we examine the impact of monetary policy interventions on the linkage between credit risk and liquidity, in the context of ECB policies over the past few years, to measure and document their differential effects.

\section{Hypothesis Development}

In this section, we provide an overview of the questions we pose and the hypotheses we test in our research. In motivating these hypotheses, we draw upon the results from the broad microstructure literature. We also take into account the specific institutional aspects of the Italian sovereign bond market, wherever appropriate.

H1 The Dynamics of Credit Risk and Liquidity: Credit risk is a significant factor in the determination of the market liquidity of Italian sovereign bonds.

We expect an increase in credit risk to increase the market illiquidity of the bond. This prediction

follows from several classical microstructure models: The inventory models interpret credit risk as one 
of the risks of the security, and an increase in the risk of a security means a riskier inventory, leading to a withdrawal of liquidity offered on the market by the market makers. If there is uncertainty regarding the recovery value of the asset, models based on asymmetry of information would suggest that the higher is the credit risk, the more likely is a credit event in the future. Hence, the more valuable is the private information on the underlying value of the security, the higher the bid-ask spread, leading to the same prediction.

Finally, a hypothesis similar to ours is presented in a search cost model by He and Milbradt (2014), who show that, in a market where bond holders are subjected to liquidity shocks, an increase in the credit risk of a company will cause the liquidity of its bonds to shrink. At the same time, a decrease in the bonds' market liquidity will cause the equity holders to make the company default earlier. While He and Milbradt's model is specifically developed under the assumption that the bonds are issued by a corporation and traded by dealers in an OTC market, the intuition of the liquidity of an asset being adversely affected by its credit risk applies under broader conditions, as previous microstructure models showed.

The literature pioneered by Bagehot (1971), Glosten and Milgrom (1985), Kyle (1985), and Easley and O'Hara (1987) argues that asymmetry of information about the value of an asset has a positive impact on illiquidity, in particular the bid-ask spread, in a quote-driven equity market. The intuition is that, if the market maker anticipates that there is a higher probability of trading with a market participant with superior information, she will raise her bid-ask spread for all participants to compensate for this possibility. As argued by Kyle, this effect translates into other proxies for liquidity, such as volume, market breadth, depth, and price impact. In this context, this asymmetry of information relates to the assessment of credit risk by various agents in the market, i.e., the probability of default and the defaulted bond's recovery value. Hence, the asymmetry of information will be most pronounced ahead of a credit event: the more likely is the occurrence of the credit event (i.e., the higher the credit risk), the more valuable will be the private information of the traders as opposed to the market makers, and therefore, the more the market maker will widen the asset's bid-ask spread. As argued in He and Milbradt (2014), the qualitative results of models based on search costs would not change if asymmetry of information was the driving force rather than search costs.

Inventory models of microstructure (such as Garbade and Silber (1976), Garman (1976), Amihud and Mendelson (1980), and Ho and Stoll (1980)) support the hypothesis of credit risk negatively affecting market liquidity, as they conclude that the greater is the risk of an asset, the greater will be the aversion of market makers to hold the asset (long or short), due to its opportunity costs, and hence the higher will be the bid-ask spread they post. To the extent that the asymmetry of information about an asset is correlated with its underlying risk, the two strands of the microstructure literature, based on inventory models and asymmetry of information, lead to the same conclusion: an increase in the (credit) risk of an asset adversely affects its liquidity.

In the remainder of this paper we study the effect of a change in credit risk on the market liquidity. Nonetheless, we acknowledge in this section that an increase in credit risk could affect the liquidity provided by a bond market maker either directly, since an increase in credit risk affects the inventory concerns of the market maker, or indirectly, as an increase in the credit risk would augment the value of private information, due to the uncertainty regarding the expected recovery in case of the more 
likely credit event. While we do not aim to disentangle the two interpretations, both the asymmetry of information and the inventory cost literatures imply that an increase in credit risk causes the market maker to diminish the provision of market liquidity.

Finally, a similar conclusion follows from risk management practices based on value-at-risk (VaR) models used widely by market participants, particularly the market makers. In many cases, the market makers are part of the major international banks, which have come under increasing pressure to maintain their capital adequacy since the advent of the global financial crisis. A portfolio with an excessively large VaR, based on the assessment of credit risk, erodes the dealers' buffer risk capacity, implying a greater aversion of the dealer to holding the asset, which results in the dealer setting higher bid-ask spreads (lowering market liquidity). The link between the practice of risk management based on VaR models and our hypothesis also has implications for the dynamics of the relationship between credit risk and market liquidity: risk constraints are typically based on the agent's risk exposure on the previous day. That is, day $t$ liquidity depends on the VaR calculated at the end of day $t-1$. In periods of market stress, however, the VaR is often monitored at an intraday frequency, implying that day $t$ liquidity will depend on the contemporaneous, day $t$, credit risk. We address this practice-based implication in our analysis of the dynamic relation between Italian credit risk and market liquidity.

The prior literature on bond markets has focused on the distinction between the two components of the bond yield spread: the liquidity component and the credit risk component $5^{5}$ We take a step back and argue that, although both market liquidity and credit risk are priced cross-sectionally in the bond yield spread so that more liquid and safer bonds trade at a premium, there are important dynamic elements closely linking market liquidity to credit risk. For example, the market's perception of credit risk could itself depend on market liquidity, especially under conditions of market stress, as posited by He and Milbradt (2014), which we explicitly address in this hypothesis. To the best of our knowledge, ours is the first formal study to present empirical evidence on the dynamic relationship between credit risk and market liquidity, exploiting the time-series evolution of credit risk, rather than cross-sectional differences in credit ratings. While previous work has emphasized the cross-sectional differences in liquidity between bonds of companies with varying creditworthiness, there has been very little work on the (time-series) dynamic relationship between credit risk and market liquidity.

Based on the theoretical background presented in this section, we expect the change in credit risk to be a relevant variable in characterizing the dynamics of liquidity in the market through the inventory and risk concerns of the market makers. Hence, we investigate whether there is any leadlag relationship between credit risk and illiquidity, and the directionality of this relationship. We test whether the increase in credit risk drives the reduction of liquidity in the bond market or vice versa, i.e., whether the low liquidity in the bond market increases the CDS spread, or the other way around. We attempt to define, with a lead-lag analysis in a Granger causality setting, which of the two economic variables leads the other, albeit in a statistical manner.6 While it may be argued that there is a stronger theoretical basis for credit risk influencing liquidity than for the opposite, we let the data inform us about this interaction.

\footnotetext{
${ }^{5}$ See Friewald, Jankowitsch and Subrahmanyam (2012a) and Dick-Nielsen, Feldhütter and Lando (2012) for a recent investigation of this argument in the context of corporate bonds.

${ }^{6}$ We address the contemporaneous interaction between the two variables in detail in Appendix B, via instrumental variable analysis.
} 
Global systemic factors may potentially affect market liquidity, on top of security-specific credit risk concerns, for example through the inventory channel, the increase in the risk aversion of market makers and traders in general, and through obligor-specific uncertainty and asymmetry of information. We test for the significance of widely known components of systemic risk: global uncertainty and appetite for risk, as measured by the US volatility index, USVIX, and the increase in the cost of funding due to the banking crisis, measured by the Euribor-German T-Bill spread (Euribor - DeTBill), the European counterpart to the TED spread used by Brunnermeier (2009) and several others. As a proxy for the (dollar) funding liquidity of Euro-zone banks, we also include the CCBSS. As explained by Baba, Packer and Nagano (2008) and Baba (2009), cross-currency basis swaps are used by banks to finance themselves in foreign currencies when the interbank market in the home currency is illiquid, and the market for these swaps is particularly active during periods of financial crisis.

H2 Non-linearity of the Relationship in the Credit Risk: The dynamic relationship between credit risk and market liquidity is non-linear in the creditworthiness of the sovereign.

This hypothesis is motivated by observations by market makers, portfolio managers and regulators, which suggest that the credit risk-liquidity relationship shifted as the credit quality of the Italian sovereign was eroded during the crisis. In the period under consideration, several economic and political events occurred that caused the level of credit risk to increase more than threefold (the CDS spread shot up from $145 \mathrm{bp}$ to $592 \mathrm{bp}$ ). Several conceptual arguments can be advanced for such a structural shift in the relationship. First, the adverse change in credit quality was generally accompanied or followed by downgrades in the credit rating, altering the clientele of investors who were able to hold Italian sovereign bonds. Second, margins in the repo markets are generally raised in response to a decline in credit quality, which would then have made it more expensive for investors to hold Italian sovereign bonds, hence affecting their liquidity. Third, in the presence of a sharp decline in credit quality, internal (and external) models of risk-weighting and illiquidity used by banks, a major investor segment, would necessarily predict an increase in the capital required to support the higher level of risk.

This structural break is likely to be particularly important when the worsening of creditworthiness suggests an upcoming credit rating downgrade to below investment grade, at which point the clientele effects are exacerbated. The rule of thumb for traders is that this occurs when the CDS spread goes above $500 \mathrm{bp}$, when the structural shift is likely to fundamentally alter the relationship between credit risk and market liquidity $]^{7}$ It needs to be emphasized that the existence of this threshold can be distinguished from any potential credit downgrade of Italian sovereign bonds. Indeed, even though there were some sharp credit downgrades for other European governments, and despite the sharp spike in its sovereign CDS spread, Italy maintained its investment grade rating throughout the period of our study 8

\footnotetext{
${ }^{7}$ This threshold of $500 \mathrm{bp}$ is also used by clearing houses, such as the Depository Trust and Clearing Corporation (DTCC) and LCH.Clearnet, to switch between the quotation of CDS contracts from a yield basis to one from a price basis, leading to more stringent margining. See also Footnote 33

${ }^{8}$ Changes in the credit risk of a country might encourage market participants to desert the country's primary bond auctions. However, Italian primary bond auctions (both for new issues and reopenings of existing issues) were always successful during this period, with participants consistently bidding for a larger quantity than was offered, as we show
} 
Parallel arguments for these effects have been proposed in the literature based on the actions of agents in a crisis. For example, Duffie, Garleânu and Pedersen (2007) argue that liquidity is more important in crisis periods, when inventory holding costs and search costs are higher, and asymmetric information is more significant 9 Moreover, a greater proportion of investors could shorten their investment horizons in a period of crisis. For example, both mutual funds and hedge funds could face the possibility of redemptions or be forced to meet VaR requirements and margin calls, and would, therefore, wish to hold more liquid assets to address those eventualities (see, e.g., Sadka (2010)). Individual investors could shift more of their portfolios from illiquid to liquid assets as they turn more risk averse, rendering already illiquid assets even more so, in a vicious cycle. Market makers may also face more severe funding constraints based on accentuated risk aversion, as well as a reduction in their risk limits in a crisis. In this vein, we investigate Hypothesis 2, letting the data inform us whether there is a level of CDS above which there is a statistically significant change in the relationship between changes in CDS spreads and changes in market liquidity variables 10 While we have ex ante reasons to expect $500 \mathrm{bp}$ to be a likely threshold, we allow the data to identify endogenously the presence of a structural break and its value, and then turn towards how the relationship between credit risk and liquidity would differ above and below this empirically determined threshold.

H3 Policy Intervention and Structural Breaks: The monetary policy interventions of the central bank affect the dynamic relationship between credit risk and market liquidity.

By virtue of its status as the central bank of the Euro-zone, the ECB has a major influence on its sovereign bond markets, while being virtually independent of the actions of the governments of individual countries. The ECB's monetary intervention takes many forms, ranging from jawboning and formal guidance by its board members, in particular its President, to the injection of liquidity into the major banks in the Euro-zone, which themselves hold these bonds, and even to direct purchases of sovereign bonds in the cash markets. During the Euro-zone crisis, the policy interventions by the ECB consisted of (i) the SMP, initiated in May 2010, (ii) LTRO, announced and implemented in December 2011, (iii) policy guidance, and (iv) OMT, also announced in December 2011. A significant event, classified under (iii) in the judgment of several market observers we spoke to, was the speech by Mario Draghi, the ECB President, in July 2012, which unveiled the potential for new tools to ease the European sovereign debt crisis. Against the backdrop of each of these policy interventions, we next investigate whether the nature of the dynamic relationship between credit risk and liquidity is likely to undergo a change when the macro-economic regime shifts due to the policy intervention.

The SMP was initiated in May 2010 in the aftermath of the Greek debt crisis, which spilled over into the sovereign debt markets of several countries in the Euro-zone 11 The distinctive feature of the

in Section Int.I of the internet appendix.

${ }^{9}$ There is empirical support for this hypothesis in the context of the US corporate bond market in the work of Friewald, Jankowitsch and Subrahmanyam (2012a), Bao, Pan and Wang (2011), Feldhütter (2012), and Dick-Nielsen, Feldhütter and Lando (2012).

${ }^{10}$ We use the threshold test proposed by Hansen (2000) to investigate this structural break in the level of CDS, as discussed in Appendix C.

${ }^{11}$ The ECB defines the SMP as follows: "Interventions by the Eurosystem in public and private debt securities markets in the euro area to ensure depth and liquidity in those market segments that are dysfunctional. The objective is to restore an appropriate monetary policy transmission mechanism, and thus the effective conduct of monetary policy oriented 
program is the direct purchase of sovereign debt securities in the open market by the ECB with the intent of retaining them on its balance sheet until maturity ("hold-to-maturity strategy"). It should be noted that several features of the program were not made explicit to the public at that time, nor have they been at any time since. In particular, neither the amounts proposed to be spent, nor the time frame over which the purchases would occur, nor the specific securities that would be purchased, were announced. Furthermore, the ECB does not provide a breakdown describing the composition of these assets by national origin of issuance, maturity, coupon, or other characteristics ${ }^{12}$

The SMP intervention could arguably have affected both the variables of interest in our study: It could have restored market liquidity, at least temporarily, in the Italian bond market and, through the increase in the demand for these bonds, it could have reduced their yield and, therefore, contemporaneously reduced the CDS spread. Consistent with Hypothesis 1, the SMP intervention could have affected the relationship between a change in credit risk and the resulting change in liquidity, by affecting market sentiment and, hence, the perception of investors regarding the risk of the Italian sovereign.

The second intervention measure, LTRO, provided three-year funding of $€ 489$ billion on December 21, 2011 and $€ 523$ billion on February 29, 2012. The long-term maturity of this massive funding action was unprecedented in ECB policy history, and even globally 13 Not unlike the situation surrounding the SMP, information regarding the LTRO, and, specifically, the banks' usage of LTRO funds, is very sparse. However, the event-like nature of its large funding liquidity shock qualifies it as a significant structural break impacting the market liquidity in the sovereign bond market through the availability of funding liquidity to market makers. We expect that the availability of massive amounts of mediumterm funding from the ECB, at unusually low interest rates, should have shifted the incentives of banks to hold sovereign bonds, since they would have been able to pledge them as collateral for their funding. As the incentive to hold sovereign bonds improved with the availability of cheap funding, market makers should have been less concerned with future changes in credit risk.

The third instrument of monetary policy intervention is the policy guidance offered by the ECB through various policy pronouncements made by its board members, most prominently the comment in July 2012 by the President, Mario Draghi, that they would do "whatever it takes" to address the Euro-zone crisis 14 This statement served to restore confidence in the markets and is also likely to have reduced both the CDS spread and market illiquidity in the Italian sovereign bond market.

The last type of intervention employed by the ECB is the OMT program, under which it has the

towards price stability in the medium term." See http://www.ecb.europa.eu/home/glossary/html/act4s.en.html

${ }^{12}$ Data on the outstanding aggregate value of the holding portfolio have since been published, albeit at a weekly frequency, without any reference to the specific date(s) during the week on which the securities were bought. Moreover, the ECB disclosed details of the securities holdings acquired under the program up to February 21, 2013, revealing a country-by-country breakdown. As of that date, Italian debt accounted for roughly half the total (€103 billion out of a total of $€ 218$ billion). Spain ranked second ( $€ 44$ billion), followed by Greece ( $€ 34$ billion), Portugal (€23 billion) and Ireland (€14 billion). See Corradin and Rodriguez-Moreno (2014).

${ }^{13}$ LTRO is formally defined by the ECB as follows: "A regular open market operation executed by the Eurosystem in the form of a reverse transaction." Funding actions are usually carried out through monthly standard tenders and normally have a maturity of three months, but on December 8, 2011, the ECB announced an unprecedented three-year LTRO consisting of a three-year collateralized loan, under the rubric of a set of non-standard measures launched by the ECB. See http://www.ecb.europa.eu/home/glossary/html/act4s.en.html.

${ }^{14}$ In his speech on July 26, 2012, at the Global Investment Conference in London, Mario Draghi stated: "The ECB is ready to do whatever it takes to preserve the Euro. And believe me, it will be enough." 
ability to make purchases ("outright transactions") in the secondary sovereign bond markets of the Euro-zone countries, subject to strict conditions 15 However, although the operation was announced on August 2, 2012, and the technical framework of these operations was formulated on September 6, 2012 , it has not been formally adopted thus far.

In the context of the relationship between credit risk and liquidity, a successful intervention would be one that affected the sensitivity of the market makers to changes in credit risk by providing them with improved funding liquidity, rather than one that affected either credit risk or market liquidity directly. While the SMP could be expected to directly affect bonds' prices and yields, and indirectly affect the perception of their issuers' credit risk, due to the buying pressure exerted by a large market participant (ECB), this would not provide significant funding liquidity to the market makers. The LTRO, on the other hand, aimed to provide large market players with access to cheap funding, i.e., it constituted a funding liquidity shock, which could be expected to translate into a steady provision of bond market liquidity. Finally, OMT has been announced, but not implemented, so far ${ }^{16}$

In sum, our third hypothesis considers and investigates the presence of a regime shift in the estimated relationship between credit risk and market liquidity around the dates of significant policy interventions by the ECB. Due to the large number of such interventions and their relevant implementation and announcement dates, we choose to allow the data to inform us of the presence of a structural break: Rather than test whether one specific date qualifies as a breaking point, we test whether any date could qualify as such, and link the most statistically significant candidate date to the ECB intervention schedule. Hence, we investigate endogenously whether a structural break is present in the data and if so when it takes place ${ }^{17}$

\section{MTS Market Structure and Description of Variables}

Our data consist of all real-time quotes, orders, and transactions that took place on the MTS European government bond market during our period of study, and are provided by the MTS Group. These high-frequency data cover trades and quotes for the fixed income securities issued by twelve national treasuries and their local equivalents: Austria, Belgium, Finland, France, Germany, Greece, Ireland, Italy, the Netherlands, Portugal, Slovenia, and Spain. The MTS system is the largest interdealer market for Euro-denominated government bonds and is made up of many markets, including the EuroMTS (the "European market"), EuroCredit MTS, and several domestic MTS markets. In this study, we will focus on the liquidity of Italian government bonds, regardless of whether the trading or quoting activity took place on the domestic or the European market.

The MTS trading system is an automated quote-driven electronic limit order interdealer market, in which market makers' quotes can be "hit" or "lifted" by other market participants via market orders.

\footnotetext{
${ }^{15}$ According to the ECB, "A necessary condition for Outright Monetary Transactions is strict and effective conditionality attached to an appropriate European Financial Stability Facility/European Stability Mechanism programme. [...] The involvement of the IMF shall also be sought for the design of the country-specific conditionality and the monitoring of such a programme." See http://www.ecb.europa.eu/press/pr/date/2012/html/pr120906_1.en.html.

${ }^{16}$ The more recent announcement of quantitative easing by the ECB on January 22, 2015, calls for the implementation of OMT on a large scale, although this has not been implemented on any scale, thus far.

${ }^{17}$ To investigate this issue, we perform a SupWald structural break test, a modified Chow test with an unknown break point (see Chow (1960), Andrews (1993), and Hansen (1997)). Appendix C presents the procedure in detail.
} 
EuroMTS is the reference electronic market for European benchmark bonds, which are bonds with an outstanding value higher than $€ 5$ billion ${ }^{18}$ Appendix A provides details of the market architecture, trading protocol, and data released for the MTS market.

The sample period of our study is from June 1, 2011 to December 31, 2012 19 The time period we analyze provides a good window in which to study the behavior of European government bond markets during the most recent part of the Euro-zone sovereign debt crisis and the period leading up to it. Our dataset consists of 152 Italian government bonds. Table 1 presents the distribution of these bonds in terms of maturity and coupon rate, between maturity groups as well as bond types. The maturity groups were chosen based on the time distance between each bond maturity and the closest whole year. As Table 1 shows, the large majority (in numbers) of the bonds analyzed have short maturities (from 0 to 5 years). All bonds considered in this analysis belong to one of the following types: Buoni Ordinari del Tesoro (BOT) or Treasury bills, Certificato del Tesoro Zero-coupon (CTZ) or zero coupon bonds, Certificati di Credito del Tesoro (CCT) or floating notes, or Buoni del Tesoro Poliennali (BTP) or fixed-income Treasury bonds. The vast majority of the bonds in our sample belong to the BOT and BTP types. We exclude inflation and index-linked securities from our analysis.

\section{INSERT TABLE 1 HERE}

\section{IV.I Description of Variables}

We measure bond liquidity for the MTS market by the daily Bid-Ask Spread, defined as the difference between the best ask and the best bid, per $€ 100$ of face value, proxying for the cost of immediacy that a trader will face when dealing with a small trade. We measure the bid-ask spread per bond at a five-minute frequency from the market open to the market close, namely from 8 AM to 5.30 PM, then average it per bond throughout the day, and finally average the daily bond measures across bonds to obtain a market-wide daily liquidity measure.

Since there is no consensus in the academic or policy-making literatures regarding the best metrics for assessing the liquidity of an asset, in Section VII.I, we report our results for other liquidity measures, covering a wide range of metrics that have been used extensively in the literature. However, as pointed out in Section VII.I, the bid-ask spread is correlated by more than $60 \%$ with other liquidity variables, making it an appropriate representation of market liquidity 20

The Italian-government-specific credit risk is measured by the spread of a senior five-year dollardenominated CDS contract obtained from Bloomberg. The choice of this proxy for sovereign credit risk is debatable. An alternative potential proxy for Italian sovereign risk could be the BTP-Bund yield spread. We prefer to avoid using the BTP-Bund yield spread because this variable is likely to be intimately connected to the bond quote and transaction prices that are also used to calculate our

\footnotetext{
${ }^{18}$ See also Dufour and Skinner (2004).

${ }^{19}$ The start date of this sample is dictated by the availability of detailed tick-by-tick, second-by-second, data from MTS. Prior to June 1, 2011, the MTS data on quotes and quote revisions were not quite as detailed. The end date is dictated by a major change in the market structure that was implemented in December 2012, and that changed the role of market makers acting in the European section of the MTS market. Fortuitously, the period we consider covers a large part of the Euro-zone crisis.

${ }^{20}$ Pelizzon, Subrahmanyam, Tomio and Uno (2013) study these liquidity proxies in a comprehensive manner in the context of the cross-section of the Italian sovereign bonds.
} 
liquidity measures. CDS spreads are obviously related to the BTP-Bund yield spread (as Figure 1 and Section Int.II of the internet appendix show), through arbitrage in the basis between them, but at least are determined in a different market. Moreover, as we show in Section Int.II of the internet appendix, there is no statistically significant lead-lag relationship between the two daily series, because the adjustment between them takes place on the same day, ${ }^{21}$

\section{INSERT FIGURE 1 HERE}

Finally, in order to control for and characterize the effect of global credit risk and funding liquidity, we employ several macro-economic indicators, most of which are common in the academic literature. The Euribor-DeTBill yield spread captures the (global) counterparty and credit risk and, thus, an increase in the cost of funding, and is measured as the difference between the three-month Euro-area Inter-Bank Offered Rate (Euribor) for the Euro, covering dealings from 57 prime banks, and the threemonth yield of the three-month German Treasury bill. As banks are more uncertain, they charge each other higher rates on unsecured loans; similarly, looking for high-quality collateral, they purchase safe Treasury bills, lowering their yields. This measure is the European counterpart of the TED spread used by, among others, Brunnermeier (2009). The USVIX, measuring global systemic risk, is the implied volatility index of S\&P 500 index options calculated by the Chicago Board Options Exchange (CBOE) and used widely as a market sentiment indicator. The CCBSS represents the additional premium paid per period for a cross-currency swap between Euribor and US Dollar Libor, and serves as a proxy for funding liquidity 22

\section{Descriptive Statistics}

Table 2, Panels A and B, presents the summary statistics for the market activity measures for Italian sovereign bonds traded on the MTS market and system variables, between June 2011 and December 2012, spanning the period of the Euro-zone sovereign crisis. The table reports statistics for the daily time-series of the market-wide variables: Trades, Volume, and Bid-ask Spread were calculated on a daily bond basis and then averaged across bonds to obtain the time-series. Quoted bonds is the time-series of the number of bonds quoted each day.

\section{INSERT TABLE 2 HERE}

The mean (median) number of bonds quoted each day on the MTS is 90 (90), and the daily volume of trading in the market is slightly above $€ 2$ billion ( $€ 1.9$ billion), which translates into a daily traded volume for each quoted bond of about $€ 30.5$ million. Based on these numbers, the daily trading volume in the Italian sovereign bond market (as represented by the MTS) is much smaller than in the US Treasury market, by a couple of orders of magnitude, with the average traded quantity in the

\footnotetext{
${ }^{21}$ In Section VII.II, we investigate whether the intraday volatility of the bond yield, as measured using the MTS transaction data, and the liquidity of the CDS market affect the liquidity, while controlling for the credit risk. These modifications do not significantly change the results, supporting our choice of the CDS spread as a measure of credit risk.

${ }^{22}$ All these variables were obtained from Bloomberg.
} 
latter being around $\$ 500$ billion per day ${ }^{23}$ The average daily trading volume in the MTS Italian bond market is even smaller than the US municipal market (around $\$ 15$ billion), the US corporate bond market (around $\$ 15$ billion), and the spot US securitized fixed income market (around $\$ 2.7$ billion in asset-backed securities, around $\$ 9.1$ billion in collateralized mortgage obligations, and around $\$ 13.4$ billion in mortgage-backed securities) 24

Our volume statistics are in line with the stylized facts documented in the previous literature, taken together with the consistent shrinkage of overall market volumes since the Euro-zone crisis began. Darbha and Dufour (2012) report that the volume of the Italian segment of the MTS market as a whole, over their 1,641-day sample, was $€ 4,474$ billion. This translates into an average daily volume of about $€ 3.8$ billion. Darbha and Dufour report that the daily volume per bond shrank from $€ 12$ million in 2004 to $€ 7$ million in 2007 . Their sample includes only coupon-bearing bonds; thus, their figures for overall market volume are not directly comparable to ours.

The daily number of trades on the MTS Italian sovereign bond market is 265 in total (or about 3 per bond), which is similar to the 3.47 trades a day per corporate bond on TRACE, as reported in Friewald, Jankowitsch and Subrahmanyam (2012a). Dufour and Nguyen (2011) report an average of 10 trades per day per Italian bond in an earlier period, between 2003 and 2007. As with the trading volume, the number of trades declined during the crisis period compared to earlier years. Our sample period covers the most stressed months of the Euro-zone crisis, when the creditworthiness of several European countries was seriously questioned by market participants. As we will show later, the liquidity in the MTS market was intimately related to the evolution of spreads in the sovereign CDS market, and varied just as drastically, as the time-series plots of the CDS spread and the Bid-Ask Spread in Figure 2 show. Up to the end of 2011, at the peak of the crisis, the two series share a common trend, which is not repeated in the second half of our sample.

\section{INSERT FIGURE 2 HERE}

The commonality in the two series in Figure 2 becomes particularly evident, for example, when one considers the highest spike for the Bid-Ask Spread ( $€ 4.48$ per $€ 100$ of face value), which happened on November 8, 2011. On that date, the Italian Prime Minister, Silvio Berlusconi, lost his majority in the parliament, which led to his resignation. The spike in the Bid-Ask Spread corresponds to a similar spike in the CDS Spread. The event clearly had medium-term effects, as both the Bid-Ask Spread and the CDS Spread persisted at high levels for about two months, before returning to the more moderate quantities in January 2012. In mid-2012, however, the CDS Spread reached levels close to $500 \mathrm{bp}$, while the Bid-Ask Spread oscillated around the time-series median value of $€ 0.42{ }^{25}$

\footnotetext{
${ }^{23}$ See, for example, Bessembinder and Maxwell (2008).

${ }^{24}$ Details for the corporate bond, municipal bond, and securitized fixed income markets are provided in Friewald, Jankowitsch and Subrahmanyam (2012a), Vickery and Wright (2010), and Friewald, Jankowitsch and Subrahmanyam (2012b) respectively.

${ }^{25}$ We conduct our analysis using a market-wide liquidity measure consisting of the average bid-ask spread across all bonds quoted on the market. Individual bonds differ from each other with regard to their bid-ask spread, depending on their time-to-maturity, coupon, and issue size. However, these bid-ask spreads across bonds co-move to a very large extent, making the average bid-ask spread across all bonds a reasonable representation of the liquidity of the overall bond market, as we show in Section Int.III of the internet appendix.
} 
The reasons for choosing to present our results based on the bid-ask spread as a measure of market liquidity bear mention. First, although our detailed dataset allows us to compute several liquidity measures, we present our results with regards to the quoted bid-ask spread measure because it is the most familiar and widespread measure of market liquidity. Thus, it allows for a direct comparison with the previous and contemporaneous literature on liquidity. Nonetheless, we repeat our results, presented in Section VI for the bid-ask spread, using other liquidity measures and report them in Section VII.I. Second, the large number of quotes that are aggregated into a single daily bid-ask spread time-series suggests that market makers are very active, and ensures that the computed spread is a precise estimate of their willingness to trade, since the quotes are firm. Finally, high-frequency quote updates indicate that accurate quoting in the MTS market is important for primary dealers under the supervision of the Bank of Italy. These quotes are, moreover, also used by officials at the Italian Treasury to evaluate (and eventually even disqualify) sovereign bond market makers.

The results of the Dickey-Fuller unit root test for the variables used in our empirical investigation are presented in Table 2 under the "Unit Root Test" columns for the levels of and differences in the variables. All our tests for the control variables and the CDS spread support the existence of a unit root, while the bid-ask spread shows a mean-reverting property. However, (i) the first-order autocorrelation for the liquidity measure is $76 \%$, and (ii) the unit root test did not reject the unit root null hypothesis when it was performed on the first half of the sample, for the period when the Euro-zone crisis first unfolded. In light of this fact, and in order to have a consistent, unique model for the whole data sample and to ensure well-behaved residuals, we perform our analysis in first differences.

As shown in Figure 1, the Italian CDS spread for our sample period ranges from 145 bp to 592 bp, with a mean of $401 \mathrm{bp}$ and a standard deviation of $108 \mathrm{bp}$, indicating the large changes in this variable during the period under study. Figure 4 shows the evolution of the macro-variables. The Euribor-DeTBill spread (Panel a)) also presents a significant level of volatility, with a daily standard deviation of $0.42 \%$, while the USVIX (Panel b)) ranges from $13.45 \%$ to $48 \%$. The CCBSS variable (Panel c)), which captures the general level of funding liquidity in the system, and should be close to zero in the absence of funding constraints, ranges from $0.20 \%$ to $1.06 \%$, indicating a large variability in the global liquidity conditions in the Euro-zone in the period considered. All the funding and credit variables suggest that the conditions in the Euro-zone financial system were at their worst around the third quarter of 2011, but improved somewhat during the first quarter of 2012, then worsened, although to a lesser extent, around June 2012, and continued to decline towards the end of that year.

\section{INSERT FIGURE 4 HERE}

The correlations between the credit, funding liquidity and market liquidity variables are shown in Table 3. The correlations between the variables in levels are presented above the diagonal, while those for the variables in differences are below the diagonal. In differences, bond market liquidity is most highly correlated with the Italian CDS Spread and the USVIX.

\section{INSERT TABLE 3 HERE}




\section{Results}

In this section, we address the research questions highlighted in Section III, focusing on the dynamic relationships between credit risk and market liquidity and the effect of the ECB's deus ex machina. In order to study the dynamics of the relationship between the credit risk of Italian government bonds, as measured by the CDS Spread, and the liquidity of the Italian government bonds, as measured by their Bid-Ask Spread, we first investigate, in Section VI.I, whether there is a lead-lag relationship between the two variables, using a Granger-causality test in a Vector Auto Regression (VAR) setting ${ }^{26}$

In SectionVI.II, we aim to better characterize the relationship using threshold regression techniques to show that the relationship between the two variables is non-linear in the level of the CDS Spread. Namely, a change in the CDS Spread affects the Bid-Ask Spread, and increasingly so, as the level of the CDS Spread increases. Finally, in Section VI.III, we investigate whether and how the dynamics of the relationship are affected by the ECB interventions using an endogenous structural break test that is described in detail in Appendix $\mathrm{C}$, and find that the injection of funding liquidity from the central bank lowered the sensitivity of market liquidity to the worsening credit conditions of the Italian sovereign.

\section{VI.I The Dynamics of Credit Risk and Liquidity}

H1 The Dynamics of Credit Risk and Liquidity: Credit risk is a significant factor in the determination of the market liquidity of Italian sovereign bonds.

We investigate the dynamic relationship between sovereign credit risk and market liquidity, controlling for global macro and funding liquidity variables, addressing the issue of whether the increase in credit risk drives the reduction of market liquidity or vice versa. We implement this analysis by estimating a VAR system that allows us to perform a Granger-causality test.

The Granger-causality test is a statistical notion of causality based on the relative forecasting power of two time-series for each other. It translates into time-series $j$ being said to "Granger-cause" timeseries $i$ if past values of $j$ contain information that helps predict $i$, above and beyond the information contained in past values of $i$ alone 27 The mathematical formulation of this test is based on linear regressions of the change in the Bid-Ask Spread, $\Delta B A_{t}$, and the change in the CDS Spread, $\triangle C D S_{t}$, on their $p$ lags. Since other variables can affect both the credit risk and the bond market liquidity, as we conjectured in Section III, and their omission would result in a misspecified system, we include in our VAR specification the global variables described in Section IV.I as "exogenous variables." These variables are exogenous in that we are not interested in studying the effect of the endogenous variables on their dynamics, only the opposite effect, thus describing the system using a VAR with eXogenous variables (VARX) model. The exogenous variables included in our estimations are the contemporaneous Euribor-German T-Bill spread, EuriborDeTBill, the US volatility index USVIX, and the cross-currency basis swap spread $C C B S S$.

\footnotetext{
${ }^{26}$ We conduct our analysis using the MTS data after winsorizing them at the $1 \%$ level to diminish the importance of outliers.

${ }^{27}$ For an analysis using a similar technique in the microstructure context, see Chaboud, Chiquoine, Hjalmarsson, and Vega (2014).
} 
Specifically, let $\triangle B A_{t}$ and $\triangle C D S_{t}$ be two stationary daily time-series, and $X_{t}$ a time-series $m$-vector of stationary exogenous variables. We can represent their linear inter-relationships using the following VARX model:

$$
\left(\begin{array}{c}
\Delta B A_{t} \\
\Delta C D S_{t}
\end{array}\right)=\left(\begin{array}{c}
K_{B A} \\
K_{C D S}
\end{array}\right)+\sum_{i=1}^{p}\left(\begin{array}{cc}
a_{11_{i}} & a_{12_{i}} \\
a_{21_{i}} & a_{22_{i}}
\end{array}\right)\left(\begin{array}{c}
\Delta B A_{t-i} \\
\Delta C D S_{t-i}
\end{array}\right)+\sum_{j=0}^{q} B_{j}\left(\begin{array}{c}
\Delta X 1_{t-q} \\
\Delta X 2_{t-q} \\
\vdots \\
\Delta X m_{t-q}
\end{array}\right)+\left(\begin{array}{c}
\epsilon_{B A t} \\
\epsilon_{C D S t}
\end{array}\right)
$$

where $\epsilon_{\mathbf{t}} \sim N(\mathbf{0}, \boldsymbol{\Omega})$, the $B_{j}$ s are 2-by-m matrices, and the $a_{i j_{p}}$ s are the $p$-lag coefficients of the model. This formulation allows for the presence of $m$ contemporaneous, and lagged (up to $q$ ), exogenous variables to control for factors that might affect the dynamics of the endogenous variables. We can conclude that $\triangle C D S$ Granger-causes $\triangle B A$ when the $a_{12_{p}} \mathrm{~s}$ are contemporaneously different from zero. Similarly, we can surmise that $\triangle B A$ Granger-causes $\triangle C D S$ when the $a_{21_{p}}$ s are contemporaneously different from zero. When both these statements are true, there is a feedback relationship between the two time-series.

The lag-length was chosen based on the corrected Akaike criterion, which suggests a lag-length of 3 for the endogenous variables and no lagged exogenous variables. The results of the Granger-causality test, with $p=3$ and $q=0$, for the relationship between the changes in the CDS Spread and the BidAsk Spread, are reported in Table 4, where we report the Wald test statistics for the contemporaneous significance of the cross-variable terms for each equation (the $a_{12} \mathrm{~s}$ for the bid-ask spread equation under $\Delta B A_{t}$, and the $a_{21}$ s for the CDS spread equation under $\left.\Delta C D S_{t}\right){ }^{28}$

\section{INSERT TABLE 4 HERE}

As the table shows, and as we argued in Section III, the CDS Spread Granger-causes liquidity in the bond market at a $1 \%$ level (the heteroskedasticity-robust Wald test is 16.20 and the $1 \%$ confidence value is 11.34 , and the bootstrapped results provide identical significance levels), while the opposite directionality is not significant at any of the usual confidence levels (the $p$-value is 0.94). As per Hypothesis 1, we find that a change in credit risk significantly affects the change in the market liquidity. The opposite relationship, however, posited in He and Milbradt (2014), is not statistically significant in our estimation. One possible explanation for this result may be that the arguments used by them in the context of corporate bonds do not necessarily apply to sovereign bonds, since sovereign defaults are less common, due to the availability of monetary and fiscal devices to forestall such extreme events.

The macro variables are significant in explaining the two variables. Specifically, the bond market illiquidity depends positively on the availability of funding liquidity for European banks and on the sentiment of the market, as measured by the CCBSS and USVIX, respectively. In untabulated results, however, the contemporaneous dependence of the macro variables does not lower the significance of the effect of (lagged) credit risk on market liquidity, although it contributes to lowering the residual cross-correlation.

\footnotetext{
${ }^{28}$ Throughout the paper, statistical significance is always determined on the basis of $t$-tests that are calculated using heteroskedasticity-robust standard errors.
} 
In order to interpret the dynamics of the system, we calculate the impulse response functions (IRF) for the relationships between the variables. We do this for the rescaled variables, so that they have a mean of 0 and a standard deviation of 1 , for ease of interpretation. Figure 5 presents the results, for which the $5 \%$ confidence bands were bootstrapped based on 5,000 repetitions. As shown in Panel (a) of the figure, a 1 standard deviation shock to the CDS Spread at time 0, corresponding to a $4.4 \%$ change, is followed by a change of 0.23 standard deviations in the Bid-Ask Spread, corresponding to a $4.8 \%$ increase in the same direction, and is absorbed by both variables in two days. Alternatively, it follows that a $10 \%$ change in CDS Spread is followed by a $11 \%$ change in Bid-Ask Spread. The results are, hence, both statistically and economically significant, and confirm the results of the Granger-causality tests presented above. The IRF in Panel (b) shows that a shock at time 0 to market liquidity lasts until time 1, but only affects market liquidity itself, indicating that the reaction of the CDS Spread to a shock in market liquidity is never different from zero, in line with the findings of the Granger-causality tests.

\section{INSERT FIGURE 5 HERE}

Since the focus of this study is the dynamics of the credit risk and bond market liquidity in relation to each other, and past values of bid-ask spread do not affect credit risk, as per Table 4, we focus solely on the bid-ask spread regression in the VARX system, augmenting it with the contemporaneous change in credit risk. This corresponds to a shift from a reduced-form to a structural approach to the VAR, where the contemporaneous causation runs from credit to liquidity. Since the ordering of the variables in this causation chain cannot be tested in the VAR setting (see e.g., Lütkepohl (1993)), we turn to instrumental variable (IV) methods to establish whether feedback between the contemporaneous $C D S$ Spread and Bid-Ask Spread changes - or, alternatively, other forms of endogeneity - is supported by the data. We do so to ensure that our specification does not disqualify the structural approach we take, or otherwise suggest the opposite relationship. In Appendix B, we show using several cohorts of valid and strong instruments that the CDS Spread is indeed not endogenous to the system, and hence its inclusion as a regressor is justified: the regression parameter attached to it in the bid-ask spread regression is unbiased and consistently estimated.

As both the lead-lag and the contemporaneous relationship, in the previous paragraphs and in Appendix B, respectively, indicate the direction of the Granger-causality, we only need focus in the rest of the paper on the causal effects on the liquidity measure (i.e. the $\Delta B A_{t}$ equation), in order to determine the dynamics of the system. This is sufficient to capture the dynamics of the creditliquidity relationship (including the effect of ECB interventions and potential non-linearities), given the lack of statistical support for causality in the opposite direction. Therefore, we regress changes in the liquidity measure, Bid-Ask Spread, on the contemporaneous changes in the CDS Spread, and their respective lags, and on the contemporaneous macro variables. Equation 2 presents our baseline regression specification for the remainder of the paper:

$$
\Delta B A_{t}=\alpha_{0}+\sum_{i=1}^{3} \alpha_{i} \Delta B A_{t-i}+\sum_{j=0}^{1} \beta_{j} \Delta C D S_{t-j}+\beta_{2} C C B S S+\beta_{3} U S V I X_{t}+\epsilon_{t}
$$


where $\Delta B A_{t}$ is the change in the bond-market-wide bid-ask spread from day $t-1$ to day $t$, and $\triangle C D S_{t}$ is the change in the CDS spread, as before. The statistically insignificant lags of the CDS

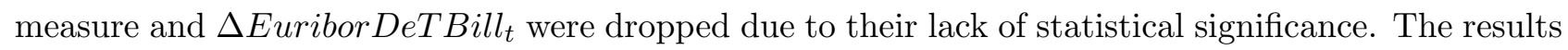
for Equation 2 are reported in Table 5 , Panel A 29

Comparing the parameters in Table 5 Panel A to those in Table 4 shows that adding the contemporaneous change in the CDS Spread does not modify our findings, with the exception of a lower level of statistical significance for the other contemporaneous variables. This was to be expected, since these other variables potentially proxy for changes in the credit risk. The lack of significance for the contemporaneous CDS spread change was also to be expected, when considering the low level of cross-residual correlation shown in Table 4 (8.2\%). Nonetheless, our baseline specification predicts the evolution of liquidity well, with a $R^{2}$ of $21.2 \%$. Moreover, the dynamics of the bid-ask spread are well accounted for, since the residuals show no autocorrelation according to the Durbin $h$-test and the Breusch-Godfrey serial correlation test (never significant at the $5 \%$ level or lower for lags up to 10 , with one exception).

\section{INSERT TABLE 5 HERE}

As for the dynamics of the system, the change in the CDS Spread has a lagged effect on market liquidity, i.e., the reaction of market liquidity, measured by the Bid-Ask Spread, to changes in the $C D S$ Spread, occurs on the next day. The Bid-Ask Spread also shows evidence of an autoregressive component, being strongly related to the change in the Bid-Ask Spread that took place the day before, with a negative sign: this suggests an overreaction adjustment dynamic in the Bid-Ask Spread, as shown already in the IRF of Figure 5 Panel (a). This effect can be ascribed to the actions of the market makers, who adjust their quotes as a reaction, not only to the changes in the traded price, but also to the changes in the quotes of the other primary dealers. A $1 \%$ increase in the CDS spread on day $t$ results in an increase in the bid-ask spread of $0.4 \%$ on day $t$ and a further increase of $0.8 \%$ on day $t+1$.

Regarding the significance of the lagged $\triangle C D S$ term, a partial explanation can be found in the timing of VaR-based models in practice. Since the calculation of the dealer's VaR generally takes place at the end of the day, the exposure to the credit risk is taken into account for the liquidity offered by the dealer only on the day following the credit shock, thus implying the significance of the lagged change in credit risk 30

\footnotetext{
${ }^{29}$ We also investigated a measure of dispersion of the market makers' Euro-Libor submissions to capture their funding liquidity difficulties, but the measure did not comove with other funding liquidity measures, so we chose $C C B S S$ over it.

${ }^{30}$ One variable that may also affect the inventory levels of market makers (e.g., through the risk management practices of dealer desks), and therefore market liquidity, is the volatility of the bond yield. In Section VII.II we repeat the analysis after including this variable and our results are robust to this inclusion. Moreover, we also test whether the $C D S$ Spread drives both changes in market liquidity and bond return volatility or whether the effects are the other way around, and show that it is the former relation that prevails, confirming that the analysis we have performed in this section is correct and robust to the insertion of volatility into the pool of endogenous variables.
} 


\section{VI.II The Non-linearity of the Relationship between Credit Risk and Liquidity}

H2 The Non-linearity of the Relationship between Credit Risk and Liquidity: The dynamic relationship between credit risk and market liquidity is non-linear in the creditworthiness of the sovereign.

Turning to Hypothesis 2, Equation 2 above implicitly assumes that the estimated relationship holds independent of the level of credit risk, in particular when the CDS Spread is above a particular threshold level. For the reasons discussed in Section III, on account of changes in the macro-economic environment, margin setting, and downgrade concerns, it is possible that the market makers' liquidity provision is more sensitive to changes in credit risk, when the CDS Spread breaches a particular threshold. We investigate this hypothesis by allowing the data to uncover the presence of a threshold in the level of the CDS Spread, above which a different relationship between changes in CDS and changes in market liquidity is observed. We use the test proposed by Hansen (2000), described in detail in Appendix C, to examine this hypothesis, estimating Equation 3 for different $\gamma$, where $I[C D S \leq \gamma]$ equals 1 if the condition is satisfied and 0 otherwise:

$$
\begin{aligned}
\Delta B A_{t} & =I[C D S \leq \gamma]\left(\alpha_{0}+\sum_{i=1}^{3} \alpha_{i} \Delta B A_{t-i}+\sum_{j=0}^{1} \beta_{j} \Delta C D S_{t-j}+\beta_{2} U S V I X_{t}+\beta_{3} C C B S S\right) \\
& +I[C D S>\gamma]\left(\tilde{\alpha}_{0}+\sum_{i=1}^{3} \tilde{\alpha}_{i} \Delta B A_{t-i}+\sum_{j=0}^{1} \tilde{\beta}_{j} \Delta C D S_{t-j}+\tilde{\beta}_{2} U S V I X_{t}+\tilde{\beta}_{3} C C B S S\right)+\epsilon_{t}
\end{aligned}
$$

Figure 6 shows, on the $y$-axis, the sum of squared residuals for the regression in Equation 3 as $\gamma$, shown on the $x$-axis, changes (the sum of squared residuals for Equation 2 is plotted at $\gamma=0$ ). The sum of squared residuals is minimized when $\gamma=496.55$. We test for the identity between parameters above and below the threshold, or, equivalently, for the presence of the threshold, $H 0: \alpha_{0}=\tilde{\alpha}_{0}, \alpha_{1}=\tilde{\alpha}_{1} \ldots$ and, since the test-statistic asymptotic distribution is non-pivotal, we bootstrap it, as described in Hansen (1996). Figure 7 shows the bootstrapped distribution of the test, where the test statistic we observe is indicated by the vertical red line. The test is significant at better than the $1 \%$ level, thus confirming the presence of a threshold.

\section{INSERT FIGURES 6 AND 7 HERE}

While the previous paragraphs confirm the presence and location of the threshold, $\hat{\gamma}=496.55 \mathrm{bp}$, Figure 8 shows the test statistic needed to determine the confidence bounds around the point estimate we find. The threshold has a point estimate of 496.55, with a $5 \%$ confidence interval between 488 and 504 , and is almost identical for various alternative specifications of the relationship (including whether or not lagged or macro variables are included) and for the range of liquidity measures we employ 31

\section{INSERT FIGURE 8 HERE}

\footnotetext{
${ }^{31}$ The results for other liquidity variables are presented in the robustness checks of Section VII.I. while the results for other specifications are available from the authors upon request.
} 
The confirmation of the presence of a structural shift in the data when the CDS spread crosses a certain threshold is, therefore, robust and strongly supported by the data and it indicates how important the level of the CDS Spread is for market liquidity. As mentioned in the hypothesis section, Section III, this break point could be identified as the dividing line between the credit spreads for investment-grade bonds and those for high-yield bonds. Once this line is crossed, it may change the clientele of investors that holds Italian sovereign bonds, and also involve different levels of margins, accounting treatment and regulatory capital requirements, fundamentally altering the relationship between changes in credit risk and market liquidity. It is striking that the value of $500 \mathrm{bp}$ included in the confidence bands was indicated by many market participants, and corroborated in our conversations with market makers, as the critical threshold for the sustainability of Italian debt. It has also been identified by reports in the main Italian news agency as a psychologically important barrier, suggesting that Italian sovereign debt would spiral out of control if the spread persisted above this level ${ }^{32}$

Moreover, on November 17, 2010, the clearing house LCH.Clearnet reported that the margins on Irish sovereign bond repo transactions would be raised from $16-18 \%$ to $31-33 \%$, arguing that this decision had been taken "in response to the sustained period during which the yield differential of 10 year Irish government debt against a AAA benchmark has traded consistently over 500 bp." 33 The same clearing house raised the initial margin for Italian bonds on November 9, 2011, the day after Silvio Berlusconi resigned, which sees one of the highest CDS spreads in the sample and the second time the spread hits and stays consistently above 500bp. Figure 9 shows the time-series of bond market bid-ask spread, CDS spread, and margin charged by another clearing house, Cassa Compensazione e Garanzia, on bonds with 7 to 10 years to maturity. The very day that the clearing houses changed the margins charged on sovereign bonds, their market liquidity suddenly worsened. According to Brunnermeier and Pedersen (2009), an increase in margins will have an effect on the security's market liquidity if the market makers' budget constraint is binding. As Figure 4 Panel (c) shows, the CCBSS, measuring the funding liquidity need for the market makers, was at its highest during the second half of 2011, when the margin changes took place. We interpret our findings as a confirmation of Brunnermeier and Pedersen (2009): In the second half of 2011, when the funding liquidity of the market makers was at its lowest and their budget constraint was binding, a change in the margins charged on sovereign bonds led to a tightening of their market liquidity.

\section{INSERT FIGURE 9 HERE}

Having now identified the presence of a threshold, we need to determine how the relationship between changes in the CDS Spread and changes in market liquidity is modified when the threshold is breached. Panel B of Table 5 reports the results for Equation 3, when $\gamma=\hat{\gamma}$, or the threshold is the point estimate found in the previous paragraphs, what we call for simplicity the 500 bp threshold. The column "Test" in Panel B reports the test statistic for whether each pair of parameters above and below the threshold is equal, e.g., the test statistic for H0: $\beta_{0}=\tilde{\beta}_{0}$ is 9.55 , significant at the $1 \%$ level.

\footnotetext{
${ }^{32}$ See ANSA-Agenzia Nazionale Stampa Associata, December 23, 2011. http://www.ilsole24ore.com/art/notizie/ 2011-12-23/spread-torna-sfiorare-quota-063646.shtml?uuid=AaXuwtWE

${ }^{35}$ Source: http://www.lchclearnet.com/risk_management/ltd/margin_rate_circulars/repoclear/2010-11-17. asp and http://ftalphaville.ft.com//2010/11/17/407351/dear-repoclear-member/
} 
As the panel shows, the relationships below and above $500 \mathrm{bp}$ are rather different from each other. When we investigate only the contemporaneous CDS variables, we find that changes in the $C D S$ Spread have a significantly larger economic impact on market liquidity above the threshold of 500 bp than below: As the regression in Panel B shows, the coefficient of the contemporaneous change below the threshold is 0.10 , but not significant, while that above it is 2.86 and statistically significant. This means that an increase in the CDS Spread by 10\%, below the threshold of 500 bp, induces a contemporaneous increase in the Bid-Ask Spread of $1 \%$ (but statistically insignificant), while above the threshold it induces an increase of $29 \%$ ! Looking at the lagged CDS variable, we find that below the $500 \mathrm{bp}$ threshold market liquidity reacts with a lag to changes in the CDS Spread, with a significant impact of the autoregressive component and the lagged component of the change in the CDS. Above $500 \mathrm{bp}$, the relationship is rather different: market liquidity reacts immediately to changes in the CDS Spread, with the impact being largely contemporaneous, since the change in the CDS spread has no impact on the change in the market liquidity the following day. Our conclusion, therefore, is that Hypothesis 2 is verified and that the relationship between credit risk and market liquidity is non-linear in the level of the CDS spread; specifically, in a stressed environment, credit shocks have an immediate impact on market liquidity 34

As the "Test" column in Table 5 Panel B indicates, the only pairs of parameters that are statistically significant are those related to the changes in CDS Spread, which supports the threshold effect being in place not because of a change in the sensitivity of liquidity to macro variables or because of a change in its autoregressive components, but solely due to a different structural dependence on changes in the Italian sovereign's creditworthiness. Therefore, we estimate a modified version of Equation 3, where we allow only the dynamics to depend on the level of the CDS Spread:

$$
\begin{aligned}
\Delta B A_{t}= & \alpha_{0}+\sum_{i=1}^{3} \alpha_{i} \Delta B A_{t-i}+I[C D S \leq \hat{\gamma}]\left(\sum_{j=0}^{1} \beta_{j} \Delta C D S_{t-j}\right) \\
& +I[C D S>\hat{\gamma}]\left(\sum_{j=0}^{1} \tilde{\beta}_{j} \Delta C D S_{t-j}\right)+U S V I X_{t}+\beta_{3} C C B S S+\epsilon_{t}
\end{aligned}
$$

The results of estimating the above specification are reported in Panel $\mathrm{C}$ of Table 5 . All the previous considerations continue to apply, with the exception of the lagged CDS change, which shows a significant adjustment when the CDS is above the $500 \mathrm{bp}$ threshold. The adjusted $R^{2}$ shows a minor improvement, due to the lower number of estimated parameters.

Since we have determined the presence of a parameter discontinuity, we should verify how that discontinuity affects the lead-lag relationship investigated in Hypothesis 1 for the two samples. While the same result applies when the CDS level is below the threshold we found, as shown in Section Int.IV of the internet appendix, we are wary about conducting the same analysis when the CDS is above the

\footnotetext{
${ }^{34}$ As shown in Section VII.I the results for the other liquidity measures we analyze are qualitatively similar, although the precise magnitudes vary. In all cases, the threshold of $500 \mathrm{bp}$ is confirmed in a statistically significant manner. The magnified impact of changes in the CDS spread on market liquidity is also confirmed, although the quantitative impact varies across measures.
} 
threshold, because those intervals are mostly non-continuous, the CDS being able to fluctuate around $500 \mathrm{bp}$, and it is not clear how we could establish any longer-term causality. Our characterization in Hypothesis 1 concerns the linear relationship between the two variables in the "normal" period, and we are cautious even about using the argument of Granger-causality during more stressful times.

\section{VI.III Policy Intervention and Structural Breaks}

Although the sample period we consider is relatively short (June 1, 2011 to December 31, 2012), we hypothesized in Section III that the various interventions that occurred during the period may have generated a structural break in the relationship between credit risk and market liquidity. Therefore, the third research aim of this paper is to examine whether such a structural break can be detected statistically and related to policy changes. Again, we let the data alert us to the presence of a structural break over time.

H3 Policy Intervention and Structural Breaks: The monetary policy interventions of the central bank affect the dynamic relationship between credit risk and market liquidity.

The period that we investigate has been characterized by many events: the onset of the Euro-zone sovereign debt crisis, several sovereign credit downgrades, a political crisis that induced changes in Euro-zone governments, and several interventions by European central banks, and, in particular, by the ECB. Of course, by virtue of its status as the central bank of the Euro-zone, the ECB has a major influence on its sovereign bond markets. As described in Section III, the ECB's monetary intervention takes many forms, ranging from formal guidance by its board members, in particular its President, to the injection of liquidity into the major banks in the Euro-zone, which themselves hold these bonds, to direct purchases of sovereign bonds in the cash markets.

The purpose of this section is not to quantify the direct effect of these interventions on the Eurozone credit risk (see Eser and Schwaab (2014)), or its bond market liquidity (see Ghysels, Idier, Manganelli and Vergote (2013)), but to examine whether the relationship between credit risk and liquidity was significantly altered by one or more of these interventions, by testing for the presence of a structural break. The scant availability of public data concerning the quantity, issuer nationality, and timing of purchases of bonds in the SMP framework prevents us from quantifying the specific effect of those purchases. Similarly, in the absence of details of the extent of banks' access to LTRO funding and its usage, we are unable to investigate how the refinancing operation affected liquidity provision by the market makers (that are mainly part of the major international and national banks). However, since the several interventions and policy-relevant events took place over finite and non-overlapping periods of time, we can investigate econometrically whether a structural break in the relationship between the two variables of interest occurred around the time of the announcement or implementation of the interventions. This analysis is relevant for our Hypothesis 2 for two main reasons: first, because if the data indeed exhibit structural breaks, our results will be biased if we ignore them, and second, because it will shed light on the relevant combination of conditions that affects the relationship between credit risk and liquidity.

It should be noticed that the SMP intervention took place largely outside of our data sample, due 
to the data-quality restrictions we imposed and, thus, if it did cause a structural break outside of our sample period, we would not be able to capture it. However, in Section VII.III we extend our dataset, while, unfortunately, compromising on the granularity of the data, to address this issue and show that the second round of SMP, which took place in August 2011, does not constitute a structural break for the relationship we address in this paper.

We investigate Hypothesis 3 by performing the "structural change breaks" test proposed by Andrews (1993) (the supF test in that paper), on Equation 4, the details of which are presented in Appendix C. Briefly, the test corresponds roughly to a Chow (1960) test but, while in the Chow test the structural change break is specified exogenously, this "structural change break" allows us to leave the structural break date unknown a priori. The test corresponds to performing a Chow test for the relationship in question on each date in the sample. The date that is most likely to constitute a break in the data sample is found endogenously, as the date with the largest Chow test value, and the presence of a break itself is tested by comparing that date's (Chow) F-test to a non-standard distribution. The test, therefore, verifies whether there is a structural break at all in the specified relationship. If the null hypothesis of "no structural break" can be rejected, the date with the largest corresponding Chow test will be selected as the structural break. Figure 10 shows the values of the Chow $F$-test calculated on each date, with the horizontal line showing the confidence band for the highest $F$-value. We find that, from a statistical perspective, the test indicates a break on December 21, 2011 for the relationship between the Bid-Ask Spread, and the CDS Spread, its lag, and the macro variables, and this structural break is significant at the $1 \%$ level.

Again, the result is robust to using each of the alternative liquidity measures. Although December 21 is identified purely based on the statistical evidence as the date where the (Chow) supF test is most significant at the $1 \%$ level for the relevant relationships between the Bid-Ask Spread and the $C D S$ Spread, it coincides exactly with the date of the allotment and the day before the settlement of the LTRO program by the ECB ${ }^{35}$ Our evidence suggests that the relationship between credit risk and liquidity changed as the ECB provided LTRO funding to the banks. To the extent that the relationship measures the sensitivity of the market makers' behavior to changes in the (credit) risk of their portfolios, our finding supports our hypothesis that the market makers were wary of providing liquidity to the government bond market. They were particularly concerned that, should an adverse credit event occur, their inventory would have suffered and they would have been left with no available funding liquidity. The large provision of funding from the ECB constituted a structural break in that relationship and had a clear impact on the sensitivity of market makers to changes in the credit riskiness of their inventories, as we quantify in the following paragraphs ${ }^{36}$

Moreover, although the margins were increased again in June, July, and August 2012 (in August to the same level as in November 2011), Figure 9 shows that the market illiquidity did not increase then as it did in November 2011, as a result of the hike in margins, but rather stayed constant. The large infusion of funding liquidity resulting from the LTRO, confirmed by the low levels of CCBSS

\footnotetext{
${ }^{35}$ The policy implementation announcement of December 8, 2011 with all the important dates for this measure can be found online at http://www.ecb.europa.eu/press/pr/date/2011/html/pr111208_1.en.html

${ }^{36}$ Testing for a structural break in Equation 2 leads to the same break date, while testing for a structural break in Equation 3 identifies a date a few (twelve) trading days later. However, no major events took place between the two dates.
} 
following January 2012 in Figure 4 Panel (c), loosened the market makers' funding constraints so that, consistent with Brunnermeier and Pedersen's (2009) prediction, the change in margins did not affect the market makers' provision of market liquidity, since their budget constraints were not binding.

In order to account for this structural break in our estimations, we split the sample into two periods, and again perform the threshold test as per Equation 4 in both sub-samples, i.e., we test whether the relationship between the changes in the bid-ask spread, and the changes in the CDS spread and its lag, varies above and below an endogenously found threshold. As shown in Figure 11 . the bootstrap procedure for the threshold test confirms the presence of different relationships below and above the threshold level of $500 \mathrm{bp}$ for the CDS spread, in the first sub-sample (June 1, 2011 to December 21, 2011), but fails to identify a threshold for the second sub-sample. This result indicates that, thanks to the assurance of massive liquidity from the ECB, even if the Italian CDS Spread had breached the level of $500 \mathrm{bp}$, post-LTRO, the relationship between changes in the CDS spread and market liquidity would not have been altered, unlike in the period before the intervention.

\section{INSERT FIGURES 10 AND 11}

Panel A of Table 6 presents the results of the estimation for the first sub-sample, before December 21, 2011, and confirms the results we presented above. The main difference is that, for the split sample, the relationship between the change in the CDS Spread and market liquidity, when the $C D S$ Spread is above $500 \mathrm{bp}$, is even stronger in the pre-LTRO regime, with a $10 \%$ increase in the $C D S$ Spread translating into a $39 \%$ contemporaneous increase in the Bid-Ask Spread.

\section{INSERT TABLE 6 HERE}

Table 6, Panel B, presents the results of the estimation for the second sub-sample, after December 21,2011 , and shows that the presence of the autoregressive component in market liquidity is still apparent. However, the contemporaneous relationship between changes in the CDS Spread and changes in market liquidity is no longer significant, while there is a lagged adjustment of market liquidity related to changes in the CDS Spread on the previous day, with an economic intensity that is about half that in the full sample reported in Table 5, Panel A (0.576 vs. 0.972), and less than one third of the of the corresponding parameter for the 2011 subsample, when the CDS is below 500 bps, reported in Table 6. Panel A (0.576 vs. 1.734). Moreover, our analysis shows that the global variable USVIX affects market liquidity only for the 2011 subsample, while, after the ECB intervention, the only significant variable is the funding liquidity measure, CCBSS.

The previous literature (e.g., Eser and Schwaab (2014) and Ghysels, Idier, Manganelli and Vergote (2013)) shows that the SMP had an effect on the yields of the bonds chosen for the program, following from the large buying pressure exerted by the central bank purchases. However, to the extent that the risk levels of the market makers were maintained, the relationship between credit risk and liquidity would have remained unaltered. Hence, the SMP, as we show in detail in Section VII.III, did not, in fact, constitute a structural break for that dependence. The LTRO, on the contrary, constituted a massive intervention targeting the availability of funding liquidity and, as such, was ideal for affecting how the banks disposed of their available capital, making them less sensitive to changes in credit risk, when providing liquidity to the market. 
We tested whether other structural breaks would emerge from the data after December 21, 2011, and no date emerged as statistically significant. When we tested Equation 2 for structural breaks in the sub-sample before December 21, 2011, we found October 31, 2011 to be a structural break but only at a $10 \%$ significance level. However, when we tested Equation 4 , we found no structural breaks with even a reasonable statistical significance. We interpret this last finding, combined with the fact that October 31, 2011 corresponds to the beginning of a streak with the CDS Spread above $500 \mathrm{bp}$, as a further confirmation of a non-linearity in the relationship between credit risk and liquidity, dependent on the level of the credit risk.

The results of the analysis of the structural break in the time series confirm what we posited in Hypothesis 3 and allow us to argue that LTRO intervention was very effective in severing the strong connections between credit risk and market liquidity. It is interesting to observe that both SMP and LTRO interventions generated injections of liquidity into the system by the ECB. However, the magnitudes were completely different ( $€ 103$ billion in August 2011 versus $€ 489$ billion in December 2011) and so were the mechanisms: in the first case, the ECB bought the sovereign bonds directly, while, in the second case, it provided money to reduce the funding liquidity constraints of the banks, which perhaps used some of the released liquidity to purchase sovereign bonds 37

\section{Robustness Checks}

\section{VII.I Results for Other Liquidity Measures}

In the main body of the paper we conducted the analyses focusing on a single measure for the (il)liquidity of the bond market, the Bid-Ask Spread, since it is both the most familiar and most indicative of market conditions. Nonetheless, in order to validate the results presented in the prior sections, we employ a cohort of other liquidity measures and show that they are all highly correlated with the bid-ask spread. Even so, we repeat most of the analysis from the earlier sections, using these measures.

The proxies we use can be divided into two main categories: quote-based and trade-based measures. Quote-based measures include the total quoted quantity (Quoted Quantity), and the market depth measure, Lambda, while the Effective Spread constitutes our trade-based measure. The Effective Spread measures the actual spread experienced by traders, while Quoted Quantity measures the largest amount a trader could buy or sell at any point in time, if she were not concerned with execution costs. The depth measure Lambda attempts to combine the bid-ask spread and the quoted quantity by measuring by how much a trader would move the best bid (ask) if she were to trade $€ 15$ million of a given bond 38 Mathematically, the Lambda on the ask side would be defined as

\footnotetext{
${ }^{37}$ One issue that we cannot disentangle is whether this effect is related to the ECB intervention or to the shortselling ban on the CDS market under the European Market Infrastructure Regulation (EMIR) imposed by the European Securities Market Authority (ESMA), which may have reduced the relevance of this market, or at least its informativeness. However, data from the DTCC indicate that the net notional amount for Italian CDS contracts declined by just $16 \%$ in the period of our study, while the gross notional amount increased by $44 \%$. Hence, the ban seems not to have had a major effect on the traders' behavior with regard to the Italian sovereign CDS market. Moreover, when testing for a structural break, we allow the data to indicate the most likely point in the period of our sample. The date we identify statistically is not close to either the announcement or the implementation of the naked CDS ban.

${ }^{38}$ This amount was chosen since it is at the 90th percentile of the overall market in terms of trade size. As traders
} 
$\lambda^{a}=E\left[\left(P_{t}^{a}-P_{t-1}^{a}\right)\left(Q_{t}\right) \mid Q_{t}=15 M\right]=E\left[\Delta P_{t}^{a}\left(Q_{t}\right) \mid Q_{t}=15 M\right]$, where $P_{t}^{a}$ is the time $t$ ask price following a buy trade of quantity $Q_{t}=15 \mathrm{M}$, and $\lambda^{b}$ would be defined similarly. In order to represent both sides of the market, we consider the mean, $\lambda=\frac{\lambda^{a}+\lambda^{b}}{2}$, in our empirical estimations, as a market depth measure. As for the trade-based measures, the effective bid-ask spread Effective Spread is calculated as $Q \cdot(A P-M) \cdot 2$, where $Q=1$ if it is a buy order, $Q=-1$ if it is a sell order, $A P$ is the face-value-weighted trade price, and $M$ is the mid-quote in place at the time the order arrives 39

All quote-based measures are calculated at a five-minute frequency for each bond, and then averaged across bonds to calculate a daily market-wide measure 40 The effective spread is calculated for our sample of the whole market, with volume-weighting of the trades of all bonds. Figure 12 shows the time-series evolution of the liquidity variables and Table 7 shows the correlations between them. The measures tend to comove and clearly follow the same evolution. The Bid-Ask Spread is the liquidity measure that most highly correlates with the others; all absolute correlations between it and the other variables exceed $59 \%$ (44\%) in levels (differences), with $\lambda_{t}$ being the least correlated with it.

To check the robustness of the results in the previous sections, we repeat the analysis in which we estimated Equation 2, the threshold test in Equation 3 for the sample up to December 21, 2011, and the structural break of Section VI.III, using the other liquidity variables described in this subsection, namely the Quoted Quantity, the Effective Spread, and Lambda. The number of lags for each variable and the CDS Spread weare determined using the same methodology as for the Bid-Ask Spread. The results are reported in Table 8, while Figure 13 shows the plots of the identification of the threshold in the relationship between changes in liquidity and changes in the Italian CDS Spread level for the 2011 sub-sample, and the structural break test, as performed in Section VI.III for the Bid-Ask Spread.

\section{INSERT TABLES 7 AND 8 AND FIGURES 12 AND 13 HERE}

Figure 13 shows that the structural break around the LTRO settlement (Panels e, f, and i) is also a feature of the Quoted Quantity and Effective Spread, as is the $500 \mathrm{bp}$ threshold in the regression of the changes in the liquidity measure on its lags and the changes in the Italian CDS spread and its lag and the macro variables, for the 2011 sub-sample (Panels c, d, and h) for the Quoted Quantity and Lambda. A 10\% change in the Italian CDS Spread is contemporaneously associated with a $10 \%$ decrease in Quoted Quantity, a 26\% increase in the Effective Spread, and a $43 \%$ increase in Lambda,

might split up large amounts over several subsequent trades, Lambda captures the price movement caused by a relatively large trade requiring immediacy. It is conceptually equivalent to the concept of market depth defined by Kyle (1985).

${ }^{39}$ We do not include two widely known trade-based liquidity metrics, the Amihud illiquidity measure and the Roll measure, in the list of alternative liquidity measures. The MTS market is characterized by high-frequency quote updates, but not high-frequency transactions. However, the MTS database provides detailed order book information, enabling us to compute a liquidity measure, the hypothetical market impact, for buy and sell orders separately (Lambda). Thus, due to the large number of quotes relative to trades, Lambda is a far better and more granular measure for this market than the Amihud measure. Additionally, market makers in the MTS market post firm quotes that are executable immediately, so that the difference between best ask and best bid (quoted bid-ask spread) indicates the market-making risk perceived by professional market makers at any point in time. Therefore, there is no need to rely on alternative estimations of the bid-ask spread, such as the Roll measure, since the actual measure is itself available.

${ }^{40}$ It is common in the sovereign bond literature to separate the bonds into on-the-run and off-the-run issues, or to only consider the former, reckoning that the former are more liquid and more sought after by investors. The Italian sovereign issuer, the Tesoro, often reissues existing bonds, thus enhancing their liquidity, and causing the on-the-run/off-the-run dichotomy to lose its relevance. In any event, we checked whether there were differences in the quoted or effective bid-ask spread for "new" issues compared to the prior issues and did not find any significant differences. For this reason, we average our liquidity measures across all bonds without sorting them by remaining maturity or age since issue. 
when the CDS spread for Italian bonds is above $500 \mathrm{bp}$, compared to a $7 \%$ decrease, a $9 \%$ increase, and a $13 \%$ increase when the Italian CDS Spread is below the same threshold. After the ECB intervention, a change in the Italian $C D S$ Spread has no significant effect on any liquidity measure. The sensitivity of the Effective Spread is lower than that of the Bid-Ask Spread because of the endogeneity of the trading decision: Traders will choose to trade when the Bid-Ask Spread is comparatively low, thus dampening the sensitivity of the effective spread to changes in market conditions. The dynamics of the relationship between credit risk and liquidity are confirmed by the analysis of the alternative liquidity measures, so that the lagged change in credit risk is significant when the market is relatively quiet, while, in a stressed market, when the Italian CDS spread is above $500 \mathrm{bp}$, the liquidity changes contemporaneously with the credit risk 41

In the body of the paper, we report the results based on the daily bid-ask spread, obtained from MTS data by averaging the quoted bid-ask spread on a bond-day basis, and then averaging them across bonds. We repeated our analysis for the 10-year on-the-run bond, using both the bid-ask spread obtained from the MTS dataset and the one provided from Bloomberg to (i) show that the results are valid also for the most liquid bond in the cohort taken by itself, and (ii) compare the results obtained using MTS and Bloomberg data for that specific bond. While the results for the 10year on-the-run are qualitatively similar to those for the market-wide liquidity measures when using MTS data, we were not able to find any statistically significant relationship between CDS and bid-ask spread when the bid-ask spread was obtained from Bloomberg (results are shown in Section [nt.V] of the internet appendix) 42 The reasons why the bid-ask spread from Bloomberg differs from the one we calculated using MTS data, and why we employed the latter, are as follows: (i) Bloomberg covers the MTS market as well as other information providers, although the MTS market quotes are the most relevant and qualified because of their transparency and institutional supervision. (ii) Bloomberg's quotes include those from other agents on the market, from the retail clients to institutional investors, making it more difficult to disentangle the liquidity provided only by primary market makers, which are the only agents present on the MTS platform. (iii) Bloomberg does not restrict quotes to be based on a minimum amount bid or offered, to qualify for the best ask and bid, while MTS market makers have a minimum quote size requirement. Therefore, Bloomberg's quotes might reflect bid-ask spreads available for a small retail quantity, rather than a meaningful size. Finally, (iv) Bloomberg quotes are end-of-day quotes, capturing one specific time of the market, whereas we consider daily averages of the bid-ask spread, hence better representing the liquidity provision characterizing the bond market on that specific day. For all these reasons, MTS quotes are preferred, over Bloomberg's, for capturing the liquidity that is provided for meaningful trade sizes by market makers.

An alternative measure of liquidity used in previous literature for markets with few quotes and trades is the volume traded on the market, or, alternatively, the number of daily transaction. Figure 3 shows the total number of Trades and the trading Volume (in billions of euros) exchanged on the

\footnotetext{
${ }^{41}$ This is in line with the discussion in Section III. where the frequency of intervention by risk managers on an intraday basis during crisis periods was highlighted.

${ }^{42}$ It is important to stress, here, that the Italian bond market does not have a proper "on-the-run bond" because each bond is issued several times in auctions covering a long period of time since issuance. The on-the-run/off-the-run yield spread, used as a measure of liquidity in the American sovereign bond market, among others, cannot be interpreted similarly when considering the Italian sovereign bond market.
} 
MTS. It is evident that these two variables share a strong commonality in movement and a clear cyclical pattern. We reckon that the peaks coincide with auctions of new bonds, the reopening of previous issues, and the releases of relevant economic variables and events, over time. In contrast to the previous literature, we find a very low correlation between Trades (Volume) and the Bid-Ask Spread of about $-13 \%$ (-13\%). Since the Bid-Ask Spread correlates highly with other market liquidity measures, as discussed in Section VII.I below and not with the Volume, we conclude that Trades and the trading Volume in the Italian sovereign bond market are mostly driven by factors other than market liquidity and, therefore, act as a poor proxy for it.

\section{INSERT FIGURE 3 HERE}

\section{VII.II Price Volatility, CDS Liquidity, and Yield Spread}

A variable we have not included in the analysis so far is the intraday price volatility of the bonds. Microstructure models (e.g., Glosten and Milgrom (1985), among others) suggest that an increase in price volatility should decrease the amount of liquidity offered to the market by market makers because of concerns about the risk of the inventory they carry. Moreover, the effect of heightened credit risk could affect liquidity only through price volatility, and not necessarily directly. For example, a worsened public finance situation could accentuate the uncertainty regarding the true value of the sovereign bond and the informativeness of its price, and hence affect its market liquidity. As a matter of fact, the price volatility, $\sigma_{t}^{2}$, (measured as the intraday variance of the five-minute mid-quote changes for each bond, averaged into a market-wide daily measure) and the Bid-Ask Spread are highly correlated in our sample, even in differences (57\%).

We thus need to test the effect of a change in credit risk, after controlling for the effect of volatility on the liquidity measure. We therefore estimate a VAR, as in Equation 1, with the changes in the CDS Spread, Bid-Ask Spread, and bond price volatility, $\sigma_{t}^{2}$. The lag structure selected by the modified Akaike criterion is 4 , due to the stickiness of the volatility measure. Table 9 reports the estimations.

\section{INSERT TABLE 9 HERE}

The Granger-causality test shows that the changes in the CDS Spread Granger-cause both the Bid-Ask Spread and the bond price volatility, but the bond price volatility does not Granger-cause the changes in either the CDS Spread or the Bid-Ask Spread. If anything, the lagged Bid-Ask Spread leads the volatility. This means that our analysis of the relation between credit risk and market liquidity performed above is robust to the inclusion of price volatility as an additional variable in the VAR system. We also replicate Table 6 for the two sub-samples, while including the contemporaneous price volatility. The results are reported in Table 10.

\section{INSERT TABLE 10 HERE}

Table 10 shows that the contemporaneous bond price volatility is indeed significant at the $1 \%$ level: it increases the adjusted $R^{2}$ by about $20 \%$ and is always significant in the two sub-samples considered, with a significant reduction of the coefficient from 0.117 to 0.058 from 2011 to 2012 . However, the 
magnitude and significance of the parameters related to the CDS Spread dynamics are not widely affected by the inclusion of the volatility measure.

Another variable that could affect the dynamics of the system we analyze is the market liquidity of the CDS contract itself: If the CDS spread is affected by the demand and supply of credit-event insurance, measured by its own bid-ask spread, and we do not include this liquidity variable in our system, we could be ignoring a significant determinant of the system's dynamics. We investigate this issue in detail. In Section Int.VI of the internet appendix, we show that the CDS bid-ask spread, measured as the daily time-weighted average from Credit Market Analysis (CMA) data, is marginally significant in the Granger-causality tests, but shows no economic significance in affecting the bond market liquidity and CDS spread. Moreover, repeating the analysis from Sections VI.I and VI.II does not lead us to any different conclusion regarding the dynamics between credit risk and bond market liquidity.

We also verify whether the CDS spread follows or leads the bond yield spread counterpart and find that the two measures indeed comove, i.e., reflect the same changes on the same day, and hence, neither of them leads or lags the other, and thus, neither adjusts to the other measure's change. These results are provided in Section Int.II of the internet appendix.

\section{VII.III Extending the Dataset}

The intraday MTS dataset that we use in this analysis extends back to June 2011. Prior to that date, MTS provided data only on the three best bid and ask quotes on each date, a much more limited quote sample than the granular tick-by-tick data used in the previous analysis. While, as we argued earlier, the financial crisis is the most relevant period in which to investigate the issue of credit risk and liquidity, we would like to investigate whether our findings on the relationship between the $C D S$ Spread and the Bid-Ask Spread are robust to the use of a longer sample period. Moreover, regarding the ECB interventions, the second round of SMP purchases took place in August 2011, at the very beginning of our sample period, and it is important to verify whether our structural break results still carry through, or identify a different break, possibly around the time of the SMP intervention.

To investigate this issue, we extended the database back to July 1, 2010, calculating the Bid-Ask Spread from the three best bid and ask quotes each day. The Granger-causality tests based on the VAR estimation confirm our previous results: the CDS Spread Granger-causes the Bid-Ask Spread and not vice versa. The results are reported in Table 11.

\section{INSERT TABLE 11] HERE}

Furthermore, we performed the structural break test for the extended sample, using the same methodology as in Section VI.III, and the results confirm, at the $10 \%$ level, that a break took place on December 21, 2011, as presented in Figure 13 Panel A. We then repeated the structural break test for the part of the sample before December 21, 2011, to test whether other ECB interventions, and, in particular, the SMP, constituted structural breaks. The results of the test are reported in Figure 13 Panel B, and highlight the lack of statistical support for the presence of another break before the LTRO (the test statistic is 16.61 , while the $10 \%$ significance level is 20.91) Therefore, the conclusions 
reached earlier, based on the dataset starting from June 2011, strictly do not depend on the chosen time frame. Finally, the results regarding the 500 bp CDS level threshold also carry through when we test Equations 3 and 4 in the extended dataset, as Figure 14 shows for the latter.

\section{Conclusion}

The sovereign debt crisis in the Euro-zone has been the most important development in the global economy in the past years. This crisis stemmed from both liquidity and credit risk concerns in the market and led to a sharp spike in CDS and sovereign bond yield spreads in late 2011, particularly in the Euro-zone periphery. It was only after the launch of the LTRO program and after Mario Draghi's "whatever it takes" comment in July 2012 that the market's alarm diminished: CDS spreads and sovereign bond yields had dropped to sustainable levels in most Euro-zone countries by late 2012. Hence, there is no doubt, prima facie, that the ECB programs were a crucial factor in, at least partially, abating the crisis.

These events provide us with an unusual laboratory in which to study how the interaction between credit risk and illiquidity played out, in a more comprehensive framework than has been used in previous studies of corporate or other sovereign bond markets, for the reasons we highlighted in the introduction. We employ a wide range of liquidity measures and investigate several hypotheses about the main drivers of the dynamic relationship between credit risk and market liquidity, controlling for global systemic factors and funding liquidity. We conclude that credit risk was a main driving force in the determination of the liquidity of the bond market, by a Granger-causality analysis aimed at investigating whether liquidity risk drives credit risk or vice versa. We verify the robustness of our results through a cohort of tests, where we control for bond return volatility and other variables, and employ a longer time-series of data. On top of the specific Italian sovereign risk, other global factors such as the USVIX and the funding liquidity measure CCBSS are relevant for the dynamics of market liquidity.

A second main finding is that, prior to ECB intervention, the relationship between credit risk and market liquidity was strong, and depended not simply on the changes in credit risk, but also on the level of credit risk. Using an econometric methodology that allows us to identify the threshold above which the relationship is altered, we estimate that this level corresponds to a CDS spread of $500 \mathrm{bp}$. This break point of $500 \mathrm{bp}$ is often identified as the dividing line between the credit spread for investment-grade bonds and that for speculative-grade bonds. Once this threshold is crossed by the Italian sovereign, the clientele of investors that holds its bonds may be fundamentally altered. Furthermore, the margin requirements, as we show, will be quite different, thus fundamentally altering the relationship between changes in credit risk and market liquidity. We link our findings to the growing literature on funding liquidity, providing a fitting example of the Brunnermeier and Pedersen (2009) theoretical prediction on the effect of funding liquidity on market liquidity.

We also examine the improvement in market liquidity following the intervention by the ECB. Our analysis of the data indicates that there is a clear structural break following the allotment and settlement of the LTRO on December 21, 2012. Remarkably, the data show that, following the ECB intervention, the improvement in funding liquidity available to the banks strongly attenuated the 
dynamic relationship between credit risk and market liquidity. Although the CDS spread breached the $500 \mathrm{bp}$ mark and margins were raised once again, market liquidity and the relationship between credit risk and market liquidity did not change significantly between the regimes below and above this level. Actually, the only variable that still has an impact on market liquidity after the ECB intervention is the global funding liquidity variable, CCBSS. Thus, the ECB intervention not only vastly improved the funding liquidity of the market, but also substantially loosened the link between credit risk and market liquidity.

Our results will be of interest to the Euro-zone national treasuries, helping them to understand the dynamic nature of the relationship between credit risk, funding liquidity, and market liquidity, which has strong consequences for the pricing of their issues in the auctions as well as in secondary markets. The ECB may also derive some insights from our analysis that could help them to better understand the impact of the unconventional instruments of new monetary policy. Apart from targeting both funding and market liquidity, the central bank ought also to focus on the market's perceptions of sovereign credit risk. 


\section{Appendix A: The MTS Datasets and Market Structure}

There are four types of database currently offered by MTS. At the highest level, "daily summaries" including aggregate price and volume information regarding the trading of European bonds are published. At the second level, the "trade-by-trade" data including all transactions, stamped at the millisecond level, are available. However, neither of the two aggregate databases has any information on the price quotations of the instruments at the dealer, or even the market-wide, level. The publicly available dataset at the third level includes the three best bid and ask prices and the aggregate quantities offered at those levels. Prior studies, not using the dataset at the third level, are unable to describe the market in its entirety, as the two dimensions indicating willingness to trade, quotes, and orders, for primary dealers and dealers respectively, were not available previously. Only actual trading events are observable in the second-level dataset, and trading intent as a pre-trade measure cannot be measured. Thus, it is not possible to study liquidity provision, as measured by the dealers' willingness to trade, as evidenced by their bid and offer quotations, based on this dataset. In contrast, the dataset we analyze in the present study is at the fourth level, is by far the most complete representation of the market available, and has been released only recently. It covers all trades, quotes, and orders that took place on the MTS market between June 1, 2011 and December 31, 2012. Every event is stamped at the millisecond level, and the order IDs permit us to link each order to the trade that was eventually consummated from it. Every quote in this market, henceforth called "proposals", can be followed in the database in terms of their "revisions" over time, thanks to a "single proposal" identifier.

Market participants can decide whether they want to trade a government bond on the European market or on that country's domestic market. While every Euro-zone bond is quoted on the domestic markets, only bonds that are issued for an amount higher than a certain threshold can be traded on the EuroMTS platform. Even though the two markets are not formally linked, most dealers participate in both venues. The previous literature (Cheung, de Jong and Rindi (2005), Caporale and Girardi (2011)) has shown that the two markets essentially constitute a single venue ${ }_{43}^{43}$ Thus, in our analysis, we consider trading in both markets. The liquidity measures used in this paper do not depend on where the order placement and trading activity take place.

There are two kinds of trader in the sovereign bond markets, primary dealers and other dealers. Primary dealers are authorized market-making members of the market. That is, they issue standing quotes, which can either be single-sided or double-sided, on the bonds they have been assigned. They indicate the quantity they are willing to trade and the non-negative fraction of that quantity they are willing to "show" to the market. Primary dealers can be on the passive side, when their proposals are "hit" or "lifted," and/or on the active side of the market, when they submit orders aimed at "hitting" or "lifting" another primary dealer's standing quote. Primary dealers have market-making obligations that, in spite of some relaxations that were made after 2007, still require each primary dealer not to diverge from the average quoted times and spreads calculated among all market makers. In this market, the event of crossed quotes is guaranteed not to occur, except by chance, since, when the opposite

\footnotetext{
${ }^{43}$ By this we mean that a sell or buy order could "trade-through" a better price if the trader sent the order to the market with the worse of the bid or ask price, respectively. However, MTS assures market participants that their trading platforms always show quotations from both the domestic and the European market, when available.
} 
sides of two proposals cross, a trade takes place for the smaller of the two quoted quantities 44 Other dealers with no market-making responsibilities can originate a trade only by "hitting" or "lifting" the primary dealers' standing quotes with market orders. However, it should be noted that primary dealers are also on the active side of $96 \%$ of the trades present in our database.

\footnotetext{
${ }^{44}$ While this is one way for the primary dealers to trade, it seldom happens. Hence, we do not include trades originating in this manner in our sample.
} 


\section{Appendix B: Instrumental Variable Analysis}

In Section VI we focused on the bid-ask spread equation of the VAR system, augmenting it with the contemporaneous changes in CDS spread. In order to test whether the causality runs one way or both ways, i.e., whether the variables suffer from contemporaneity, we re-estimate Equation 2 and test for the endogeneity of $\triangle C D S_{t}$ by instrumenting it with several cohorts of variables.

Conditional on the instruments being valid - i.e., strong, exogenous, and relevant - if the HausmanWu test cannot reject the null hypothesis of the ordinary least squares (OLS) and IV estimators being the same - under the null hypothesis both are consistent- we can conclude that the OLS estimate is to be preferred in virtue of having a smaller estimator variance. On the other hand, if the Hausman-Wu test rejects the null hypothesis, only the IV estimator is consistent and hence preferred, regardless of its larger estimator variance. In this appendix we will describe our cohorts of instruments, claim their exogeneity, show that they are strong and relevant, and finally present the IV results together with the Hausman-Wu test results.

We have three cohorts of instruments:

- Other European government CDS/bond yields:

- Germany: The German 10-year yield is likely to be correlated with the Italian CDS. In the case of a flight-to-quality, as the Italian CDS rises the German yield could plummet due to investors switching from holding Italian bonds to German bonds. If the change in German yield were perfectly correlated with the change in Italian CDS, however, the German yield should not be correlated with the residuals from Equation 2, since the CDS is on the right-hand side, and hence, it would constitute a good instrument. If, however, a flight to liquidity depended also on the relative change in the CDS compared to the yield and the two were not perfectly correlated, then the instrument would not be exogenous. Nevertheless, we repeat the analysis using the lagged value of the change in the German bond yield, in order to account for this possible endogeneity.

- Finland: The flight-to-quality argument applies less stringently for a relatively safer country with a small bond market. The Finnish government debt amounted to $€ 90 \mathrm{~B}$ during the period of our study, a small fraction of both the Italian and German outstanding government debt. Bai, Julliard and Yuan (2012) report that the Finnish bond market has a similar bid-ask spread to the German and Italian ones, while the trading volume is an order of magnitude smaller. Moreover, in our sample, the changes in Italian and Finnish CDS spreads are correlated at the $70 \%$ level, while those of Germany and Italy are correlated at $-57 \%$. Hence the data hardly support a flight-to-quality from Italian to Finnish bonds. The change in Finnish CDS spread hence qualifies as a valid instrument.

- The CDS of Italian-government-owned/controlled companies significantly comove with the government CDS (with correlations above $56 \%$ in the changes), and moreover, would not constitute a safer security since a government-owned company would be hit hard if the central government were to fail, thus disqualifying it from a safe-to-quality or other asset substitution perspective. 
We consider all government-owned companies that had a traded CDS spread during our sample period, namely

- ENI: the national oil and gas company,

- ENEL: the national electricity company,

- Finmeccanica: a large industrial group, specialized in aerospace, defence, and security.

- The European stock market index Euro50 is highly correlated with the Italian CDS spread ($61 \%$ ), so when the crisis mounted for the sovereign it also pushed the stock exchange down, also partially due to the presence of some Italian companies in the index. In order for Euro50 to be correlated with the regression residuals - that is partially correlated with bond-market liquidity after controlling for the overall worsening of the crisis through the Italian CDS, for investor sentiment with the VIX, and for the funding liquidity with the CCBSS - there should be a substitution effect between Italian bonds and Euro50-included companies. We are not aware of any academic study showing this phenomenon.

Table 12 presents the results from the IV estimation, for both the first and the second-stage regression, in Panels A and B, respectively. First of all, all our instruments are strong, with $F$-test results well above 10, the level recommended in Greene (2012) among others. The F-test IV row presents the $F$-test results regarding whether the added exogenous variables are contemporaneously zero. As one might expect, the weakest instrument is the lagged German yield change. However, even for Model 3, the $F$-statistic is 21.22. The adjusted $R^{2}$ of all the models are very high, supporting our claims of instrumental strength.

As shown in Panel B, presenting the second stage, the Hausmann-Wu test is not statistically significant for any of the specifications, thus supporting the exogeneity of $\triangle C D S_{t}$ in Equation 2. Indeed, the parameter estimates are very similar to those in Table 5 Panel A. The standard errors used for the significance of the second-stage regression are not heteroskedasticity-corrected, which explains the significance of $\triangle C D S_{t}$ in some specifications. The specification with the highest difference in parameters (and thus the highest Hausman-Wu test) is that using only $\Delta Y i e l d_{t-1}^{D E}$ as an additional instrument, which we attribute to the poor predictive power provided by the additional instrument in the first-stage regression.

Using different sets of instrumental variables, we have shown that $\triangle C D S_{t}$ is not endogenous (implying contemporaneous feedback effects) in Equation 2. Therefore, we have justified the use of a single equation in explaining the dynamics of the CDS/bid-ask spread system in the remainder of the paper. 


\section{Appendix C: Methodological Appendix}

\section{Threshold Analysis}

In empirical settings, a regression such as the OLS specification $y_{i}=\beta^{\prime} x_{i}+e_{i}$, where $y_{i}$ is the dependent variable that is regressed on the independent variable $x_{i}$, is often repeated for sub-samples, either as a robustness check or to verify whether the same relationship applies to appropriately grouped observations. The sample split is often conducted in an exogenous fashion, thus dividing the data according to the distribution of a key variable (such as size and book-to-market quantile portfolios in a Fama-French (1993) setting). Hansen (1996, 2000) develops the asymptotic approximation of the distribution of the estimated threshold value $\hat{\gamma}$, when the sample split, based on the values of an independent variable $q_{i}$, can be rewritten as

$$
Y=X \theta+X_{\gamma} \delta+e \quad \text { where } X_{\gamma}=X I(q \leq \gamma)
$$

or $y_{i}=\theta^{\prime} x_{i}+\delta I\left(q_{i} \leq \gamma\right) x_{i}+e_{i}$, where $I\left(q_{i} \leq \gamma\right)$ equals 1 if $q_{i} \leq \gamma$, and 0 otherwise. He shows that, under a set of regularity conditions, which exclude time-trending and integrated variables, the model can be estimated by least squares, minimizing $\operatorname{SSR}_{n}(\theta, \delta, \gamma)=\left(Y-X \theta-X_{\gamma} \delta\right)^{\prime}(Y-X \theta-$ $\left.X_{\gamma} \delta\right){ }_{45}^{45}$ Concentrating out all parameters but $\gamma$, i.e. expressing them as functions of $\gamma$, yields $S_{n}(\gamma)=$ $S S R_{n}(\hat{\theta}(\gamma), \hat{\delta}(\gamma), \gamma)=Y^{\prime} Y-Y^{\prime} X_{\gamma}^{*}\left({ }^{\prime} X_{\gamma}^{*}{ }^{\prime} X_{\gamma}^{*}\right)^{-1} X_{\gamma}^{* \prime} Y$ with $X_{\gamma}^{*}=\left[\begin{array}{ll}X & X_{\gamma}\end{array}\right]$. The parameters $\theta$ and $\delta$ are formulated as functions of $\gamma$, and the sum of squared residuals depends exclusively on the observed variables and on $\gamma$. Thus, the value of $\gamma$ that minimizes $S_{n}(\gamma)$ is its least squares estimator $\hat{\gamma}$, and the estimators of the remaining parameters $\hat{\theta}(\hat{\gamma})$ and $\hat{\delta}(\hat{\gamma})$ can be calculated.

When there are $N$ observations, there are at most $N$ values of the threshold variable $q_{i}$, or equivalently $N$ values that the $S S R(\gamma)$ (step-)function can take. After re-ordering the values $q_{i}$ in $\left(q_{(1)}, q_{(2)}, \ldots q_{(N)}\right)$, such that $q_{(j)} \leq q_{(j+1)}$, the method is implemented by

1. estimating by OLS $y_{i}=\theta_{2}^{\prime} x_{i}+\delta I\left(q \leq q_{(j)}\right) x_{i}+e_{i}$ (or equivalently, when all parameters are allowed to depend on the threshold, estimating separately $y_{i}=\theta_{1}^{\prime} x_{i}+e_{1 i}$ where $q_{i} \leq q_{(j)}$ and $y_{i}=\theta_{2}^{\prime} x_{i}+e_{2 i}$ where $\left.q_{i}>q_{(j)}\right)$,

2. calculating the sum of squared residuals, $S S R\left(q_{(j)}\right)=\sum e_{i}\left(\right.$ or $\left.=\sum e_{1 i}+\sum e_{2 i}\right)$,

3. repeating 1 and 2 with $q_{(j+1)}$,

4. finding the least squares estimate of $\gamma$ as $\hat{\gamma}=\arg \min _{q_{(j)}} S\left(q_{(j)}\right)$, and

5. repeating the estimation of the equations on the sub-samples defined by the $\hat{\gamma}$ threshold, calculating heteroskedasticity-consistent standard errors for the parameters.

As suggested by Hansen (1999), we allow each equation to contain at least $20 \%$ of the observations, and, to minimize computing time, we search only through 0.5\%-quantiles. Although Hansen (1999) presents an extension of the procedure to several thresholds, we focus in this paper on a single sample split.

\footnotetext{
${ }^{45}$ A theory for the latter case was developed in Caner and Hansen (2001).
} 
To test the presence of the threshold, thus testing whether $\theta_{1}=\theta_{2}$, the usual tests cannot be used, since $\gamma$ is not identified under the null hypothesis ("Davies' Problem", as analyzed by Davies (1977, 1987)). Hansen (1996) provides a test whose asymptotic properties can be approximated by boostrap techniques.

To provide confidence intervals for the threshold estimate $\hat{\gamma}$, Hansen (2000) argues that no-rejection regions should be used. To test $\gamma=\gamma_{0}$, the likelihood ratio test can be used such that $L R(\gamma)=$ $(S S R(\gamma)-S S R(\hat{\gamma})) / \hat{\sigma}^{2}$, where $\hat{\sigma}^{2}=S S R(\hat{\gamma}) / N$ is the estimated error variance, will be rejected if $\hat{\gamma}$ is sufficiently far from $\gamma$, i.e. the test statistic is large enough. In its homoskedastic version, the test has a non-standard pivotal distribution, such that the test is rejected at an $\alpha$-confidence level if $L R(\gamma)>-2 \ln (1-\sqrt{\alpha})$. In this paper, we choose $\alpha=0.95$, consistent with Hansen (2000); thus, the null hypothesis is considered rejected if $L R(\gamma)>=-2 \ln (1-\sqrt{0.95})=7.35$. This level is plotted as a horizontal line in the plots of the test. The confidence interval for the threshold will be $\left[\gamma_{L}, \gamma_{U}\right]$, such that $L R\left(\gamma \mid \gamma<\gamma_{U}\right)>7.35$, and $L R\left(\gamma \mid \gamma>\gamma_{U}\right)>7.35$, or, graphically, the portion of the $x$-axis where the plot of the test is below the 7.35 horizontal line.

\section{Structural Break Tests}

The Chow test is a standard break point analysis used widely in the economics literature. Based on two nested regressions, it follows an $f_{k, T-2 k}$-distribution and its statistic is

$$
F=\frac{\left(S S R_{0}-S S R_{1}\right) / k}{S S R_{1} /(T-2 k)}
$$

where $S S R_{0}$ and $S S R_{1}$ are the sum of squared residuals of the restricted regression, $y_{t}=x_{t}^{\prime} \beta+\epsilon_{t}$ (with $t=1, \ldots, T)$, and the unrestricted regression, $y_{t}=x_{t}^{\prime} \beta+g_{t} x_{t}^{\prime} \gamma+\epsilon_{t}$, respectively. In the unrestricted regressions, the observations following the break point $t^{*}$, selected by the dummy variable $g_{t}$ (such that $g_{t}=1$ if $t<t^{*} \leq T$ and 0 otherwise), are allowed to depend on $x_{t}$ through the composite parameters $\beta+\gamma$, while the previous observations depend on $x_{t}$ through $\beta$ only. The restriction $\gamma=0$ thus imposes the condition that all $y_{t}$ depend on $x_{t}$ in a homogeneous fashion 46

A drawback of the Chow test is that the breakpoint has to be specified exogeneously. The Chow test has a null hypothesis, which is that the parameters after a specific date are equal to those that generated the data before the break date. The alternative hypothesis is that the two sets of parameters are indeed different. However, a test statistic can be calculated from the statistics resulting from the Chow test, the $F$ s, to test whether a structural break took place at an unknown date. After computing the $F$-statistics for a subset of dates, e.g. all the dates in the sample except for the first and last i\%, several test statistics can be calculated from them.

Andrews (1993) and Andrews and Ploberger (1994) show that the supremum and the average, respectively, of the $F$-statistics converge to a pivotal non-standard distribution, depending on the number of parameters tested and the relative number of dates tested. The test statistics that we

\footnotetext{
${ }^{46}$ We exclude the first and last $10 \%$ of the observations, in order to estimate meaningful regressions.
} 
calculate to test for a structural break at an unknown date are therefore

$$
\begin{aligned}
& \sup F=\sup _{t} F_{t} \\
& \text { aveF }=\frac{\sum_{t} F_{t}}{T}
\end{aligned}
$$

where the $F_{t}$ are found with the Chow test estimation. We then compare the supF and aveF test statistics with the corresponding confidence levels, that can be found in Andrews (2003) (which rectified those tabulated in Andrews (1993)) and Andrews and Ploberger (1994). 


\section{Tables}

Table 1: Maturity and Coupon Rate by Maturity Group and Bond Type. This table presents the distribution of the bonds in the sample in terms of Maturity and Coupon Rate, by maturity group (Panel A) and bond type (Panel B). Maturity groups were determined by the time distance between bond maturities and the closest whole year. Our dataset, obtained from the Mercato dei Titoli di Stato (MTS), consists of transactions, quotes, and orders for all 152 fixed-rate and floating Italian government bonds (Buoni Ordinari del Tesoro (BOT) or Treasury bills, Certificato del Tesoro Zero-coupon (CTZ) or zero coupon bonds, Certificati di Credito del Tesoro (CCT) or floating notes, and Buoni del Tesoro Poliennali (BTP) or fixed-income Treasury bonds) from June 1, 2011 to December 31, 2012

\begin{tabular}{|c|c|c|c|c|c|}
\hline \multicolumn{6}{|c|}{ Panel A } \\
\hline Maturity Group & \# Bonds & Coupon Rate & Maturity & MinMaturity & MaxMaturity \\
\hline 0.25 & 8 & $a$ & 0.26 & 0.21 & 0.27 \\
\hline 0.50 & 27 & $a$ & 0.51 & 0.36 & 0.53 \\
\hline 1.00 & 33 & $a$ & 1.01 & 0.83 & 1.03 \\
\hline 2.00 & 11 & $b$ & 2.02 & 2.01 & 2.09 \\
\hline 3.00 & 11 & 3.16 & 2.98 & 2.93 & 3.02 \\
\hline 5.00 & 13 & 3.87 & 5.03 & 4.92 & 5.25 \\
\hline 6.00 & 13 & $c$ & 6.67 & 5.29 & 7.09 \\
\hline 10.00 & 19 & 4.45 & 10.41 & 10.10 & 10.52 \\
\hline 15.00 & 7 & 4.57 & 15.71 & 15.44 & 16.00 \\
\hline 30.00 & 10 & 5.88 & 30.88 & 29.30 & 31.79 \\
\hline \multicolumn{6}{|c|}{ Panel B } \\
\hline Bond Type & $\mathrm{N}$ & Coupon Rate & Maturity & MinMaturity & MaxMaturity \\
\hline $\mathrm{BOT}$ & 68 & $\mathrm{ZCB}$ & 0.72 & 0.21 & 1.03 \\
\hline BTP & 60 & 4.34 & 11.91 & 2.93 & 31.79 \\
\hline $\mathrm{CCT}$ & 13 & Floating & 6.70 & 5.29 & 7.09 \\
\hline $\mathrm{CTZ}$ & 11 & $\mathrm{ZCB}$ & 2.02 & 2.01 & 2.09 \\
\hline
\end{tabular}

${ }^{a}$ All bonds in this group are BOT, Buoni Ordinari del Tesoro (Treasury bills)

${ }^{b}$ All bonds in this group are CTZ, Certificati del Tesozo Zero-coupon (zero coupon bonds, ZCB)

${ }^{c}$ All bonds in this group are CCT, Certificati di Credito del Tesoro (floating bonds) 
Table 2: Time-series Descriptive Statistics of the Variables. This table shows the timeseries and cross-sectional distribution of various variables defined in Section IV.I. The sample consists of the quotes and trades from 406 days in our sample for bond market data and end-of-day quotes for the other measures. Quoted Bonds is the number of bonds actually quoted on each day, Trades is the total number of trades on the day, and Volume is the daily amount traded in $€$ billion(million) on the whole market. The liquidity measure Bid-Ask Spread is the difference between the best bid and the best ask, the global systemic variables are the spread between three-month Euribor and threemonth German government yield, the USVIX, and the Cross-Currency Basis Swap Spread CCBSS Our bond-based data, obtained from the Mercato dei Titoli di Stato (MTS), consist of transactions, quotes, and orders for all 152 fixed-rate and floating Italian government bonds (Buoni Ordinari de Tesoro (BOT) or Treasury bills, Certificato del Tesoro Zero-coupon (CTZ) or zero coupon bonds, Certificati di Credito del Tesoro (CCT) or floating notes, and Buoni del Tesoro Poliennali (BTP) or fixed-income Treasury bonds) from June 1, 2011 to December 31, 2012. All other data were obtained from Bloomberg.

\begin{tabular}{c|ccccc|cc}
\hline \multicolumn{7}{c}{ Time Series } & Unit Root Test \\
\hline \multicolumn{7}{c}{ Panel A: Market Measures } \\
\hline Variable & Mean & STD & 5th Pct & Median & 95 th Pct & Level & Difference \\
\hline Quoted Bonds & 89.781 & 2.108 & 87.000 & 90.000 & 92.000 & & \\
Trades & 265.256 & 108.064 & 116.000 & 249.000 & 321.000 & & \\
Volume & 2.027 & 0.953 & 0.772 & 1.888 & 2.431 & & \\
\hline \multicolumn{7}{c}{ Panel B: System Variables } \\
\hline Bid-Ask Spread & 0.506 & 0.376 & 0.176 & 0.419 & 0.551 & $-3.700^{* * *}$ & $-12.122^{* * *}$ \\
Italian CDS & 401.523 & 108.244 & 194.015 & 421.296 & 552.843 & -2.338 & $-10.402^{* * *}$ \\
USVIX & 21.888 & 7.377 & 14.800 & 18.860 & 37.320 & -2.099 & $-11.578^{* * *}$ \\
CCBSS & 50.214 & 20.285 & 24.500 & 50.938 & 87.860 & -1.339 & $-10.354^{* * *}$ \\
Euribor-DeTBill & 0.818 & 0.420 & 0.248 & 0.720 & 1.507 & -0.186 & $-11.332^{* * *}$ \\
\hline
\end{tabular}


Table 3: Time-series Correlations of Trade- and Quote-based Liquidity Measures. This table shows the time-series correlations between the variables defined in Section IV.I in levels (differences) above (below) the diagonal. The sample consists of the quotes and trades from the 406 days in our sample. Each day's data are summarized by the cross-sectional (across bonds) average. The liquidity measure Bid-Ask Spread is the difference between the best bid and the best ask, the global systemic variables are the spread between three-month Euribor and three-month German government yield, the USVIX, and the Cross-Currency Basis Swap Spread (CCBSS). Our bond-based data, obtained from the Mercato dei Titoli di Stato (MTS), consist of transactions, quotes, and orders for all 152 fixed-rate and floating Italian government bonds (Buoni Ordinari del Tesoro (BOT) or Treasury bills, Certificato del Tesoro Zero-coupon (CTZ) or zero coupon bonds, Certificati di Credito del Tesoro (CCT) or floating notes, and Buoni del Tesoro Poliennali (BTP) or fixed-income Treasury bonds) from June 1, 2011 to December 31, 2012. All other data were obtained from Bloomberg.

\begin{tabular}{c|ccccc}
\hline Differences $\backslash$ Levels & Bid-Ask Spread & Italian CDS & USVIX & CCBSS & Euribor-DeTBill \\
\hline Bid-Ask Spread & 1 & 0.496 & 0.456 & 0.591 & 0.634 \\
Italian CDS & 0.228 & 1 & 0.354 & 0.803 & 0.564 \\
USVIX & 0.221 & 0.354 & 1 & 0.523 & 0.696 \\
CCBSS & 0.191 & 0.415 & 0.294 & 1 & 0.854 \\
Euribor-DeTBill & 0.053 & 0.108 & 0.026 & 0.022 & 1 \\
\hline
\end{tabular}


Table 4: Results for the Granger-Causality Analysis of Italian CDS Spread and Bid-Ask Spread. This table presents the results for the regressions of the day $t$ changes in Bid-Ask Spread, $\Delta \mathrm{BA}_{t}$, and Italian CDS spread $\triangle C D S_{t}$, on the lagged terms of both variables and on contemporaneous macro variable changes, in a $\operatorname{VARX}(3,0)$ setting as shown in Equation 1. The data have a daily frequency. The significance refers to heteroskedasticity-robust $t$-tests. Heteroskedasticity-robust $F$-test statistics and their significance are reported for the null hypothesis of $\Delta B A_{t}=$ $\Delta B A_{t-1} \ldots=0(B A \stackrel{G C}{\longrightarrow} C D S)$, and $\triangle C D S_{t}=\Delta C D S_{t-1} \ldots=0(C D S \stackrel{G C}{\longrightarrow} B A)$ respectively. We also report the contemporaneous correlation in the model residuals. Our dataset consists of 406 days of trading in Italian government bonds, from June 1, 2011 to December 31, 2012, and is obtained from the MTS (Mercato dei Titoli di Stato) Global Market bond trading system. The CDS spread refers to a USD-denominated, five-year CDS spread. The CDS spread and the macro variables are obtained from Bloomberg.

\begin{tabular}{l|cc}
\hline Variable & $\Delta B A_{t}$ & $\Delta C D S_{t}$ \\
\hline Intercept & -0.001 & 0.001 \\
$\Delta B A_{t-1}$ & $-0.366^{* * *}$ & -0.008 \\
$\Delta C D S_{t-1}$ & $1.097^{* * *}$ & $0.190^{* * *}$ \\
$\Delta B A_{t-2}$ & $-0.171^{* * *}$ & -0.004 \\
$\Delta C D S_{t-2}$ & -0.248 & $-0.095^{*}$ \\
$\Delta B A_{t-3}$ & $-0.157^{* * *}$ & -0.002 \\
$\Delta C D S_{t-3}$ & 0.111 & 0.029 \\
$\Delta E$ uribor DeTBill $t$ & 0.079 & $0.058^{*}$ \\
$\Delta C C B S S_{t}$ & $0.525^{* * *}$ & $0.269^{* * *}$ \\
$\Delta U S V I X_{t}$ & $0.434^{* * *}$ & $0.146^{* * *}$ \\
\hline Adj $R^{2}$ & 0.206 & 0.262 \\
\hline \multicolumn{3}{c}{ Granger-Causality Tests } \\
\hline BA GC $C D S$ & $\cdot$ & 0.41 \\
$C D S \stackrel{G C}{\longrightarrow} B A$ & $16.20^{* * *}$ &. \\
\hline \multicolumn{3}{c}{ Residuals Correlation } \\
\hline$\Delta B A_{t}$ & 1.000 & 0.082 \\
$\Delta C D S_{t}$ & 0.082 & 1.000 \\
\hline
\end{tabular}

\footnotetext{
${ }^{*}$ Significant at a $10 \%$ level. ${ }^{* *}$ Significant at a $5 \%$ level. ${ }^{* * *}$ Significant at a $1 \%$ level.
} 
Table 5: Results for the Regression of the Bid-Ask Spread on CDS spread and Macro Variables. This table presents the results for the regression of the change in the Bid-Ask Spread (the change in the quoted bid-ask spread) on day $t$, $\Delta \mathrm{BA}_{t}$, on its lagged terms, and the change in the CDS spread on day $t, \Delta \mathrm{CDS}_{t}$, and its lagged terms and on macro variables, using daily data. The regressions are presented in Equations 2, 3, and 4, for Panels A, B, and C, respectively. Parameters multiplying the identity operator $[C D S \leq(>) 500]$ are reported under the $[C D S \leq(>) 500]$ column. The statistical significance refers to heteroskedasticity-robust $t$-tests. The Test columns report the heteroskedasticity-robust test for the two parameters above and below the threshold as being equal and distributed as chi-square (1). Our dataset consists of 406 days of trading in Italian government bonds, from June 1, 2011 to December 31, 2012, and is obtained from the Mercato dei Titoli di Stato (MTS) Global Market bond trading system. The CDS spread refers to a USD-denominated, five-year CDS spread and macro variables were obtained from Bloomberg.

\begin{tabular}{|c|c|c|c|c|c|c|c|c|}
\hline \multirow[t]{2}{*}{ Variable } & \multirow{2}{*}{$\begin{array}{c}\text { Panel A } \\
\text { Whole Sample }\end{array}$} & \multicolumn{3}{|c|}{ Panel B } & \multicolumn{4}{|c|}{ Panel C } \\
\hline & & $\mathrm{I}[\mathrm{CDS} \leq 500]$ & $\mathrm{I}[\mathrm{CDS}>500]$ & Test & Restricted & $\mathrm{I}[\mathrm{CDS} \leq 500]$ & $\mathrm{I}[\mathrm{CDS}>500]$ & Test \\
\hline$\Delta \mathrm{CDS}_{t}$ & 0.436 & 0.104 & $2.858^{* * *}$ & $9.55^{* * *}$ & . & 0.102 & $2.973^{* * *}$ & $12.06^{* * *}$ \\
\hline$\Delta \mathrm{CDS}_{t-1}$ & $0.972^{* * *}$ & $1.266^{* * *}$ & -0.647 & $8.38^{* * *}$ & . & $1.276^{* * *}$ & $-0.839^{*}$ & $11.19^{* * *}$ \\
\hline$\Delta \mathrm{BA}_{t-1}$ & $-0.373^{* * *}$ & $-0.337^{* * *}$ & $-0.332^{* * *}$ & 0.00 & $-0.336^{* * *}$ & . & & \\
\hline$\Delta \mathrm{BA}_{t-2}$ & $-0.177^{* * *}$ & $-0.141^{* *}$ & -0.152 & 0.01 & $-0.144^{* *}$ & . & . & . \\
\hline$\Delta \mathrm{BA}_{t-3}$ & $-0.153^{* * *}$ & $-0.145^{* *}$ & $-0.169^{* *}$ & 0.05 & $-0.153^{* * *}$ & . & . & . \\
\hline$\Delta \mathrm{CCBSS}_{t}$ & $0.408^{* *}$ & $0.473^{* *}$ & 0.032 & 1.01 & $0.346^{*}$ & . & 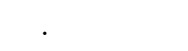 & . \\
\hline$\Delta$ USVIX $_{t}$ & $0.376^{* *}$ & 0.224 & $0.632^{*}$ & 1.08 & $0.324^{* *}$ & . & & . \\
\hline Intercept & -0.002 & 0.003 & -0.016 & 0.52 & -0.001 & . & & . \\
\hline $\begin{array}{l}\text { Adj } R^{2} \\
\mathrm{~N}\end{array}$ & $\begin{array}{c}0.212 \\
402\end{array}$ & \multicolumn{3}{|c|}{$\begin{array}{c}0.257 \\
402\end{array}$} & \multicolumn{4}{|c|}{$\begin{array}{c}0.262 \\
402\end{array}$} \\
\hline
\end{tabular}

${ }^{*}$ Significant at a $10 \%$ level. ${ }^{* *}$ Significant at a $5 \%$ level. ${ }^{* * *}$ Significant at a $1 \%$ level. 
Table 6: Results for the Regression of the Bid-Ask Spread on CDS Spread and Macro Variables for Sub-Samples Based on the Structural Break. This table presents the results for the regression of the change in the Bid-Ask Spread (the change in the quoted bid-ask spread) on day $t, \Delta \mathrm{BA}_{t}$, on its lagged terms, and the change in the CDS spread on day $t, \Delta \mathrm{CDS}_{t}$, and its lagged terms, using daily data for the Bid-Ask Spread and the CDS spread. The regressions are presented for Equations 3 and 2, in Panels A and B respectively. Parameters multiplying the identity operator $[C D S \leq(>) 500]$ are reported under the $[C D S \leq(>) 500]$ column. The statistical significance refers to heteroskedasticity-robust $t$-tests. The Test columns report the heteroskedasticity-robust test results for the two parameters above and below the threshold being equal and distributed as chi-square (1). Panel A (B) is based on the pre-(post-)structural-break sample. Our dataset consists of 406 days of trading in Italian government bonds, from June 1, 2011 to December 31, 2012, and is obtained from the Mercato dei Titoli di Stato (MTS) Global Market bond trading system. The CDS spread refers to a USD-denominated, five-year CDS spread and macro variables were obtained from Bloomberg.

\begin{tabular}{|c|c|c|c|c|c|}
\hline \multirow[t]{2}{*}{ Variable } & \multicolumn{4}{|c|}{ Panel A: 2011} & \multirow{2}{*}{ Panel B: 2012} \\
\hline & All Sample & $\mathrm{I}[\mathrm{CDS} \leq 500]$ & $\mathrm{I}[\mathrm{CDS}>500]$ & Test & \\
\hline Intercept & 0.007 & . & . & & -0.005 \\
\hline$\Delta \mathrm{CDS}_{t}$ & . & 0.350 & $3.940 * * *$ & $14.78^{* * *}$ & 0.004 \\
\hline$\Delta \mathrm{CDS}_{t-1}$ & 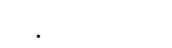 & $1.734^{* * *}$ & $-1.713^{* *}$ & $15.36^{* * *}$ & $0.576^{* *}$ \\
\hline$\Delta \mathrm{BA}_{t-1}$ & $-0.211^{* *}$ & . & . & . & $-0.500 * * *$ \\
\hline$\Delta \mathrm{BA}_{t-2}$ & -0.066 & . & . & . & $-0.296 * * *$ \\
\hline$\Delta \mathrm{BA}_{t-3}$ & $-0.174^{* *}$ & . & . & 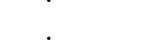 & $-0.189^{* * *}$ \\
\hline$\Delta \mathrm{CCBSS}_{t}$ & 0.054 & . & . & . & $0.875^{* * *}$ \\
\hline$\Delta \mathrm{USVIX}_{t}$ & $0.558^{* * *}$ & . & . & . & -0.096 \\
\hline $\begin{array}{l}\text { Adj } R^{2} \\
\mathrm{~N}\end{array}$ & \multicolumn{4}{|c|}{$\begin{array}{c}0.354 \\
142\end{array}$} & $\begin{array}{c}0.238 \\
260\end{array}$ \\
\hline
\end{tabular}

${ }^{*}$ Significant at a $10 \%$ level. ${ }^{* *}$ Significant at a $5 \%$ level. ${ }^{* * *}$ Significant at a $1 \%$ level.

Table 7: Time-series Correlations of Trade- and Quote-based Liquidity Measures. This table shows the time-series correlations between the bid-ask spread and the liquidity measures defined in Section VII.I in levels (differences) above (below) the diagonal. The sample consists of the quotes and trades from 406 days in our sample. Bid-Ask Spread is the difference between the best bid and the best ask, Effective Spread is the effective bid-ask spread paid by the traders, Quoted Quantity is the face value quantity offered on average per bond on the bid and ask side in millions of euros, Lambda is a measure of depth. Our bond-based data, obtained from the Mercato dei Titoli di Stato (MTS), consist of transactions, quotes, and orders for all 152 fixed-rate and floating Italian government bonds (Buoni Ordinari del Tesoro (BOT) or Treasury bills, Certificato del Tesoro Zerocoupon (CTZ) or zero coupon bonds, Certificati di Credito del Tesoro (CCT) or floating notes, and Buoni del Tesoro Poliennali (BTP) or fixed-income Treasury bonds) from June 1, 2011 to December 31, 2012.

\begin{tabular}{l|cccc}
\hline Differences $\backslash$ Levels & Bid-Ask Spread & Quoted Quantity & Lambda & Effective Spread \\
\hline Bid-Ask Spread & 1.000 & -0.591 & 0.904 & 0.890 \\
Quoted Quantity & -0.600 & 1.000 & -0.496 & -0.557 \\
Lambda & 0.437 & -0.402 & 1.000 & 0.789 \\
Effective Spread & 0.512 & -0.508 & 0.240 & 1.000 \\
\hline
\end{tabular}


Table 8: Other Liquidity Variables: Results for Sub-samples Based on Time and CDS Level. This table presents the results for the regression of the changes in several liquidity measures on their lagged terms, and the change in the CDS spread on day $t, \Delta \mathrm{CDS}_{t}$, and its lagged terms, and contemporaneous changes in macro variables, using daily data. Panel $\mathrm{A}(\mathrm{C})$ reports the regressions as specified in Equation 2 for the whole (post-structural-break) sample and Panel B reports the regressions as specified in Equation 3 . The alternative liquidity measures employed here are Quoted Quantity $\Delta Q Q_{t}$, Effective Spread $\Delta E S_{t}$, and Lambda $\Delta \lambda_{t}$, described in Section VII.I Parameters multiplying the identity operator $[C D S \leq(>) 500]$ are reported under the $[C D S \leq(>) 500]$ column. The statistical significance refers to heteroskedasticityrobust $t$-tests. The Test columns report the heteroskedasticity-robust test results for the two parameters above and below the threshold being equal and distributed as chisquare (1). The sub-samples are based on our dataset, which consists of 406 days of trading in Italian government bonds, from June 1, 2011 to December 31, 2012, and is obtained from the MTS (Mercato dei Titoli di Stato) Global Market bond trading system. The CDS spread refers to a USD-denominated, five-year CDS spread and macro variables were obtained from Bloomberg.

\begin{tabular}{|c|c|c|c|c|c|}
\hline \multirow[t]{2}{*}{ Variable } & \multirow{2}{*}{$\begin{array}{c}\text { Panel A } \\
\text { All Sample }\end{array}$} & \multicolumn{3}{|c|}{ Panel B: 2011} & \multirow[t]{2}{*}{ Panel C: 2012} \\
\hline & & $I[C D S \leq \hat{\gamma}]$ & $I[C D S>\hat{\gamma}]$ & Test & \\
\hline \multicolumn{6}{|c|}{ Dependent Variable: Quoted Quantity, $Q Q_{t}$} \\
\hline Intercept & -0.000 & -0.007 & 0.028 & 1.52 & -0.004 \\
\hline$\Delta C D S_{t}$ & -0.077 & 0.292 & $-0.946^{* *}$ & $6.18^{* *}$ & -0.203 \\
\hline$\Delta C D S_{t-1}$ & -0.265 & $-0.662^{* *}$ & 0.281 & $2.84^{*}$ & -0.036 \\
\hline$\Delta Q_{t-1}$ & $-0.330 * * *$ & $-0.318^{* *}$ & -0.091 & 0.98 & $-0.393^{* * *}$ \\
\hline$\Delta Q_{t-2}$ & $-0.309^{* * *}$ & $-0.185^{*}$ & 0.018 & 1.46 & $-0.479 * * *$ \\
\hline$\Delta Q_{t-3}$ & $-0.201^{* * *}$ & -0.154 & -0.069 & 0.44 & $-0.289 * * *$ \\
\hline$\Delta C C B S S_{t}$ & -0.098 & -0.187 & 0.272 & 1.05 & $-0.270^{*}$ \\
\hline$\Delta U S V I X_{t}$ & $-0.280^{* * *}$ & $-0.316^{* * *}$ & $-1.167^{* * *}$ & $9.45^{* * *}$ & 0.022 \\
\hline Adj. $R^{2}$ & 0.191 & & 0.309 & & 0.255 \\
\hline \multicolumn{6}{|c|}{ Dependent Variable: Effective Spread, $E S_{t}$} \\
\hline Intercept & -0.002 & 0.015 & $-0.098^{*}$ & $3.79^{*}$ & -0.008 \\
\hline$\Delta C D S_{t}$ & $0.851^{* *}$ & 0.625 & $2.646^{* *}$ & $2.77^{*}$ & 0.649 \\
\hline$\Delta C D S_{t-1}$ & 0.526 & $0.972^{*}$ & $1.862^{*}$ & 0.61 & -0.287 \\
\hline$\Delta \mathrm{ES}_{t-1}$ & $-0.427^{* * *}$ & $-0.233^{* * *}$ & $-0.222 *$ & 0.00 & $-0.598^{* * *}$ \\
\hline$\Delta \mathrm{ES}_{t-2}$ & $-0.320 * * *$ & $-0.205^{* *}$ & $-0.267^{* *}$ & 0.18 & $-0.458^{* * *}$ \\
\hline$\Delta \mathrm{ES}_{t-3}$ & $-0.224^{* * *}$ & $-0.220^{* *}$ & $-0.232^{*}$ & 0.01 & $-0.283^{* * *}$ \\
\hline$\triangle C C B S S_{t}$ & 0.393 & 0.234 & -0.615 & 1.11 & 0.719 \\
\hline$\Delta U S V I X_{t}$ & $0.383^{*}$ & 0.385 & 1.355 & 1.21 & 0.142 \\
\hline Adj. $R^{2}$ & 0.221 & & 0.195 & & 0.302 \\
\hline \multicolumn{6}{|c|}{ Dependent Variable: Lambda, $\lambda_{t}$} \\
\hline Intercept & 0.001 & 0.013 & -0.029 & 0.17 & -0.007 \\
\hline$\Delta C D S_{t}$ & 0.046 & -0.157 & $4.289^{* * *}$ & $6.39^{* *}$ & -0.589 \\
\hline$\Delta C D S_{t-1}$ & $1.329^{* *}$ & $2.783^{* * *}$ & -0.445 & $4.98^{* *}$ & 0.225 \\
\hline$\Delta \lambda_{t-1}$ & $-0.562^{* * *}$ & -0.490 & $-0.359 * * *$ & 0.82 & $-0.623^{* * *}$ \\
\hline$\Delta \lambda_{t-2}$ & $-0.315^{* * *}$ & -0.136 & -0.119 & 0.00 & $-0.419 * * *$ \\
\hline$\Delta \lambda_{t-3}$ & $-0.297^{* * *}$ & -0.139 & $-0.341^{* * *}$ & 1.49 & $-0.398^{* * *}$ \\
\hline$\Delta \lambda_{t-4}$ & $-0.109 * *$ & 0.072 & $-0.297^{* * *}$ & $8.18^{* * *}$ & $-0.172^{* * *}$ \\
\hline$\Delta C C B S S_{t}$ & $0.660^{*}$ & 0.392 & -0.130 & 0.26 & $1.345^{* *}$ \\
\hline$\Delta U S V I X_{t}$ & 0.299 & -0.163 & $2.370^{* *}$ & $6.25^{* *}$ & -0.146 \\
\hline Adj. $R^{2}$ & 0.264 & & 0.333 & & 0.291 \\
\hline
\end{tabular}


Table 9: Results for Granger-Causality with Variance of Returns. We regress changes in the liquidity measure, changes in credit risk, and changes in the volatility of the returns, on their own lags and the lags of the other two variables, and on contemporaneous changes in macro variables in a $\operatorname{VARX}(4,0)$ setting as shown in Equation 1 The significance refers to heteroskedasticity-robust $t$-tests. Heteroskedasticityrobust $F$-test statistics and their significance are reported for the null hypothesis of no Granger-causality from one variable to the other two. Our dataset consists of 406 days of trading in the government bonds, from June 1, 2011 to December 31, 2012, and is obtained from the MTS (Mercato dei Titoli di Stato) Global Market bond trading system. The CDS spread refers to a USD-denominated, five-year CDS spread. The CDS spread and the macro variables were obtained from Bloomberg.

\begin{tabular}{|c|c|c|c|}
\hline Variable & $\Delta B A_{t}$ & $\Delta C D S_{t}$ & $\Delta \sigma_{t}^{2}$ \\
\hline $\begin{array}{l}\text { Intercept } \\
\Delta B A_{t-1} \\
\Delta C D S_{t-1} \\
\Delta \sigma_{t-1}^{2} \\
\Delta B A_{t-2} \\
\Delta C D S_{t-2} \\
\Delta \sigma_{t-2}^{2} \\
\Delta B A_{t-3} \\
\Delta C D S_{t-3} \\
\Delta \sigma_{t-3}^{2} \\
\Delta B A_{t-4} \\
\Delta C D S_{t-4} \\
\Delta \sigma_{t-4}^{2} \\
\Delta E \text { EuriborDeTBill } \\
\Delta C C B S S_{t} \\
\Delta U S V I X_{t}\end{array}$ & $\begin{array}{l}-0.002 \\
-0.368 * * * \\
1.109 * * * \\
-0.001 \\
-0.126 \\
-0.226 \\
-0.013 \\
-0.146 * \\
-0.028 \\
-0.012 \\
-0.080 \\
0.474 * \\
0.005 \\
0.057 \\
0.500^{* *} \\
0.468^{* * *}\end{array}$ & $\begin{array}{l}0.002 \\
-0.014 \\
0.192 * * * \\
0.002 \\
-0.007 \\
-0.095^{*} \\
-0.000 \\
0.003 \\
0.039 \\
-0.001 \\
-0.008 \\
-0.062 \\
0.002- \\
0.064^{* *} \\
0.276^{* * *} \\
0.145^{* * *}\end{array}$ & $\begin{array}{l}0.007 \\
0.790^{* *} \\
0.218 \\
-0.719^{* * *} \\
0.656^{*} \\
0.346 \\
-0.578^{* * *} \\
0.374 \\
-0.066 \\
-0.396^{* * *} \\
0.242 \\
0.967 \\
0.166 * * * \\
0.967 \\
2.748^{* *} \\
1.375^{*}\end{array}$ \\
\hline \multicolumn{4}{|c|}{ Granger-Causality Tests } \\
\hline $\begin{array}{l}B A \stackrel{G C}{\longrightarrow} C D S+\sigma^{2} \\
C D S \stackrel{G C}{\longrightarrow} B A+\sigma^{2} \\
\sigma^{2} \stackrel{G C}{\longrightarrow} C D S+B A\end{array}$ & & $\begin{array}{c}1.83^{*} \\
3.67^{* * *} \\
0.61\end{array}$ & \\
\hline \multicolumn{4}{|c|}{ Residuals Correlation } \\
\hline $\begin{array}{l}\triangle B A \\
\triangle C D S \\
\Delta \sigma^{2}\end{array}$ & $\begin{array}{l}1.000 \\
0.084 \\
0.594\end{array}$ & $\begin{array}{l}0.084 \\
1.0000 \\
-0.040\end{array}$ & $\begin{array}{r}0.594 \\
-0.040 \\
1.000\end{array}$ \\
\hline
\end{tabular}

${ }^{*}$ Significant at a $10 \%$ level. ${ }^{* *}$ Significant at a $5 \%$ level. ${ }^{* * *}$ Significant at a $1 \%$ level. 
Table 10: Results for the Regression of the Bid-Ask Spread on the CDS spread, Macro Variables, and Volatility for Sub-Samples Based on the Structural Break. This table presents the results for the regression of the change in the Bid-Ask Spread (the change in the quoted bid-ask spread) on day $t, \Delta \mathrm{BA}_{t}$, on its lagged terms, and on the change in the CDS spread on day $t, \Delta \operatorname{CDS}_{t}$, and its lagged terms, using daily data for the Bid-Ask Spread and the CDS spread. The regressions are presented for Equations 3 and 2 , in Panels A and B respectively. Parameters multiplying the identity operator $[C D S \leq(>) 500]$ are reported under the $[C D S \leq(>) 500]$ column. The statistical significance refers to heteroskedasticityrobust $t$-tests. The Test columns report the heteroskedasticity-robust test results for the two parameters above and below the threshold being equal and distributed as chi-square (1). Panel A (B) is based on the pre-(post-)structural-break sample. Our dataset consists of 406 days of trading in Italian government bonds, from June 1, 2011 to December 31, 2012, and is obtained from the Mercato dei Titoli di Stato (MTS) Global Market bond trading system. The CDS spread refers to a USD-denominated, five-year CDS spread and macro variables were obtained from Bloomberg.

\begin{tabular}{|c|c|c|c|c|c|}
\hline \multirow[t]{2}{*}{ Variable } & \multicolumn{4}{|c|}{ Panel A: 2011} & \multirow[t]{2}{*}{ Panel B: 2012} \\
\hline & All Sample & $\mathrm{I}[\mathrm{CDS} \leq 500]$ & $\mathrm{I}[\mathrm{CDS}>500]$ & Test & \\
\hline Intercept & 0.003 & . & 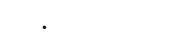 & & -0.005 \\
\hline$\Delta \mathrm{CDS}_{t}$ & & 0.619 & $2.363^{* * *}$ & $6.48^{* *}$ & 0.188 \\
\hline$\Delta \mathrm{CDS}_{t-1}$ & & $1.224^{* * *}$ & $-1.033^{*}$ & $9.43^{* * *}$ & $0.560 * *$ \\
\hline$\Delta \mathrm{BA}_{t-1}$ & -0.110 & . & . & . & $-0.384^{* * *}$ \\
\hline$\Delta \mathrm{BA}_{t-2}$ & -0.003 & . & . & . & $-0.216^{* * *}$ \\
\hline$\Delta \mathrm{BA}_{t-3}$ & $-0.139 * *$ & . & . & . & $-0.137^{* *}$ \\
\hline$\Delta \mathrm{CCBSS}_{t}$ & 0.054 & . & . & 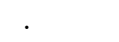 & $0.481^{* *}$ \\
\hline$\Delta \mathrm{USVIX}_{t}$ & 0.251 & . & . & · & -0.167 \\
\hline$\Delta \sigma_{t}^{2}$ & 0.117 *** & . & . & . & $0.058^{* * *}$ \\
\hline $\operatorname{Adj} R^{2}$ & \multirow{2}{*}{\multicolumn{4}{|c|}{$\begin{array}{c}0.563 \\
142\end{array}$}} & 0.388 \\
\hline $\mathrm{N}$ & & & & & 260 \\
\hline
\end{tabular}

* Significant at a $10 \%$ level. ${ }^{* *}$ Significant at a $5 \%$ level. ${ }^{* * *}$ Significant at a $1 \%$ level. 
Table 11: Results for the Granger-Causality Analysis of the Italian CDS Spread and Bid-Ask Spread: From 2010 to 2012. This table presents the results for the regressions of the day $t$ changes in Bid-Ask Spread $\Delta \mathrm{BA}_{t}$, and the Italian CDS spread $\triangle C D S_{t}$, on the lagged terms of both variables, in a $\operatorname{VAR}(3)$ setting as shown in Equation 1. The data have a daily frequency. The significance refers to heteroskedasticity-robust $t$-tests. Heteroskedasticity-robust $F$ test statistics and their significance are reported for the null hypothesis of $\Delta B A_{t}=\Delta B A_{t-1} \ldots=0(B A \stackrel{G C}{\longrightarrow} C D S)$, and $\triangle C D S_{t}=$ $\triangle C D S_{t-1} \ldots=0(C D S \stackrel{G C}{\longrightarrow} B A)$ respectively. We also report the contemporaneous correlation in the model residuals. Our dataset consists of 635 days of trading in Italian government bonds, from July 1, 2010 to December 31, 2012, and is obtained from the MTS (Mercato dei Titoli di Stato) Global Market bond trading system. The CDS spread refers to a USD-denominated, five-year CDS spread. The CDS spread is obtained from Bloomberg.

\begin{tabular}{l|ll}
\hline Variable & $\Delta B A_{t}$ & $\Delta C D S_{t}$ \\
\hline Intercept & -0.000 & 0.001 \\
$\Delta B A_{t-1}$ & $-0.377^{* * *}$ & -0.011 \\
$\Delta C D S_{t-1}$ & $1.051^{* * *}$ & $0.201^{* * *}$ \\
$\Delta B A_{t-2}$ & $-0.230^{* * *}$ & -0.008 \\
$\Delta C D S_{t-2}$ & -0.009 & $-0.089^{* *}$ \\
$\Delta B A_{t-3}$ & $-0.179^{* * *}$ & -0.001 \\
$\Delta C D S_{t-3}$ & 0.130 & 0.026 \\
$\Delta$ CCBSS $_{t}$ & $0.556^{* * *}$ & $0.217^{* * *}$ \\
$\Delta$ USVIX $_{t}$ & $0.402^{* *}$ & $0.142^{* * *}$ \\
\hline
\end{tabular}

Granger-Causality Tests

\begin{tabular}{l|cc}
\hline$C D S \stackrel{G C}{\longrightarrow} B A$ & $5.776^{* * *}$ & $\cdot$ \\
$B A \stackrel{G C}{\longrightarrow} C D S$ &. & 0.445 \\
\hline
\end{tabular}

\begin{tabular}{l|ll}
\hline \multicolumn{3}{c}{ Residuals Correlation } \\
\hline$\Delta B A_{t}$ & 1.000 & 0.102 \\
$\Delta C D S_{t}$ & 0.102 & 1.000 \\
\hline
\end{tabular}

${ }^{*}$ Significant at a $10 \%$ level. ${ }^{* *}$ Significant at a $5 \%$ level. ${ }^{* * *}$ Significant at a $1 \%$ level. 
Table 12: Results for the Instrumental Variable Analysis. This table presents the results for the instrumental variable analysis of Appendix B. The first-stage regressions are presented in Panel A, where $\Delta C D S_{t}$ is regressed on the second-stage right-hand-side variables and several combinations of variables exogenous to Equation 2 The significance of the parameters refers to heteroskedasticity-robust t-tests. The $F$-test row reports the (standard) $F$-test for the hypothesis that all regression parameters are contemporaneously 0 , while $F$ Test IV reports the $F$-test for the hypothesis that only the parameters of the exogenous variables added to the second-stage variables are contemporaneously equal to 0 . Panel B reports the IV estimators of Equation 2 when using different combinations of exogenous variables in the first stage. The Hausmann-Wu test verifies whether the OLS and the IV estimates are significantly different under the assumption that both are consistent against the alternative that only the IV set is. Our dataset consists of 406 days of trading in Italian government bonds, from June 1, 2011 to December 31, 2012, and is obtained from the Mercato dei Titoli di Stato (MTS) Global Market bond trading system. The CDS spread refers to a USD-denominated, five-year CDS spread and was obtained together with the other exogenous variables from Bloomberg.

\begin{tabular}{|c|c|c|c|c|c|c|c|}
\hline \multicolumn{8}{|c|}{ Panel A: First-Stage Regression } \\
\hline Variable & MODEL1 & MODEL2 & MODEL3 & MODEL 4 & MODEL5 & MODEL6 & MODEL7 \\
\hline Intercept & 0.001 & 0.000 & 0.001 & 0.001 & 0.000 & 0.001 & 0.000 \\
\hline$\Delta C D S_{t-1}$ & $0.092 * *$ & $0.193^{* * *}$ & 0.099 & 0.058 & 0.034 & $0.156^{* * *}$ & 0.013 \\
\hline$\Delta B A_{t-1}$ & -0.001 & -0.008 & -0.015 & -0.003 & -0.008 & -0.005 & -0.003 \\
\hline$\Delta B A_{t-2}$ & 0.006 & -0.002 & -0.008 & 0.003 & 0.001 & -0.001 & 0.006 \\
\hline$\Delta B A_{t-3}$ & 0.002 & 0.002 & 0.0 & 0.0 & 0.002 & 0.004 & 0.003 \\
\hline$\Delta C C B S S_{t}$ & $0.088 * * *$ & $0.198^{* * *}$ & $0.271 * * *$ & $0.109 * * *$ & 0.05 & $0.152 * * *$ & 0.019 \\
\hline$\Delta U S V I X_{t}$ & 0.024 & 0.049 & $0.151 * * *$ & $0.08^{* *}$ & $0.064 * *$ & -0.008 & 0.011 \\
\hline$\Delta Y$ ield ${ }_{t}^{D E}$ & $-0.394 * * *$ & $-0.583 * * *$ & . & . & . & . & $-0.273 * * *$ \\
\hline$\Delta C D S_{t}^{\text {Finland }}$ & $0.571 * * *$ & . & . & $0.689 * * *$ & . & . & $0.374 * * *$ \\
\hline$\Delta Y$ ield $t_{t-1}^{D E}$ & . & . & $-0.161 * *$ & . & . & . & -0.064 \\
\hline$\Delta C D S_{t}^{E N E L}$ & . & . & . & . & $0.492 * * *$ & . & 0.369 *** \\
\hline$\Delta C D S_{t}^{E N I}$ & . & . & . & . & $0.129 *$ & . & 0.014 \\
\hline$\Delta C D S_{t}^{F I N M E C C}$ & . & . & . & . & $0.129 * * *$ & & 0.035 \\
\hline$\Delta$ Euro50t $_{t}$ & . & . & . & . & . & $-1.388 * * *$ & -0.054 \\
\hline Adj R-Sq & 0.594 & 0.427 & 0.261 & 0.522 & 0.591 & 0.429 & 0.701 \\
\hline$F$ Test & $74.368^{* * *}$ & $43.627^{* * *}$ & $21.217^{* * *}$ & $63.632^{* * *}$ & $65.423^{* * *}$ & $43.999 * * *$ & $73.209^{* * *}$ \\
\hline$F$ Test IV & $167.79^{* * *}$ & $121.78^{* * *}$ & $6.09^{* *}$ & $225.05^{* * *}$ & $110.44^{* * *}$ & $123.70^{* * *}$ & $85.71 * * *$ \\
\hline \multicolumn{8}{|c|}{ Panel B: Second-Stage Regression } \\
\hline Variable & MODEL1 & MODEL2 & MODEL3 & MODEL 4 & MODEL5 & MODEL6 & MODEL7 \\
\hline intercept & -0.007 & -0.003 & -0.006 & -0.003 & -0.003 & -0.003 & -0.003 \\
\hline$\Delta C D S_{t}$ & $0.725^{* *}$ & 0.784 & 3.352 & $0.695^{*}$ & $0.741^{* *}$ & 0.721 & $0.694^{* *}$ \\
\hline$\Delta C D S_{t-1}$ & $0.922^{* * *}$ & $0.912^{* * *}$ & 0.472 & $0.927^{* * *}$ & $0.919^{* * *}$ & $0.923^{* * *}$ & $0.927^{* * *}$ \\
\hline$\Delta B A_{t-1}$ & $-0.369 * * *$ & $-0.368^{* * *}$ & $-0.334^{* * *}$ & $-0.37^{* * *}$ & $-0.369 * * *$ & $-0.369^{* * *}$ & $-0.37^{* * *}$ \\
\hline$\Delta B A_{t-2}$ & $-0.175^{* * *}$ & $-0.174 * * *$ & $-0.152^{* *}$ & $-0.175^{* * *}$ & $-0.174 * * *$ & $-0.175^{* * *}$ & $-0.175^{* * *}$ \\
\hline$\Delta B A_{t-3}$ & $-0.152^{* * *}$ & $-0.152^{* * *}$ & $-0.15^{* * *}$ & $-0.152^{* * *}$ & $-0.152^{* * *}$ & $-0.152^{* * *}$ & $-0.152^{* * *}$ \\
\hline$\Delta C C B S S_{t}$ & 0.329 & 0.314 & -0.381 & 0.338 & 0.325 & 0.331 & 0.338 \\
\hline$\Delta U S V I X_{t}$ & $0.332^{* *}$ & $0.324^{* *}$ & -0.059 & $0.337^{* *}$ & $0.33^{* *}$ & $0.333^{* *}$ & $0.337^{* *}$ \\
\hline Hausmann-Wu & 1.1 & 0.8 & 1.5 & 0.8 & 1.16 & 0.66 & 1.33 \\
\hline
\end{tabular}

${ }^{*}$ Significant at a $10 \%$ level. ${ }^{* *}$ Significant at a $5 \%$ level. ${ }^{* * *}$ Significant at a $1 \%$ level. 
Figures 


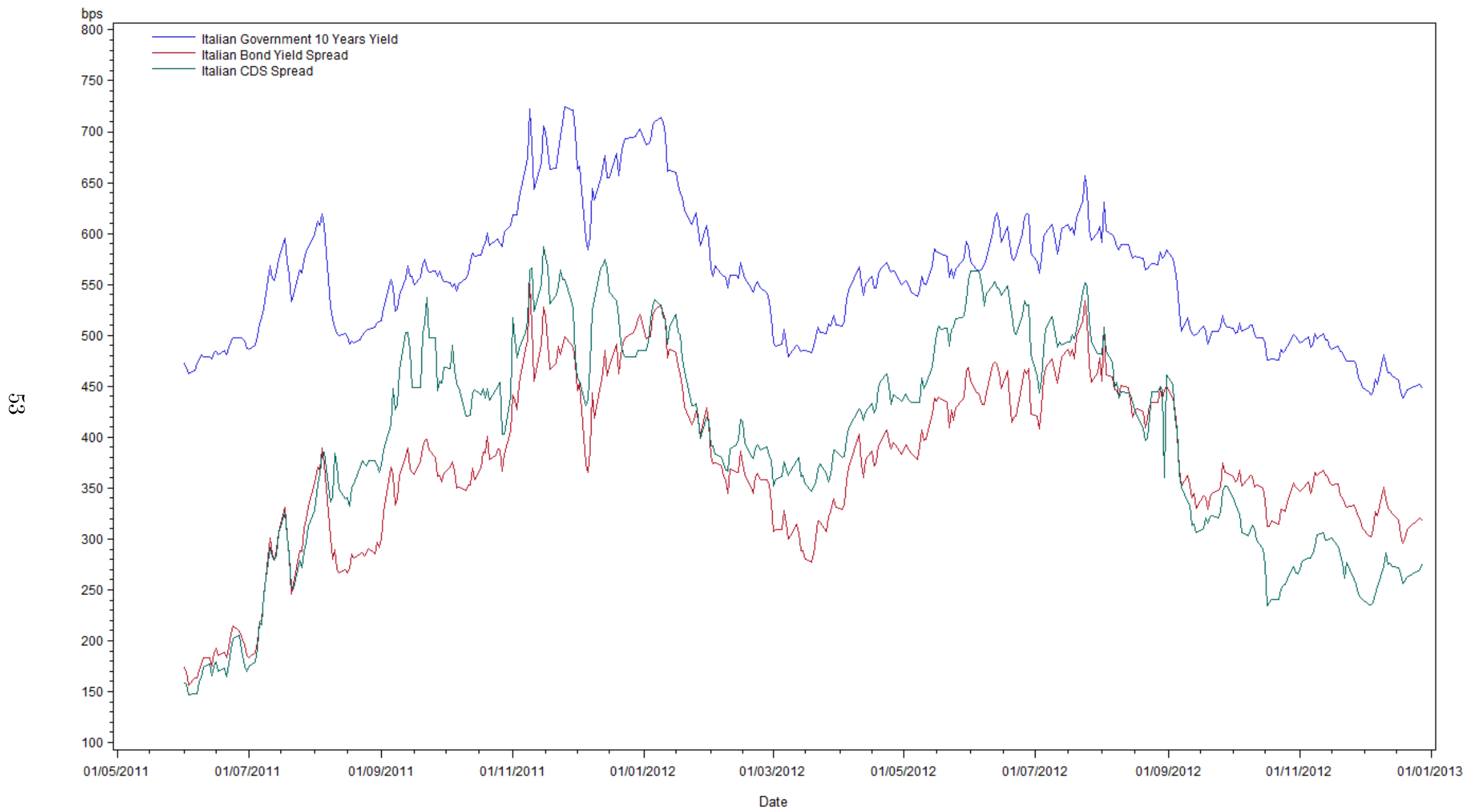

Figure 1: Time-Series of Bond Yield, Bond Yield Spread and CDS Spread. The bond yield spread (in red) is calculated between the Italian (in blue) and German bonds with ten years to maturity. The CDS Spread (in green) is the spread for a five-year US-denominated CDS contract. All data were obtained from Bloomberg and span our sample period of June 1, 2011 to December 31, 2012. 


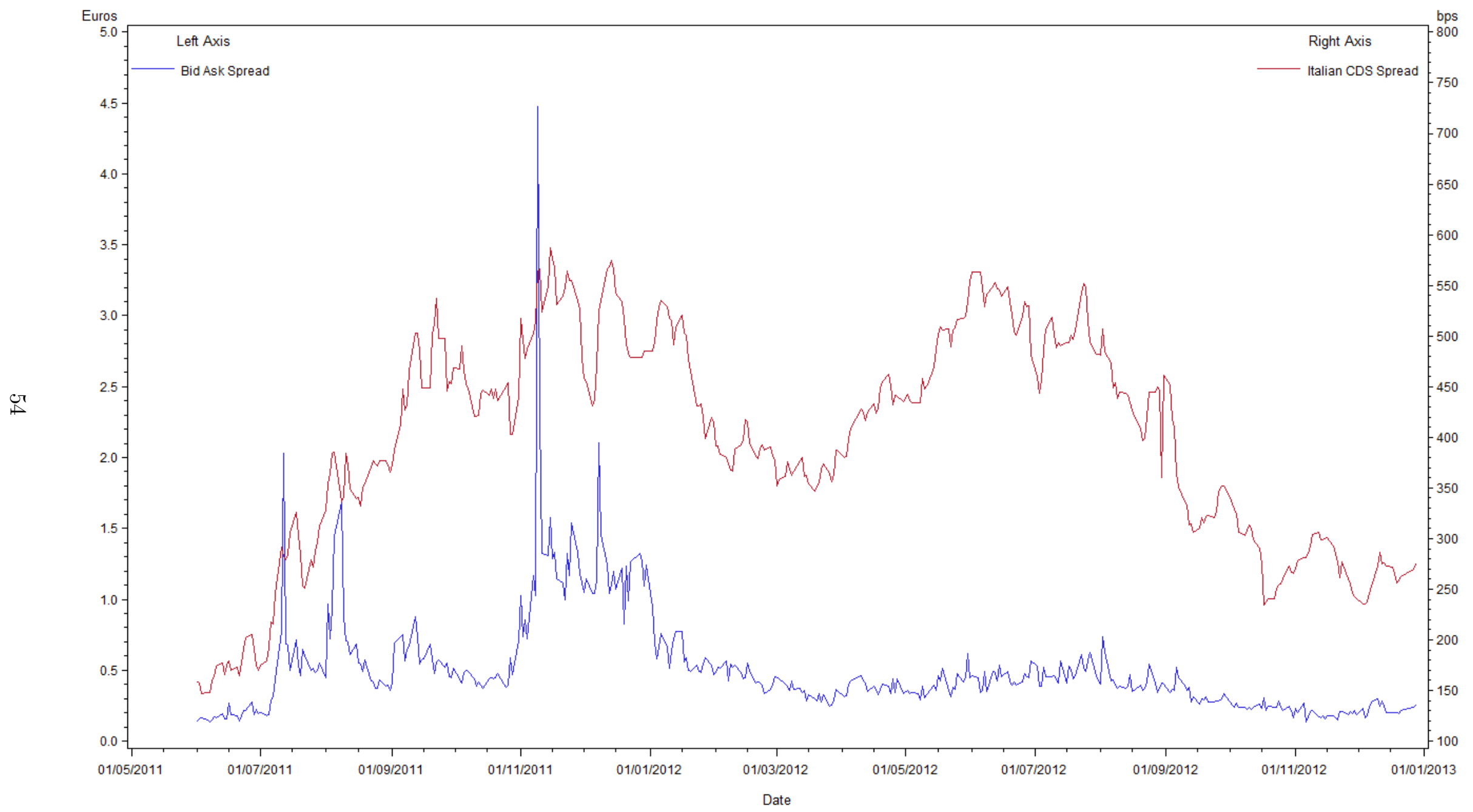

Figure 2: Time-Series of Bid-Ask Spread and CDS Spread. This figure shows the evolution of the MTS bid-ask spread, left-hand axis (in blue), in euros, and the Italian CDS spread, right-hand axis (in red), in bps. Our dataset consists of transactions, quotes, and orders for all 152 fixed-rate and floating Italian government bonds (Buoni Ordinari del Tesoro (BOT) or Treasury bills, Certificato del Tesoro Zero-coupon (CTZ) or zero coupon bonds, Certificati di Credito del Tesoro (CCT) or floating notes, and Buoni del Tesoro Poliennali (BTP) or fixed-income Treasury bonds) from June 1, 2011 to December 31, 2012.2 Data for the CDS spread were obtained from Bloomberg for a five-year US-denominated CDS contract. 


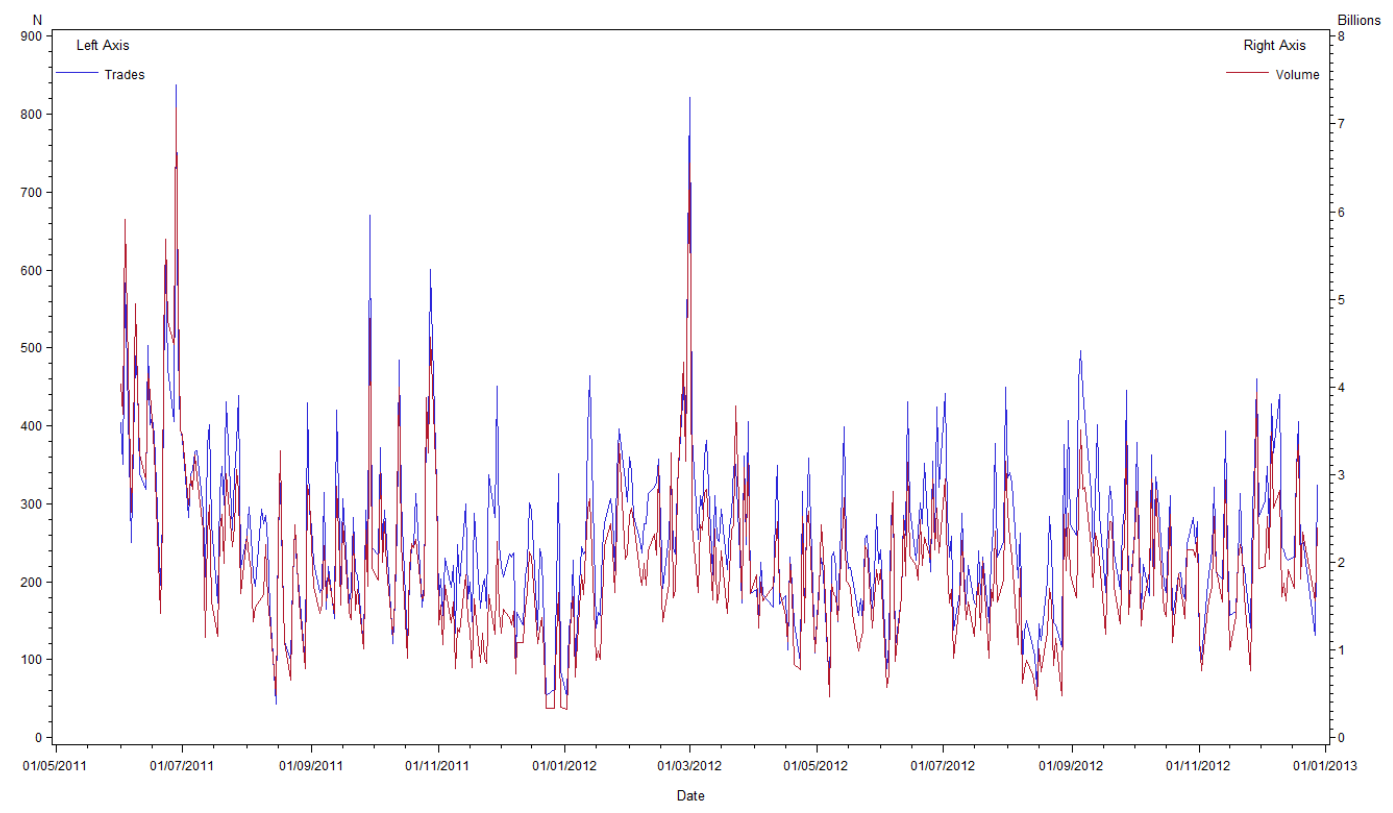

Figure 3: Time-Series of Trades and Volume. The time-series evolution of the overall market volume, right-hand axis (in red), in billions of euro, and the overall number of trades, left-hand axis (in blue). Our dataset consists of transactions, quotes, and orders for all 152 fixed-rate and floating Italian government bonds (Buoni Ordinari del Tesoro (BOT) or Treasury bills, Certificato del Tesoro Zero-coupon (CTZ) or zero coupon bonds, Certificati di Credito del Tesoro (CCT) or floating notes, and Buoni del Tesoro Poliennali (BTP) or fixed-income Treasury bonds) from June 1, 2011 to December 31, 2012. 


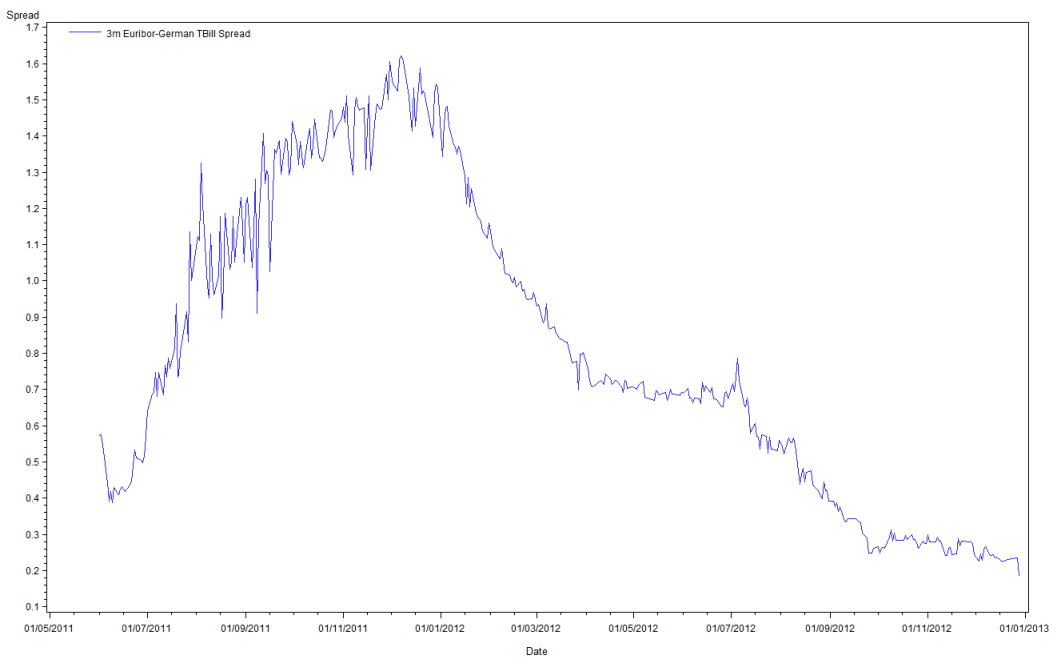

(a) 3-Month Euribor-German T-Bill Spreads

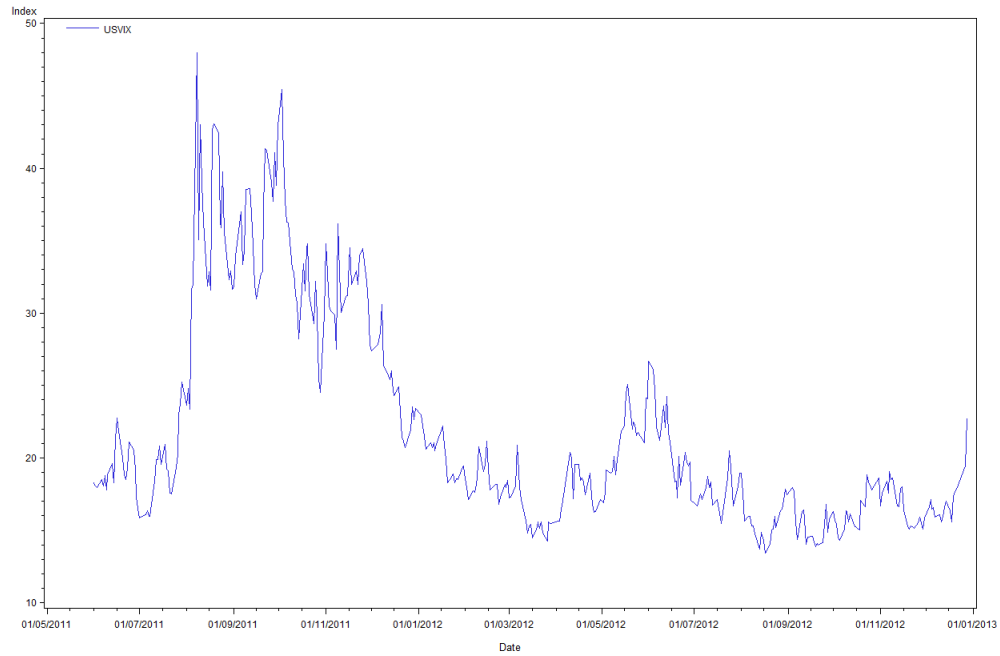

(b) USVIX Index

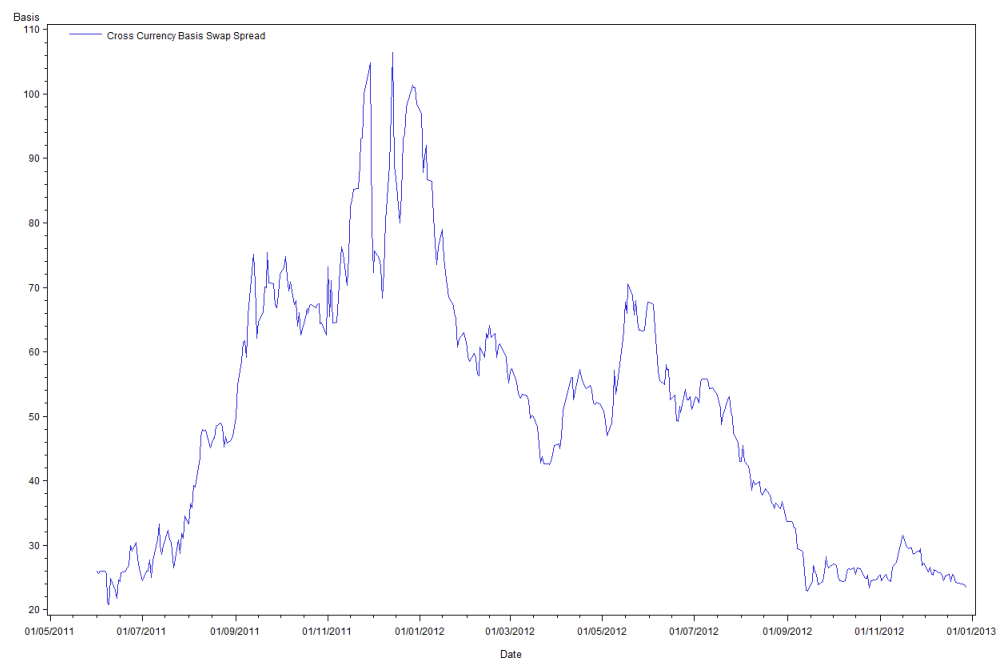

(c) Cross-Currency Basis Swap Spread

Figure 4: Time-Series of Macro variables. The time-series evolution of the global variables: the spread between the three-month Euribor and the three-month yield of the German TBill, the USVIX, and the Cross-Currency Basis Swap Spread are shown in Panels (a), (b), and (c), respectively. Global variables are described in detail in Section IV.T. Our dataset was obtained from Bloomberg and covers the period from June 1, 2011 to December 31, 2012. 
Impulse Response from CDS

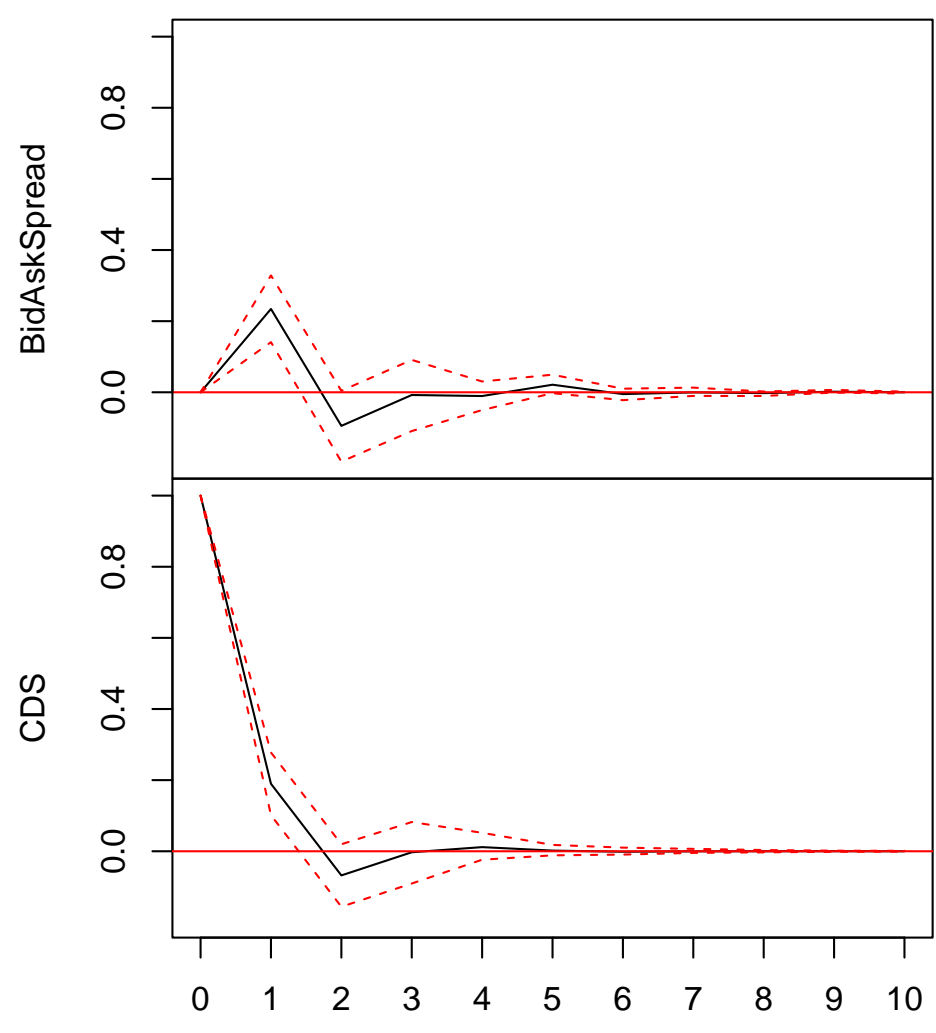

$95 \%$ Bootstrap Cl, 5000 runs
Impulse Response from BidAskSpread

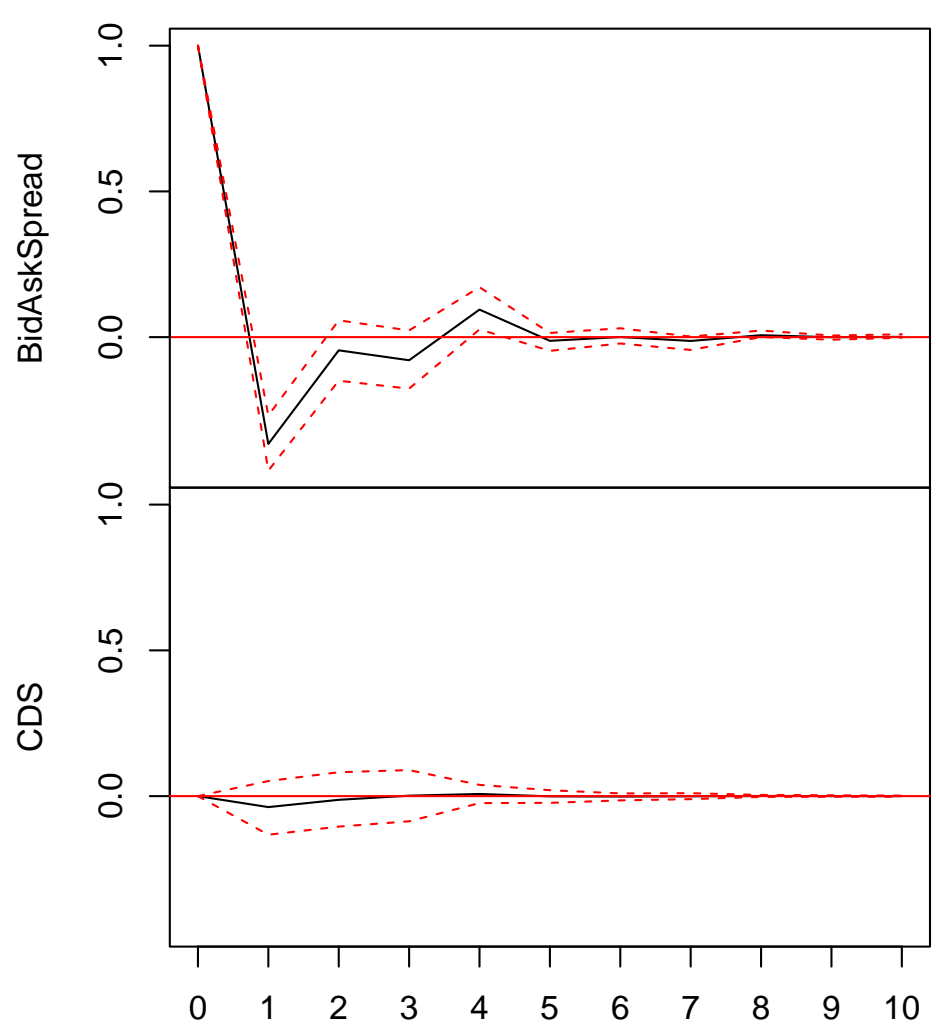

$95 \%$ Bootstrap Cl, 5000 runs

(a) Shock to CDS spread

(b) Shock to the bond market liquidity

Figure 5: Impulse Response Functions for the VARX(3,0) System. This graph shows the evolution of the impulse response functions (IRFs) following a shock in the CDS spread and the bond market liquidity, as measured by the Bid-Ask Spread, in Panels (a) and (b) respectively. The VARX(3,0) system that produces these IRFs is presented in Equation 1 and discussed in Section VI.I. Our dataset consists of transactions, quotes, and orders for all 152 fixed-rate and floating Italian government bonds from June 1, 2011 to December 31, 2012. 


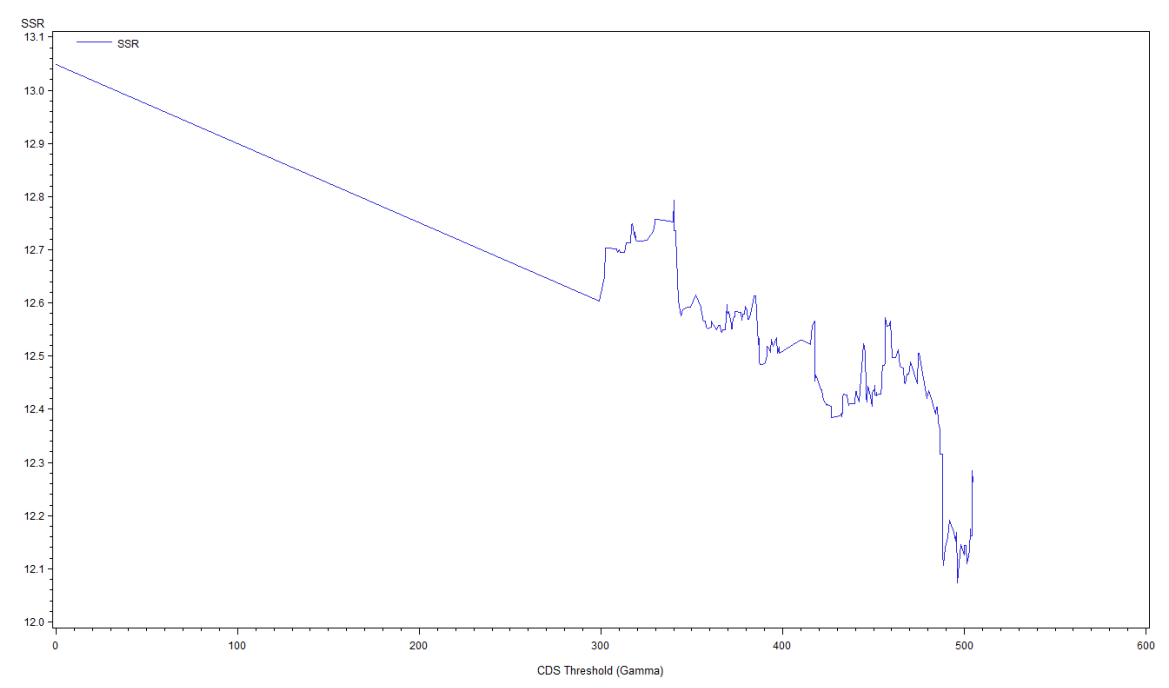

Figure 6: Sum of Squared Residuals as $\gamma$ Changes. The evolution of the sum of squared residuals (SSR) from Equation 3 is plotted as the threshold value $\gamma$ changes. The $\gamma$ that minimizes SSR $(\hat{\gamma})$ is the estimate for the threshold. The point at $\gamma=0$ is the SSR for Equation 2, namely the regression with no threshold. Our dataset consists of transactions, quotes, and orders for all 152 fixed-rate and floating Italian government bonds, from June 1, 2011 to December 31, 2012.

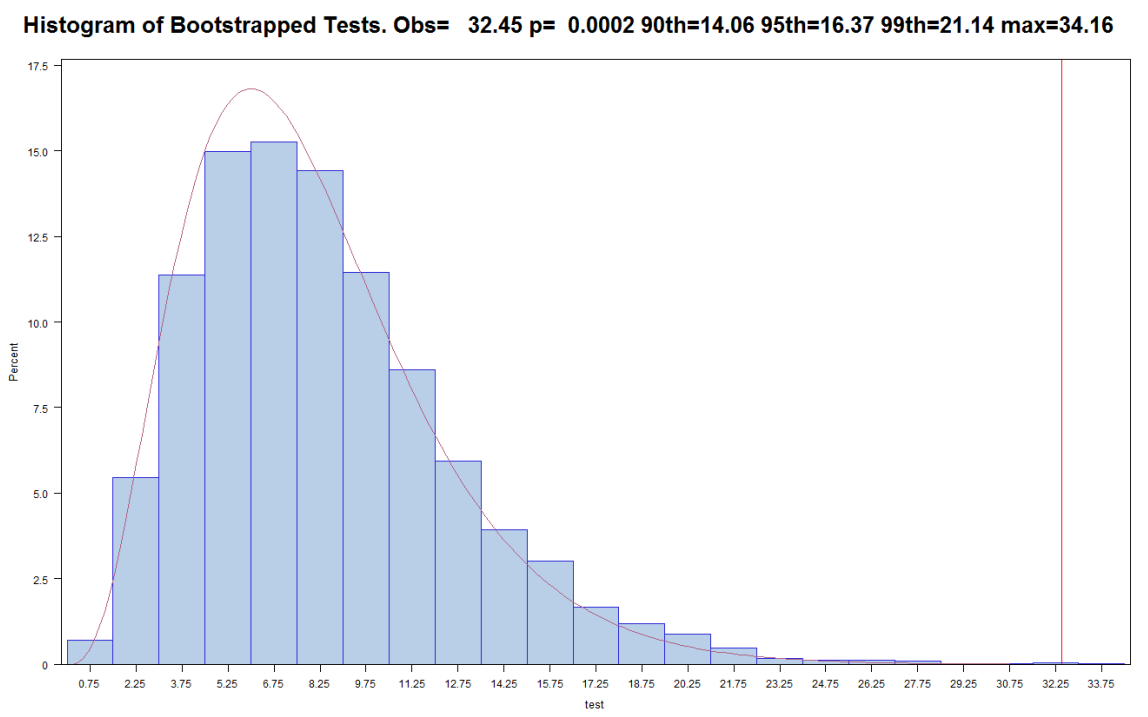

Figure 7: Bootstrapped Distribution for the Test for Threshold Presence and Observed Test Value. We bootstrapped the distribution of the test for the presence of threshold for Equation 3 and its distribution is plotted. The vertical red line marks the observed test value, while the curve superimposed on the empirical distribution is a chi-square distribution with as many degrees of freedom as parameters that are allowed to change in the specification, for reference. Our dataset consists of transactions, quotes, and orders for all 152 fixed-rate and floating Italian government bonds, from June 1, 2011 to December 31, 2012. 


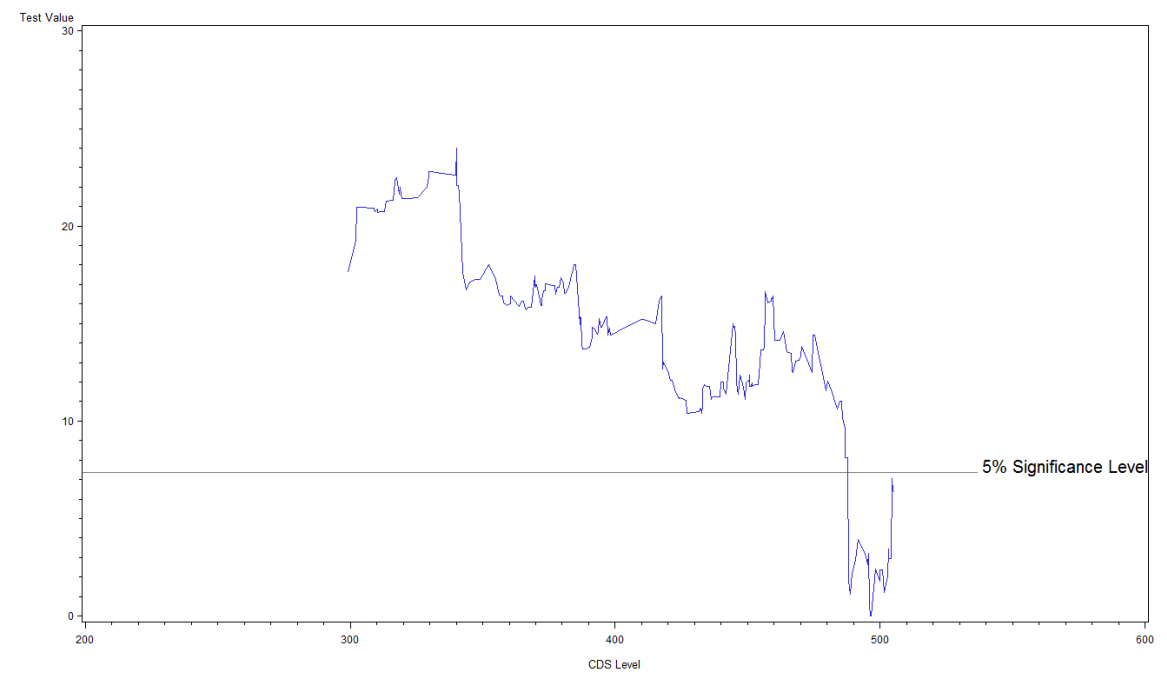

Figure 8: Test to Determine Confidence Bands around the CDS Threshold. The test statistic described in Appendix $\mathrm{C}$ is plotted here for Equation 3 The test statistic is normalized at 0 at the threshold that minimizes the sum of squared residuals. The horizontal line at 7.35 marks the $5 \%$ confidence values for the threshold. Our dataset consists of transactions, quotes, and orders for all 152 fixed-rate and floating Italian government bonds, from June 1, 2011 to December 31, 2012.

\section{Margins, CDS spread, and Bid-Ask Spread}

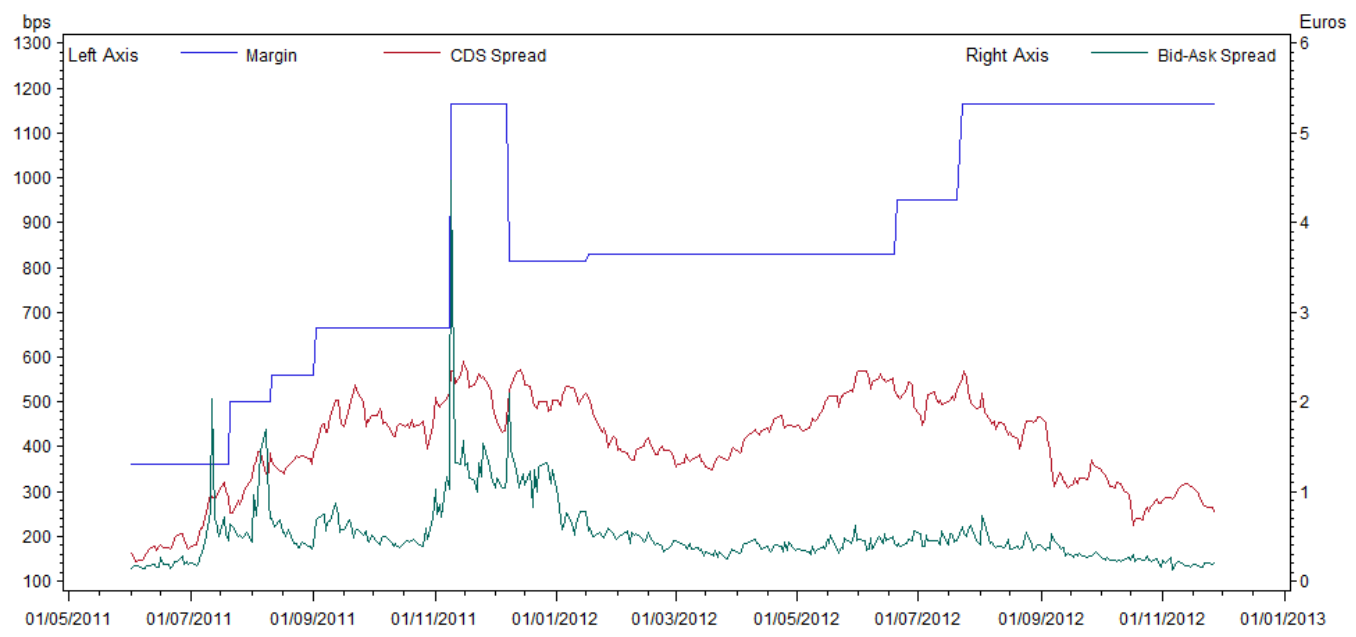

Date

Figure 9: Time-Series of Margins, CDS Spread, and Bid-Ask Spread. This graph shows the time-series of margins (in blue) set by Cassa Compensazione e Garanzia, a clearing house, the spread of a five-year CDS contract (in red), and the liquidity of the bond market (in green), as measured by the market-wide bid-ask spread. Our dataset consists of transactions, quotes, and orders for all 152 fixed-rate and floating Italian government bonds, from June 1, 2011 to December 31, 2012. 


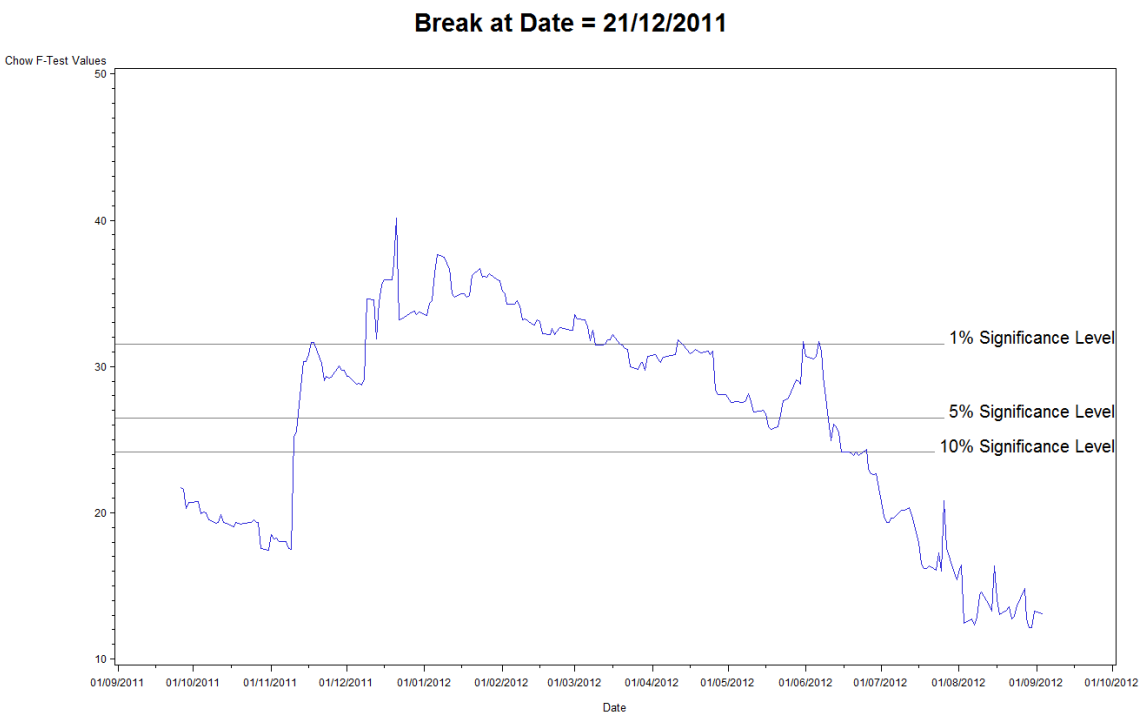

Figure 10: Structural Break Test. This figure shows the $F$-test results for the Chow test performed for Equation 4 for each day in our sample, excluding the first and last $20 \%$ of observations. The horizontal lines mark the $10 \%, 5 \%$, and $1 \%$ levels of significance for the largest of the $F$-test values. Our dataset consists of transactions, quotes, and orders for all 152 fixed-rate and floating Italian government bonds, from June 1, 2011 to December 31, 2012. The CDS data were obtained from Bloomberg. 


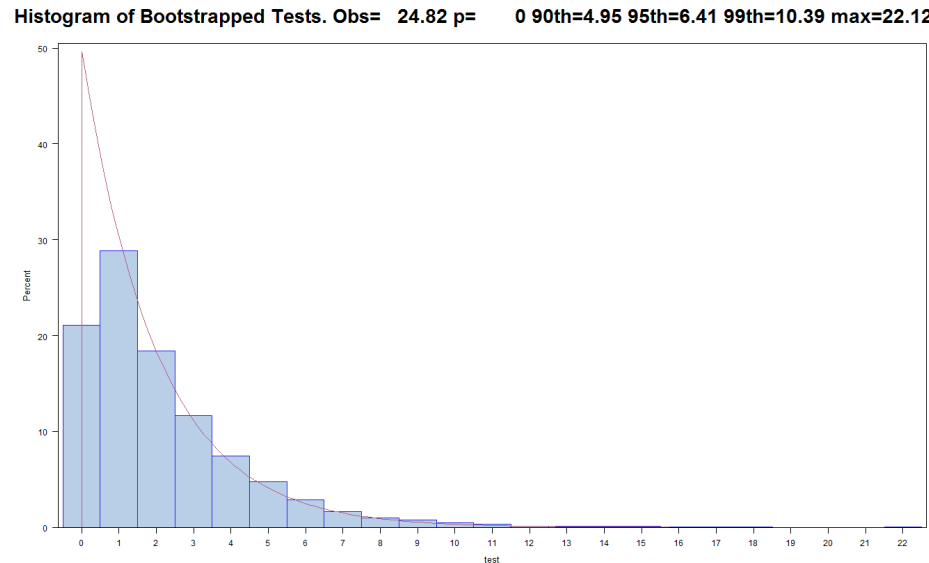

(a) Threshold Presence Test: 2011 Sample

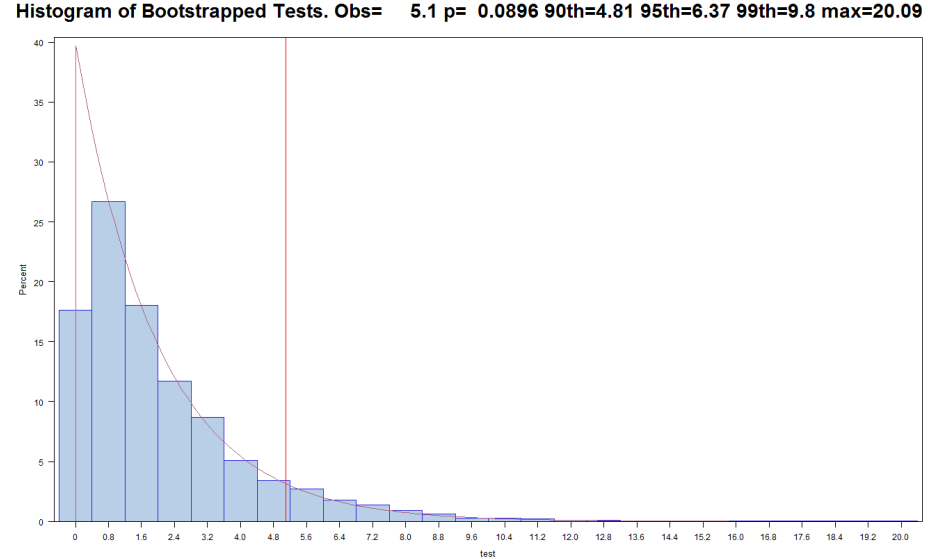

(b) Threshold Presence Test: 2012 Sample

Threshold Confidence Bands. Threshold= 446.37

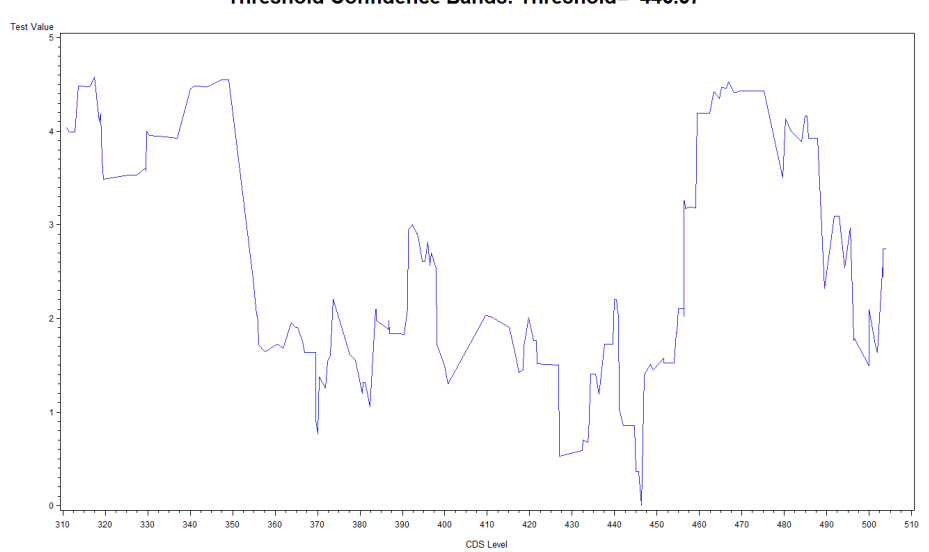

(d) Threshold Confidence Bands Determination: 2012 Sample (c) Threshold Confidence Bands Determination: 2011 Sample

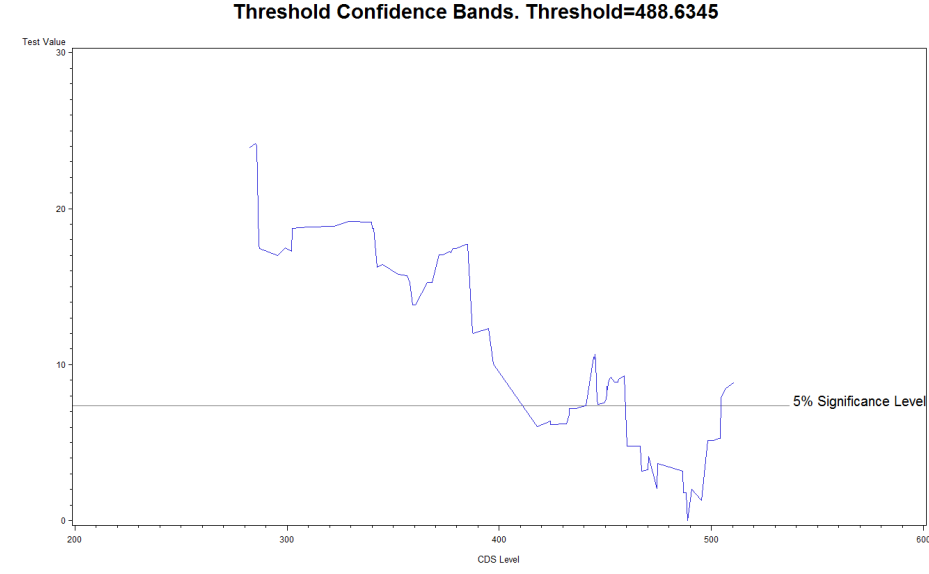

Figure 11: Bootstrapped Threshold Significance Test Distribution and Confidence Bands Determination for Two Subsamples. We bootstrapped the distribution of the test for the presence of a threshold and plot the distribution in Panels (a) and (b) for the sub-samples before and after the structural break, respectively. The vertical red lines mark the observed test values, while the curve superimposed on the empirical distribution is a chi-square distribution with as many degrees of freedom as parameters that are allowed to change in the specification, for reference. The test statistic described in Appendix C is plotted here for Equation 4 in Panels (c) and (d) for the sub-samples before and after the structural break, respectively. The test statistic is normalized at 0 at the threshold that minimizes the sum of squared residuals. The horizontal line at 7.35 marks the $5 \%$ confidence values for the threshold. 


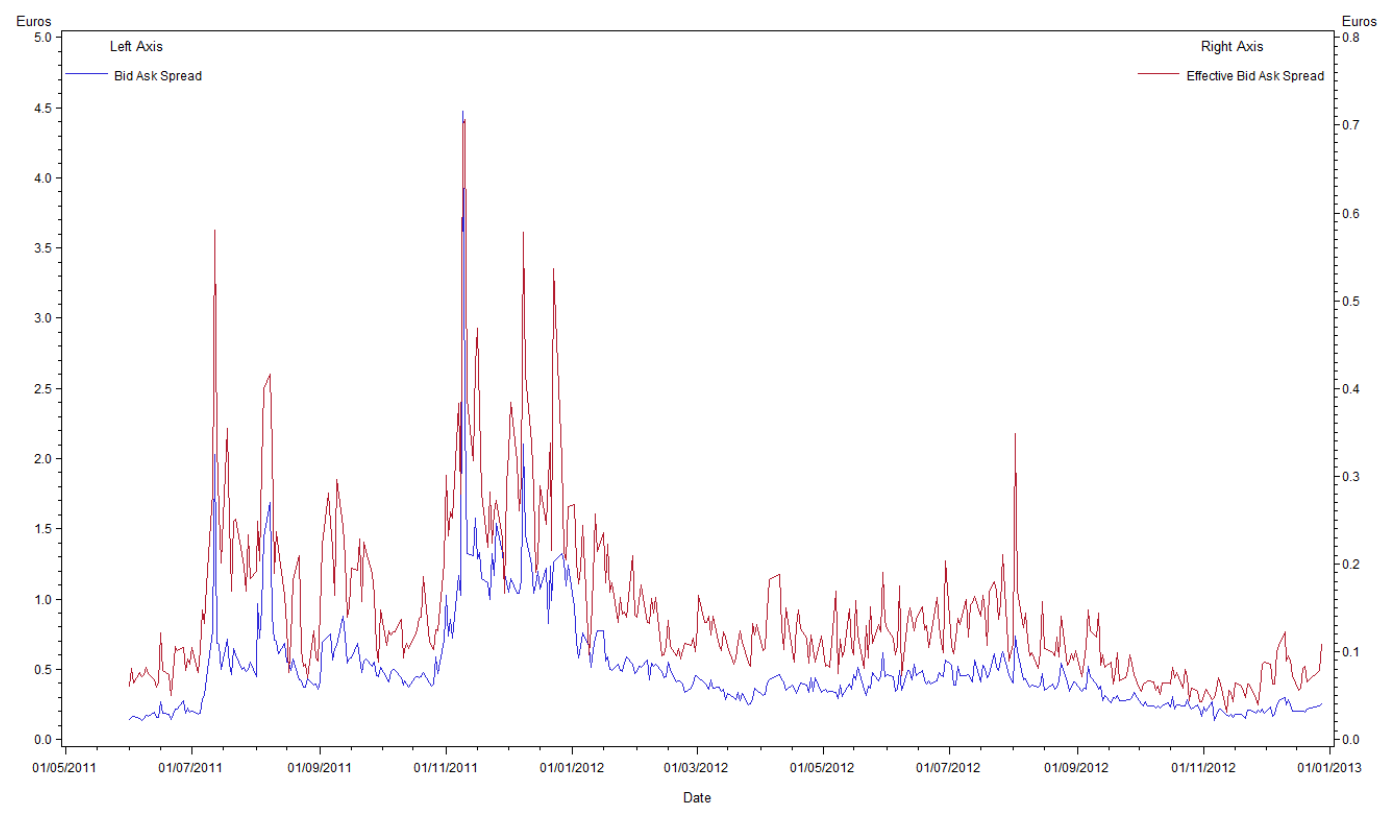

(a) Quoted and Effective Bid-Ask Spread

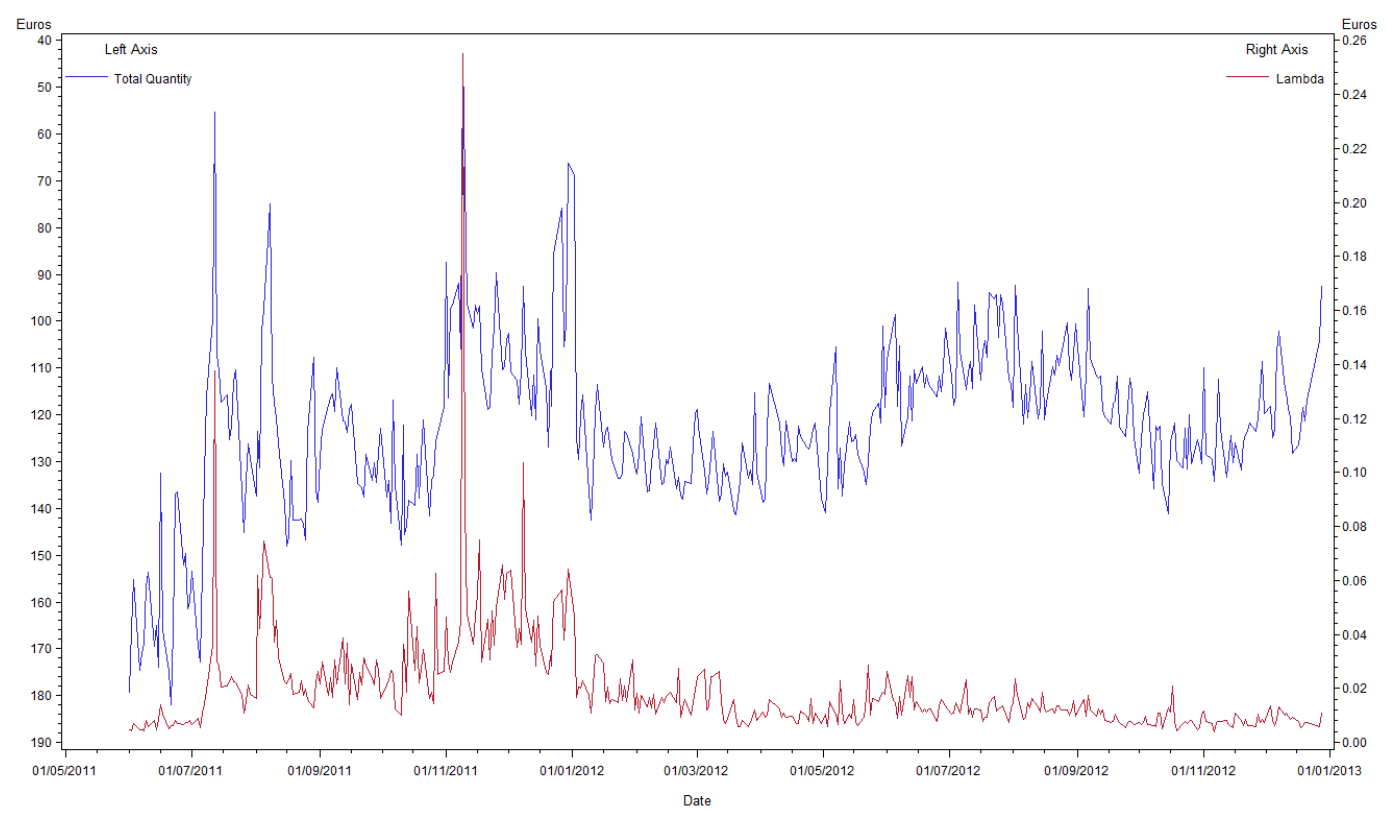

(b) Quoted Quantity and Lambda

Figure 12: Time-Series of Liquidity Measures. Panel (a) shows the time-series evolution of the Quoted (in blue) and Effective (in red) Bid-Ask Spread, while Panel (b) shows the depth measure Lambda (in red) and Quoted Quantity (in blue). Our liquidity measures are described in detail in Section VII.I. Our dataset consists of transactions, quotes, and orders for all 152 fixed-rate and floating Italian government bonds (Buoni Ordinari del Tesoro (BOT) or Treasury bills, Certificato del Tesoro Zero-coupon (CTZ) or zero coupon bonds, Certificati di Credito del Tesoro (CCT) or floating notes, and Buoni del Tesoro Poliennali (BTP) or fixed-income Treasury bonds) from June 1, 2011 to December 31, 2012. 


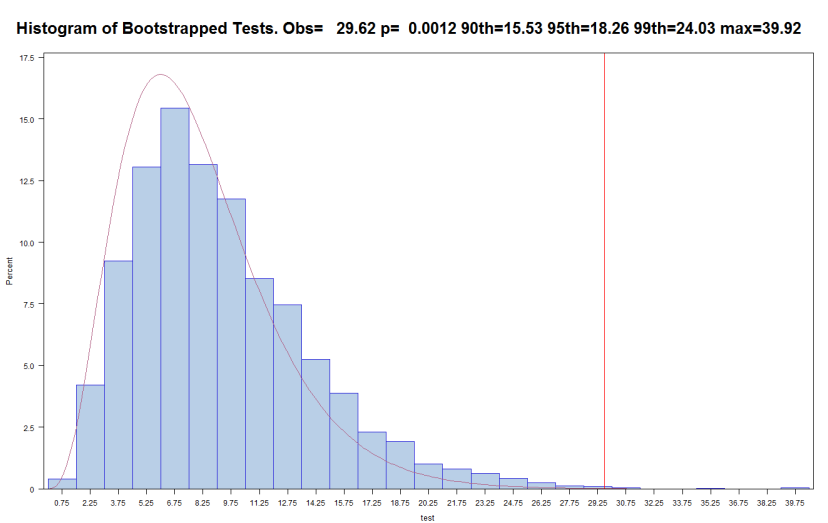

(a) Quoted Quantity: Threshold Presence Test

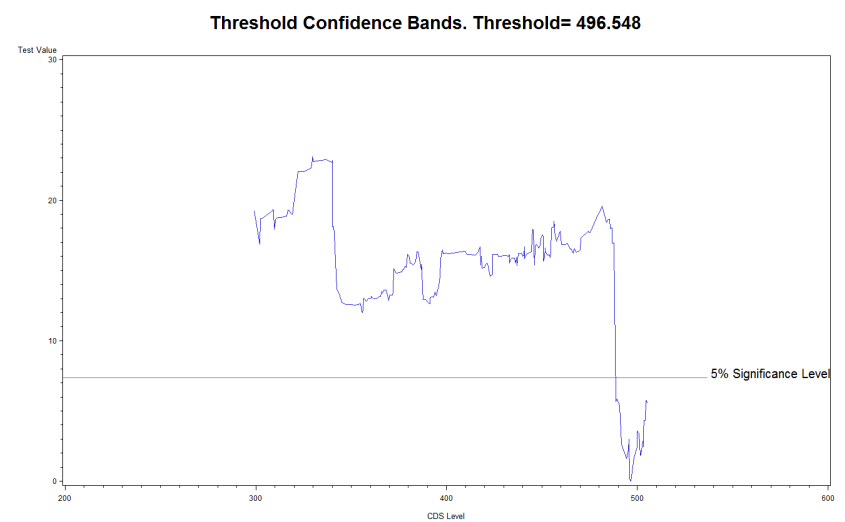

(c) Quoted Quantity: Threshold Confidence Bands Determination

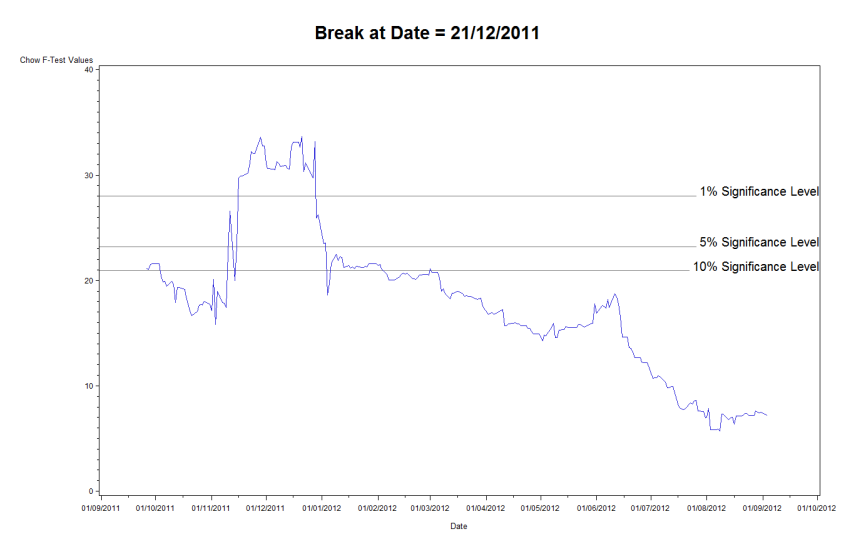

(e) Quoted Quantity: Structural Break

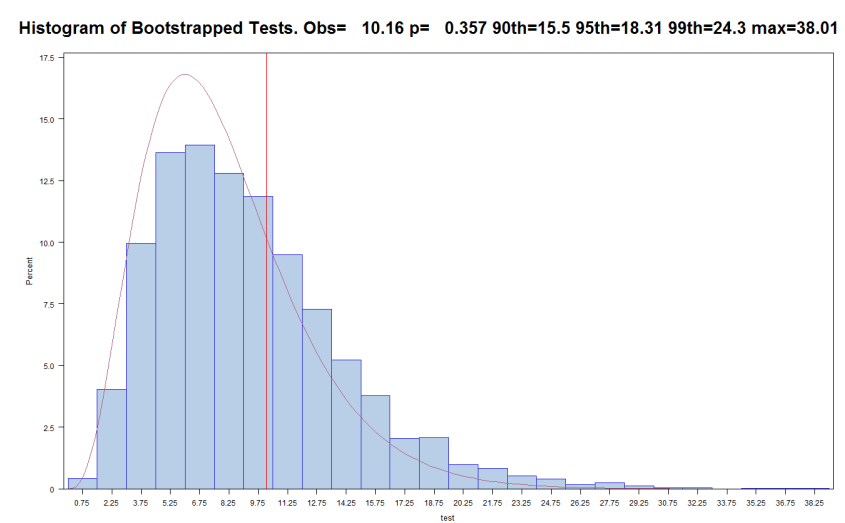

(b) Effective Spread: Threshold Presence Test

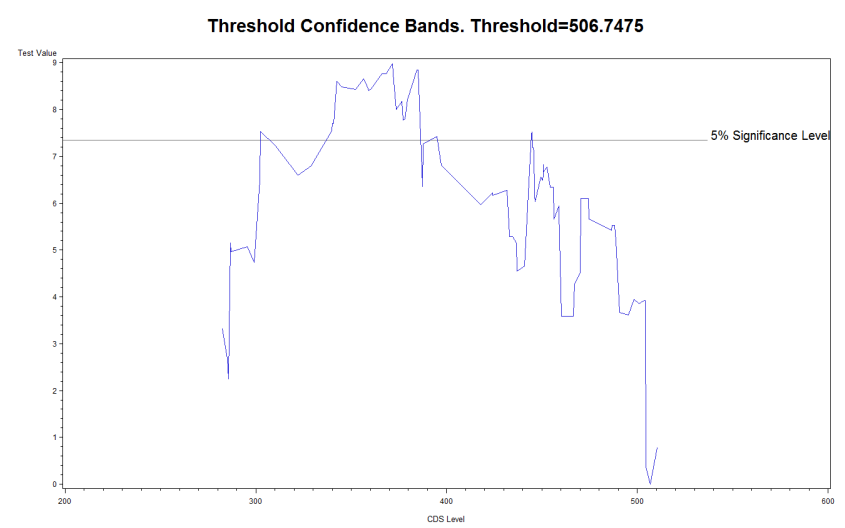

-(d) Effective Spread: Threshold Confidence Bands Determination

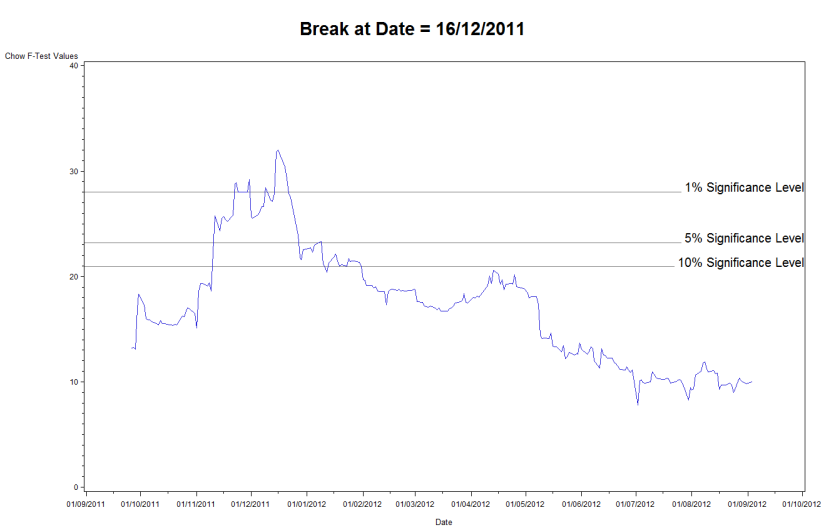

(f) Effective Spread: Structural Break

Figure 13: Bootstrapped Threshold Significance Test Distribution and Confidence Bands Determination for the 2011 Sub-Sample and Structural Break Test for Alternative Liquidity Measures. We bootstrapped the distribution of the test for the presence of a threshold and plot it in Panels (a), (b), and (g) for the 2011 sub-samples, for Equation 3 performed using Quoted Quantity, Effective Spread, and Lambda, respectively, instead of the Quoted Spread as liquidity measure. The vertical red lines mark the observed test values, while the curve superimposed on the empirical distribution is a chi-square distribution with as many degrees of freedom as parameters that are allowed to change in the specification, for reference. [Continued] 


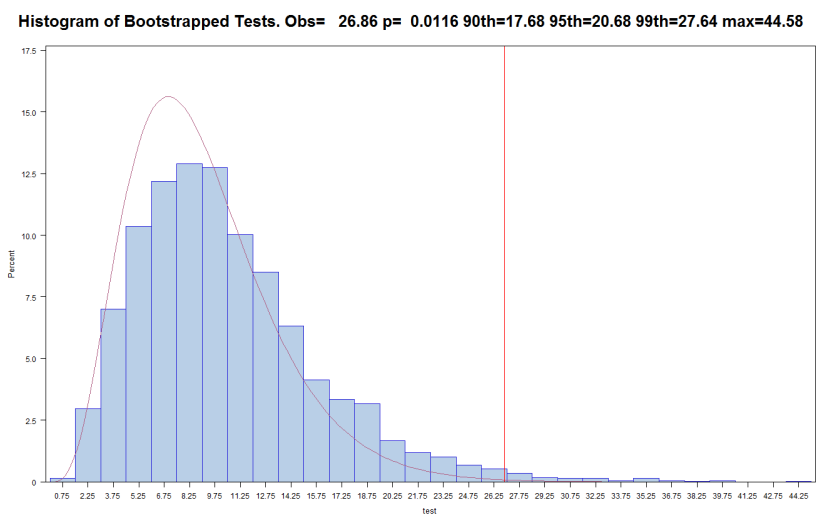

(g) Lambda: Threshold Presence Test

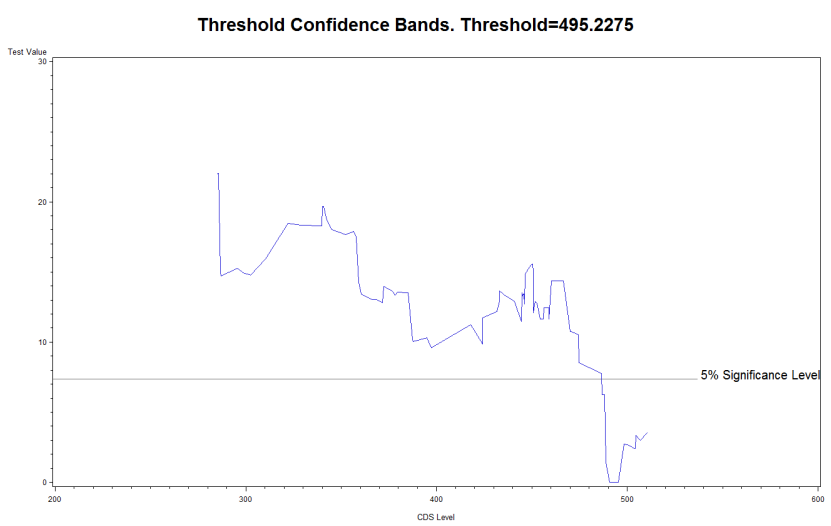

(h) Lambda: Threshold Confidence Bands Determination

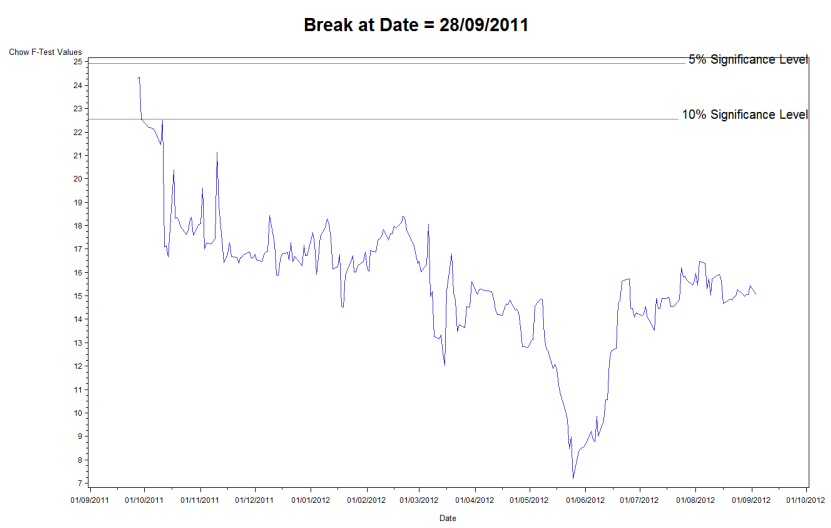

(i) Lambda: Structural Break

Figure 12: Bootstrapped Threshold Significance Test Distribution and Confidence Bands Determination for the 2011 Sub-Sample and Structural Break Test for Alternative Liquidity Measures. [Continued] The test statistic described in Appendix C is plotted here for Equation 3 in Panels (c), (d), and (h) for the 2011 sub-samples for Equation 3 performed using Quoted Quantity, Effective Spread, and Lambda, respectively, instead of the Bid-Ask Spread as liquidity measure. The test statistic is normalized at 0 at the threshold that minimizes the sum of squared residuals. The horizontal line at 7.35 marks the $5 \%$ confidence values for the threshold. Panels (e), (f), and (i) present the structural break for Equation 3 performed using Quoted Quantity, Effective Spread, and Lambda, respectively, instead of the Bid-Ask Spread as liquidity measure. The horizontal lines mark the $10 \%, 5 \%$, and $1 \%$ significance levels for the largest of the Chow $F$-values. 
Break at Date $=\mathbf{2 1 / 1 2 / 2 0 1 1}$

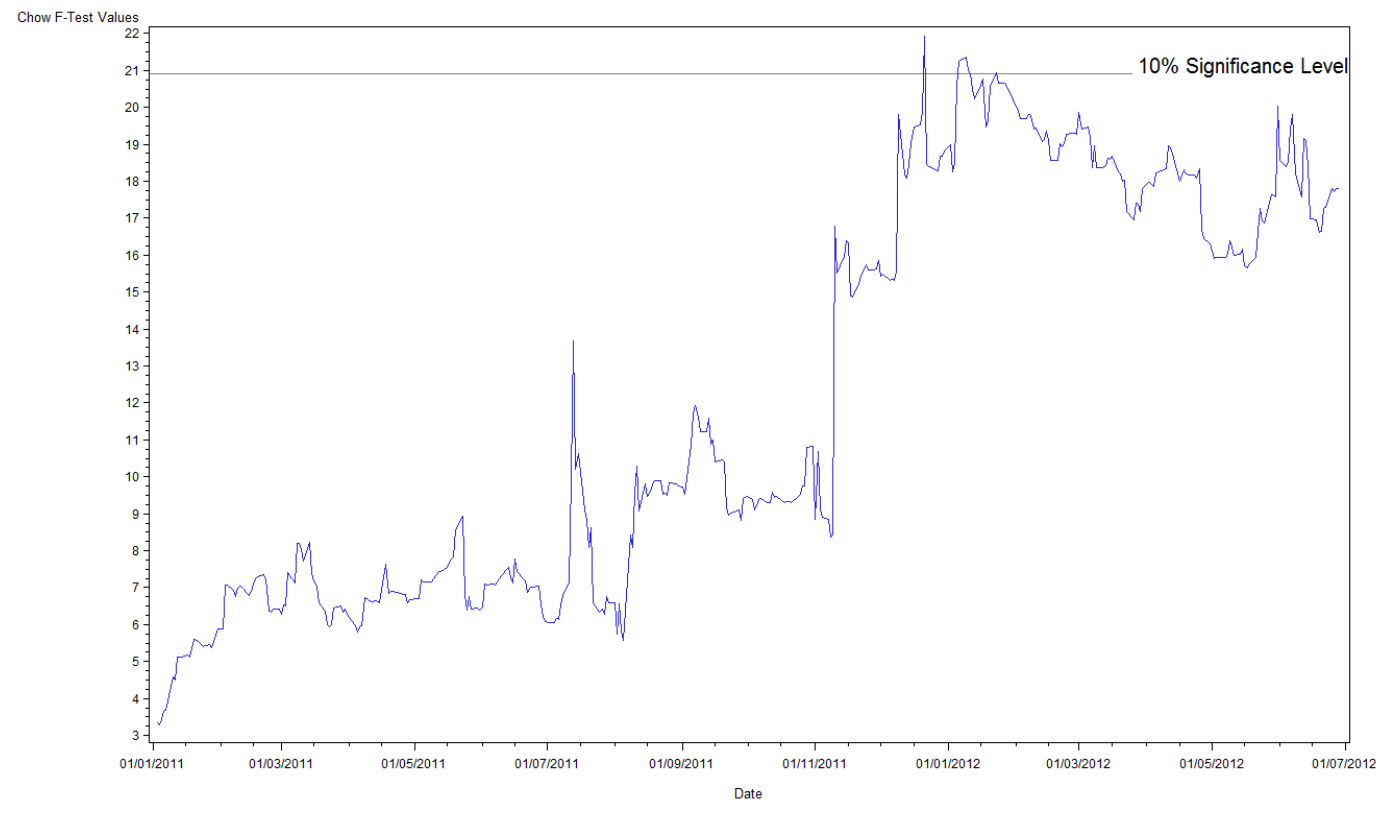

(a) Structural Break in the Extended Sample

Break at Date $=05 / 09 / 2011$

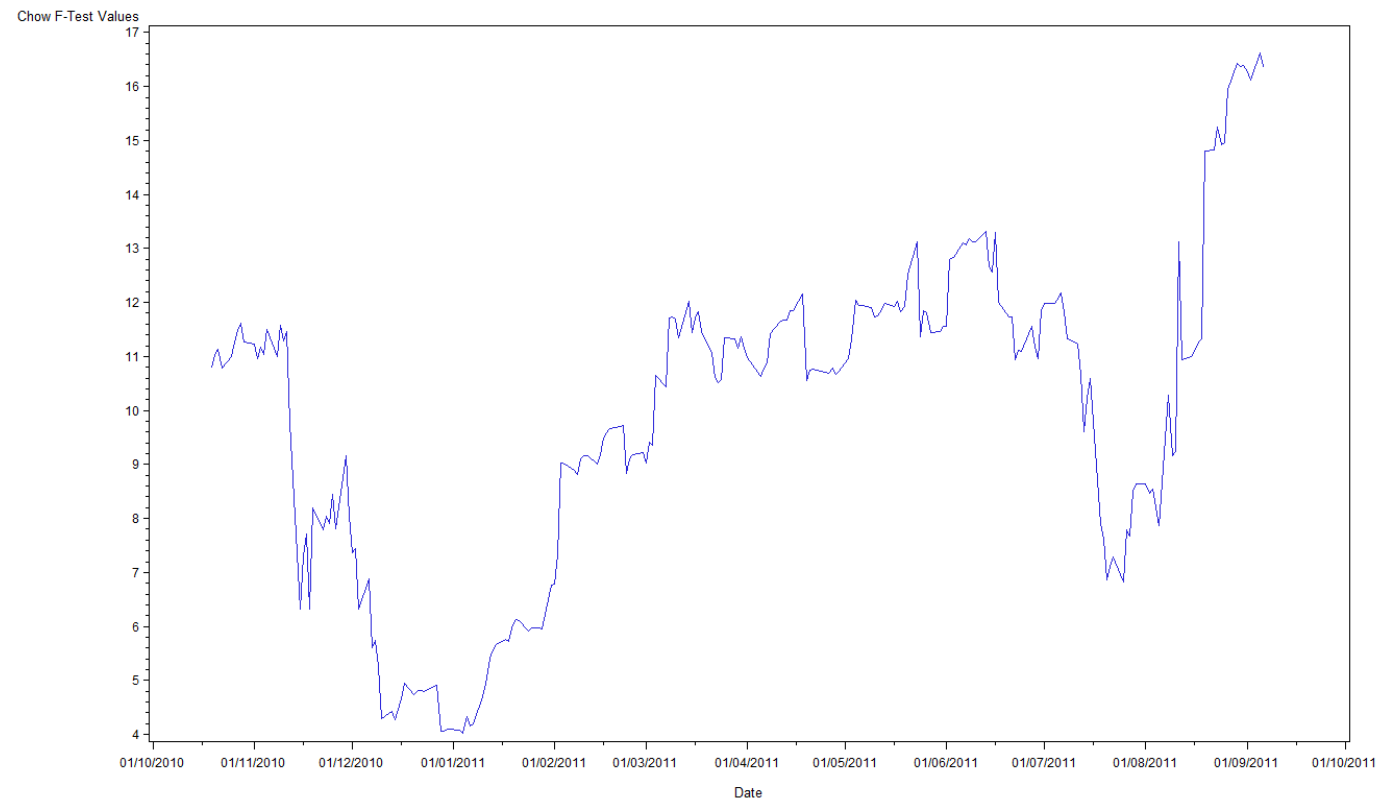

(b) Structural Break in the Extended Sample before December 21, 2011.

Figure 13: Structural Break Test. Panel A shows the $F$-test results for the Chow test performed for Equation 4 for each day in our extended sample, from July 2010 to December 2012, excluding the first and last $20 \%$ of observations. Panel B shows the same test for the sub-sample before the structural break found in Panel A. The horizontal lines mark the $10 \%, 5 \%$, and $1 \%$ levels of significance for the largest of the $F$-test values. However, they are outside of the y-axis (21 or above) for Panel B. Our dataset consists of the best bid and ask for Italian government bonds, from July 1, 2010 to December 31, 2012. The CDS and macro variable data were obtained from Bloomberg. 


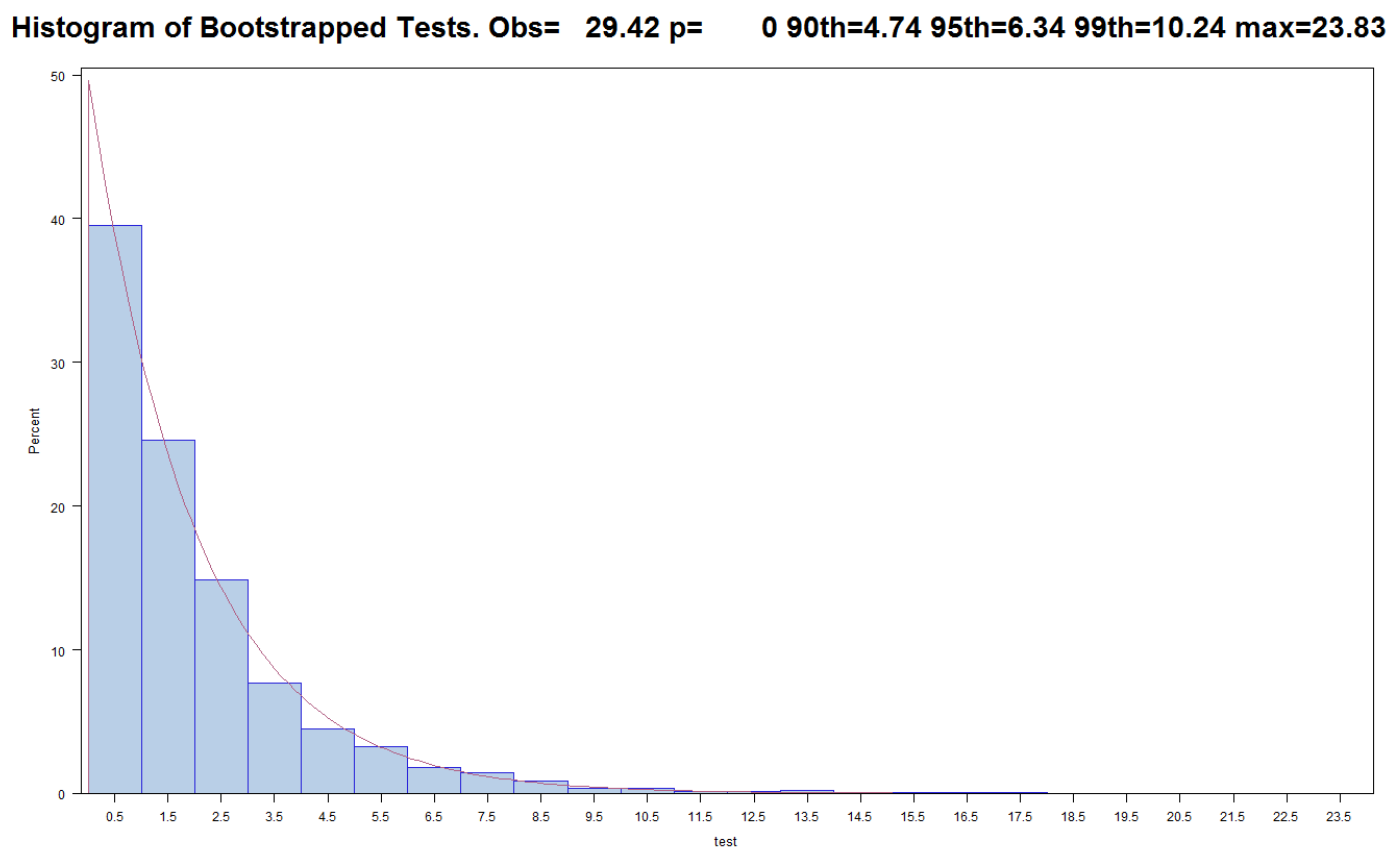

(a) Threshold Presence Test for the Extended Sample

Threshold Confidence Bands. Threshold= 496.548

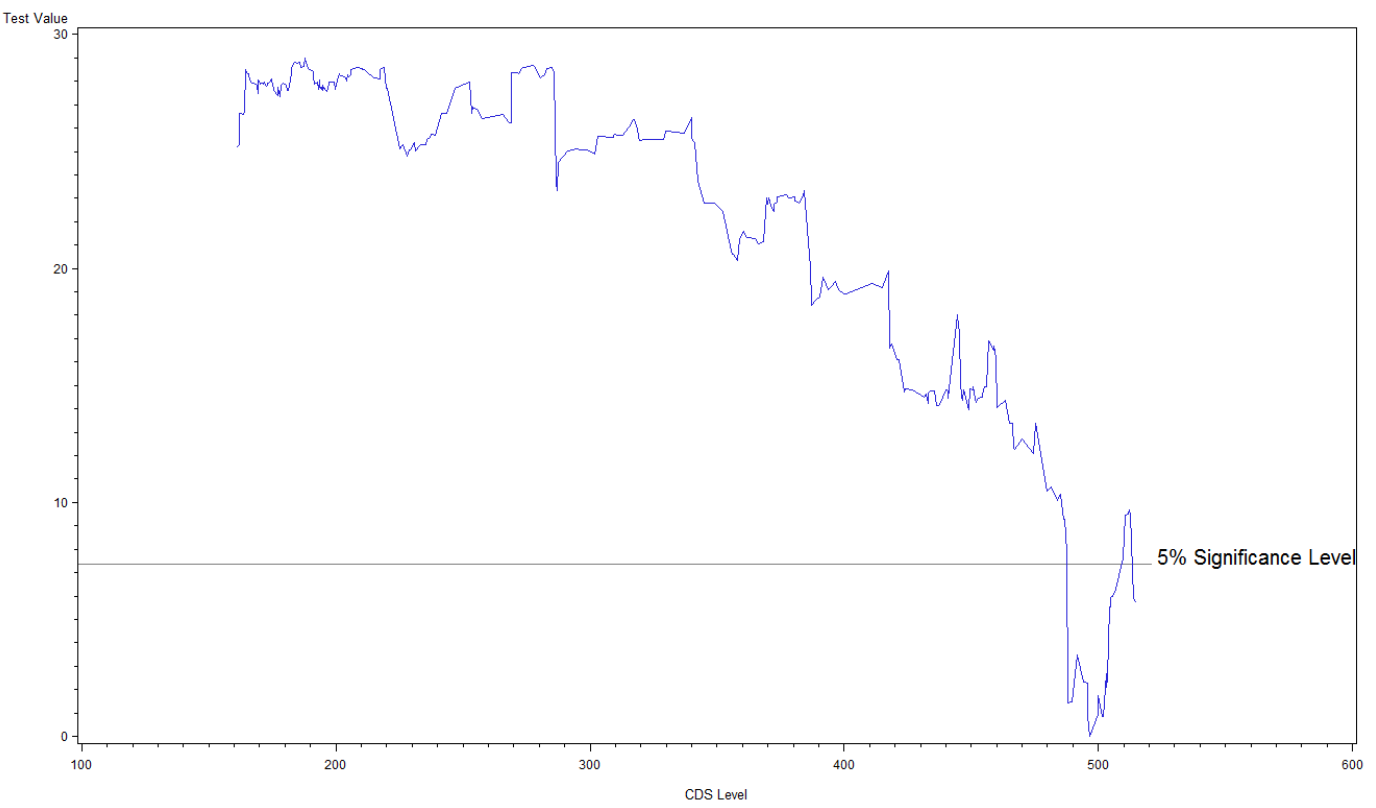

(b) Threshold Confidence Bands Determination for the Extended Sample

Figure 14: Bootstrapped Threshold Significance Test Distribution and Confidence Bands Determination for Extended Sample. We bootstrapped the distribution of the test for the presence of a threshold in Equation 4 and plot it in Panel (a) for a sample that extends back to July 2010. The vertical red lines mark the observed test value of 29.42 (outside of the x-axis), while the curve superimposed on the empirical distribution is a chi-square distribution with as many degrees of freedom as parameters that are allowed to change in the specification, for reference. The test statistic described in Appendix $\mathrm{C}$ is plotted here for Equation 4 in Panel (b). The test statistic is normalized at 0 at the threshold that minimizes the sum of squared residuals. The horizontal line at 7.35 marks the $5 \%$ confidence values for the threshold. 


\section{References}

Acharya, V. V., Drechsler, I., and Schnabl, P., 2012, A Pyrrhic victory? Bank bailouts and sovereign credit risk. National Bureau of Economic Research Working Paper.

Amihud, Y., and Mendelson, H., 1980, Dealership market: Market-making with inventory. Journal of Financial Economics, 8(1), 31-53.

Andrews, D., 1993, Tests for Parameter Instability and Structural Change with Unknown Change Point. Econometrica, 61(4), 821-856.

Andrews, D., 2003, Tests for Parameter Instability and Structural Change with Unknown Change Point: a Corrigendum. Econometrica, 71(1), 395-397.

Andrews, D., and Ploberger, W., 1994, Optimal Tests when a Nuisance Parameter is Present Only under the Alternative. Econometrica, 62(6), 1383-1414.

Baba, N., 2009, Dynamic spillover of money market turmoil from FX swap to cross-currency swap markets: evidence from the 2007-2008 turmoil. The Journal of Fixed Income, 18(4), 24-38.

Baba, N., Packer, F., and Nagano, T., 2008, The spillover of money market turbulence to FX swap and cross-currency swap markets. BIS Quarterly Review, March 2008.

Bagehot, W., 1971, The only game in town. Financial Analysts Journal, 27(2), 12-14.

Bai, J., Julliard, C., and Yuan, K., 2012, Eurozone Sovereign Bond Crisis: Liquidity or Fundamental Contagion. Federal Reserve Bank of New York Working Paper.

Bao, J., Pan, J., and Wang, J., 2011, Liquidity and corporate bonds. Journal of Finance, 66, 911-946.

Beber, A., Brandt, M. W., and Kavajecz, K. A., 2009, Flight-to-quality or flight-to-liquidity? Evidence from the Euro-area bond market. Review of Financial Studies, 22(3).

Bessembinder, H., and Maxwell, M., 2008, Markets: Transparency and the corporate bond market. The Journal of Economic Perspectives, 22(2), 217-234.

Boissel, C., Derrien, F., Örs, E., and Thesmar, D., 2014, Systemic Risk in Clearing Houses: Evidence from the European Repo Market. Working Paper.

Brunnermeier, M. K., 2009, Deciphering the liquidity and credit crunch 2007-08. Journal of Economic Perspective, 23(1), 77-100.

Brunnermeier, M. K., and Pedersen, L. H., 2009, Market liquidity and funding liquidity. Review of Financial Studies, 22(6), 2201-2238.

Caner, M., and Hansen, B. E., 2001, Threshold autoregression with a unit root. Econometrica, 69(6), 1555-1596. 
Caporale, G. M., and Girardi, A., 2011, Price formation on the EuroMTS platform. Applied Economics Letters, 18(3), 229-223.

Chaboud, A., Chiquoine, B., Hjalmarsson, E., and Vega, C., 2014, Rise of the Machines: Algorithmic Trading in the Foreign Exchange Market, Journal of Finance, 69(5), 2045-2084.

Chakravarty, S., and Sarkar, A., 1999, Liquidity in U.S. fixed income markets: A comparison of the bid-ask spread in corporate, government and municipal bond markets. Federal Reserve Bank of New York Staff Report.

Cheung, Y. C., de Jong, F., and Rindi, B., 2005, Trading European Sovereign Bonds: The Microstructure of the MTS Trading Platforms. European Central Bank Working Paper.

Chow, G. C., 1960, Test of equality between sets of coefficients in two linear regressions. Econometrica, 28(2), 591-605.

Coluzzi, C., Ginebri, S., and Turco, M., 2008, Measuring and Analyzing the Liquidity of the Italian Treasury Security Wholesale Secondary Market. Università degli Studi del Molise Working Paper.

Corradin, A., and Maddaloni, A., 2015, The Importance of Being Special: Repo Markets during the Crisis. Working Paper.

Corradin, A., and Rodriguez-Moreno, M., 2014, Limits to arbitrage: Empirical evidence from Euro area sovereign bond markets. European Central Bank Working Paper.

Darbha, M., and Dufour, A., 2012, Measuring Euro Area Government Bond Market liquidity and its Asset Pricing Implications. University of Reading Working Paper.

Davies, R. B., 1977, Hypothesis Testing when a Nuisance Parameter is Present Only under the Alternative. Biometrika, 64, 247-254.

Davies, R. B., 1987, Hypothesis Testing when a Nuisance Parameter is Present Only under the Alternative. Biometrika, 74, 33-43.

Dick-Nielsen, J., Feldhütter, P., and Lando, D., 2012, Corporate bond liquidity before and after the onset of the subprime crisis. Journal of Financial Economics, 103, 471-492

Duffie, D., Garleânu, N., and Pedersen, L. H., 2007, Valuation in over-the-counter markets. Review of Financial Studies, 20(6), 1865-1900.

Dufour, A., and Nguyen, Minh, 2011, Permanent Trading Impacts and Bond Yields. University of Reading Working Paper.

Dufour, A., and Skinner, F., 2004, MTS Time Series: Market and Data Description for the European Bond and Repo Database. University of Reading Working Paper.

Dunne, P., Hau, H., and Moore, M., 2009, A Tale of Two Platforms: Dealer Intermediation in the European Sovereign Bond Market. Working Paper. 
Easley, D., and O'Hara, M., 1987, Price, trade size, and information in securities markets. Journal of Financial Economics, 19(1), 69-90.

Edwards, A. K., Harris, L. E., and Piwowar, M. S., 2007, Corporate Bond Market Transaction Costs and Transparency. The Journal of Finance, 62, 1421-1451.

Engle, R., 2002, New frontiers for ARCH models. Journal of Applied Econometrics, 17, 425-446.

Engle, R., Fleming, M. J., Ghysels, E., and Nguyen, G., 2011, Liquidity and Volatility in the U.S. Treasury Market: Evidence from A New Class of Dynamic Order Book Models. Federal Reserve Bank of New York Working Paper.

Eser, F., and Schwaab, B., 2014, Assessing asset purchases within the ECB's Securities Markets Programme. European Central Bank Working Paper.

Fama, E. F., and French, K. R., 1993, Common risk factors in the returns on stocks and bonds. Journal of Financial Economics, 33(1), 3-56.

Favero, C., Pagano, M., and Von Thadden, E., 2010, How does liquidity affect government bond yields? Journal of Financial and Quantitative Analysis, 45(1), 107-134.

Feldhütter, P., 2012, The same bond at different prices: Identifying search frictions and selling pressures. The Review of Financial Studies, 25(4), 1155-1206.

Fleming, M. J., 2003, Measuring Treasury Market Liquidity. Federal Reserve Bank of New York Economic Policy Review 2003.

Fleming, M. J., and Mizrach, B., 2009, The Microstructure of a U.S. Treasury ECN: The BrokerTec Platform. Federal Reserve Bank of New York Staff Report.

Fleming, M. J., and Remolona, E. M., 1999, Price formation and liquidity in the U.S. Treasury market: The response to public information. The Journal of Finance, 54(5), 1901-1915.

Friewald, N., Jankowitsch, R., and Subrahmanyam, M. G., 2012a, Illiquidity or credit deterioration: A study of liquidity in the U.S. corporate bond market during financial crises. Journal of Financial Economics, 105, 18-36.

Friewald, N., Jankowitsch, R., and Subrahmanyam, M. G., 2012b, Liquidity, Transparency and Disclosure in the Securitized Product Market. New York University Working Paper.

Garbade, K. D., and Silber, W. L., 1976, Price dispersion in the government securities market. The Journal of Political Economy, 721-740.

Garman, M. B., 1976, Market microstructure. Journal of Financial Economics, 3(3), 257-275.

Ghysels, E., Idier, J., Manganelli, S., and Vergote, O., 2013, A high frequency assessment of the ECB securities markets. University of North Carolina Working Paper. 
Glosten, L. R., and Milgrom, P. R., 1985, Bid, ask and transaction prices in a specialist market with heterogeneously informed traders. Journal of Financial Economics, 14(1), 71-100.

Goyenko, R., Subrahmanyam, A., and Ukhov, A., 2011, The term structure of bond market liquidity and its implications for expected bond returns. Journal of Financial and Quantitative Analysis, 46(1), 111-139.

Greene, W. H., 2012, Econometric Analysis, Seventh Edition, Pearson.

Hansen, B., 1996, Inference when a nuisance parameter is not identified under the null hypothesis. Econometrica, 64(2), 413-430.

Hansen, B., 1997, Approximate asymptotic p values for structural-change tests. Journal of Business \& Economic Statistics, 15(1), 60-67.

Hansen, B., 1999, Threshold effects in non-dynamic panels: Estimation, testing, and inference. Journal of Econometrics, 93, 345-368.

Hansen, B., 2000, Sample Splitting and Threshold Estimation. Econometrica, 68(3), 575-603.

He, Z., and Milbradt, K., 2014, Endogenous liquidity and defaultable bonds. Econometrica, 82(4), 1443-1508.

Ho, T., and Stoll, H. R., 1980, On dealer markets under competition. The Journal of Finance, 35(2), 259-267.

Jankowitsch, R., Nagler, F., and Subrahmanyam, M., 2014, The determinants of recovery rates in the US corporate bond market. Journal of Financial Economics, 114(1), 155-177.

Jankowitsch, R., Nashikkar, A., and Subrahmanyam, M., 2011, Price dispersion in OTC markets: A new measure of liquidity. Journal of Banking and Finance, 35, 343-357.

Kyle, A. S., 1985, Continuous auctions and insider trading. Econometrica, 1315-1335.

Lin, H., Wang, J., and Wu, C., 2011, Liquidity risk and expected corporate bond returns. Journal of Financial Economics, 99, 628-650.

Lütkepohl, H., 1993, Introduction to Multiple Time Series Analysis, Second Edition, Springer-Verlag.

Mahanti, S., Nashikkar, A., Subrahmanyam, M., Chacko, G., and Mallik, G., 2008, Latent liquidity: A new measure of liquidity, with an application to corporate bonds. Journal of Financial Economics, $88,272-298$.

Mesters, G., Schwaab, B., and Koopman, S. J., 2014, A Dynamic Yield Curve Model with Stochastic Volatility and Non-Gaussian Interactions. Working Paper.

Nashikkar, A., Subrahmanyam, M., and Mahanti, S., 2011, Liquidity and arbitrage in the market for credit risk. Journal of Financial and Quantitative Analysis, 46, 627-656. 
Pasquariello, P., Roush, J., and Vega, C., 2011, Government Intervention and Strategic Trading in the U.S. Treasury Market. University of Michigan Working Paper.

Pasquariello, P., and Vega, C., 2006, Informed and Strategic Order Flow in the Bond Markets. Board of Governors of the Federal Reserve System Working Paper.

Pelizzon, L., Subrahmanyam, M., Tomio, D., and Uno, J., 2013, The Microstructure of the European Sovereign Bond Market: A Study of the Euro-zone Crisis. New York University Working Paper.

Ronen, T., and Zhou, X., 2009, Where Did All the Information Go? Trade in the Corporate Bond Market. Rutgers University Working Paper.

Sadka, R., 2010, Liquidity risk and the cross-section of hedge-fund returns. Journal of Financial Economics, 98(1), 54-71.

Vickery, J. I., and Wright, J., 2010, TBA Trading and Liquidity in the Agency MBS Market. Federal Reserve Bank of New York. 


\section{Internet Appendix}

\section{Int.I BTP Primary Market Participation}

This section addresses the issue of the primary market liquidity. It could be expected that the deterioration of the secondary market liquidity that was experienced in the Italian bond market in 2011 was driven by a low degree of participation in the bond primary auctions. Figure Int.1 shows the ratio of the quantity requested by market participants to the quantity assigned by the Italian Treasury at the initial issuances and further re-openings of the 10-year on-the-run bond. The quantity requested is always at least $18 \%$ larger than the quantity the Treasure assigned, showing that market participants never deserted the auctions and that the primary market never suffered from a lack of liquidity, not even in the re-opening auctions taking place months after the issuance. In only 4 out of the 19 auctions did the Treasury issue less than $99 \%$ of the maximum amount they declared they would issue, meaning that in only 4 cases did the Treasury decide to issue an amount lower than the amount that would have completely cleared the double auction (participants bid in yield and quantity) at a yield the Treasury was willing to accept.

Ratio of Quantity Requested and Quantity Assigned in Primary Auctions

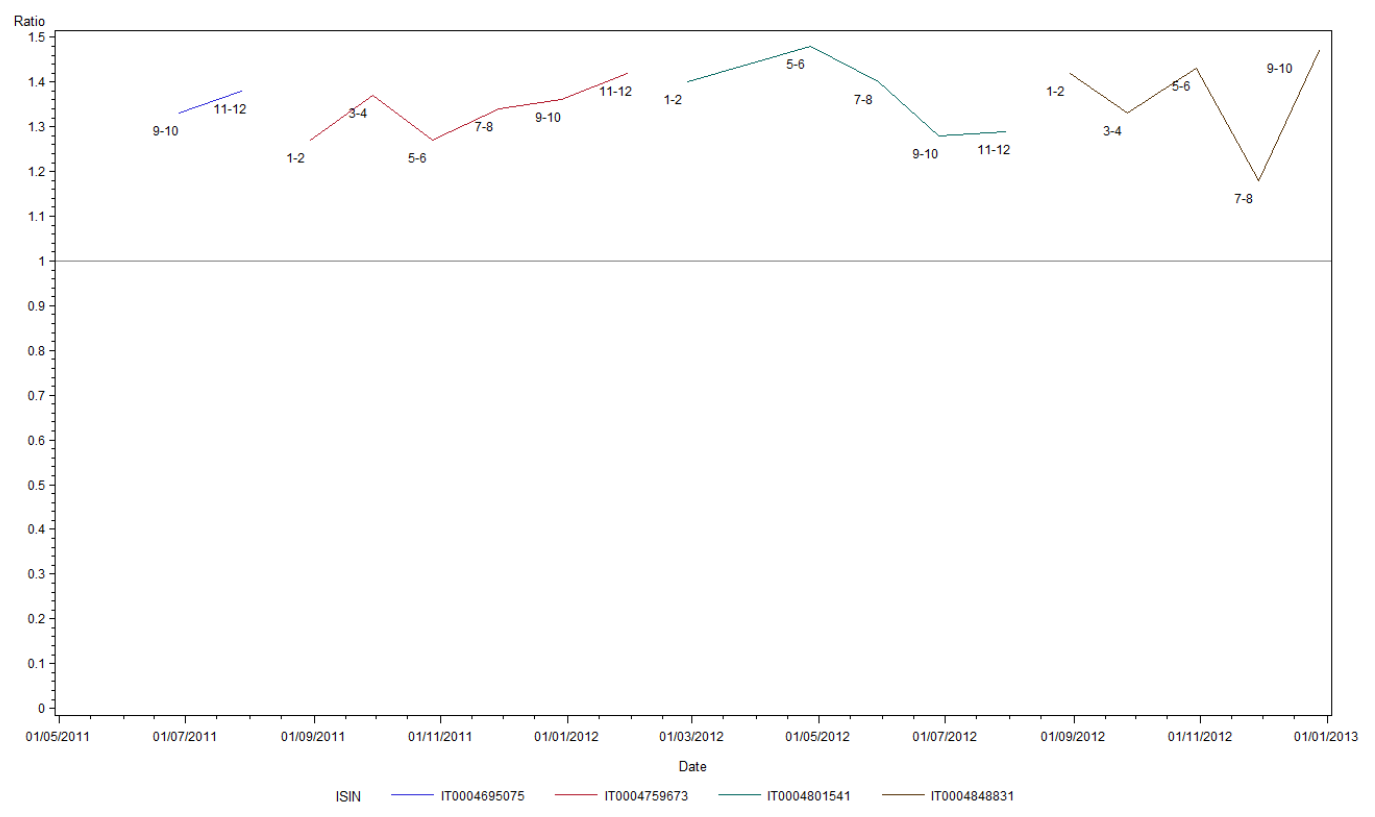

Figure Int.1: This graph presents the ratio of the quantity requested by the market participants to the quantity assigned by the Italian Treasury in the primary auctions (and re-openings) of the 10-year on-the-run bond. The graph spans our sample period of June 1, 2011 to December 31, 2012 and indicates the ISIN of the on-the-run bonds and the number of the re-opening, from the issuing (1) to eleventh re-opening (12). 


\section{Int.II Yield Spread - CDS Dynamics}

In this section, we address the concern that between the CDS spread and the BTP yield spread with the German government bond counterpart, two alternative measures of credit risk, there exists a leadlag relationship or, alternatively, that the credit risk discovery happens first in one of the markets and is then transmitted to the other. Figure Int.2 shows that the two measures are very highly correlated in the changes $(79 \%)$, confirming that the two measures do indeed comove to a very high extent.

\section{Scatterplot of CDS and Yield Spread Changes}

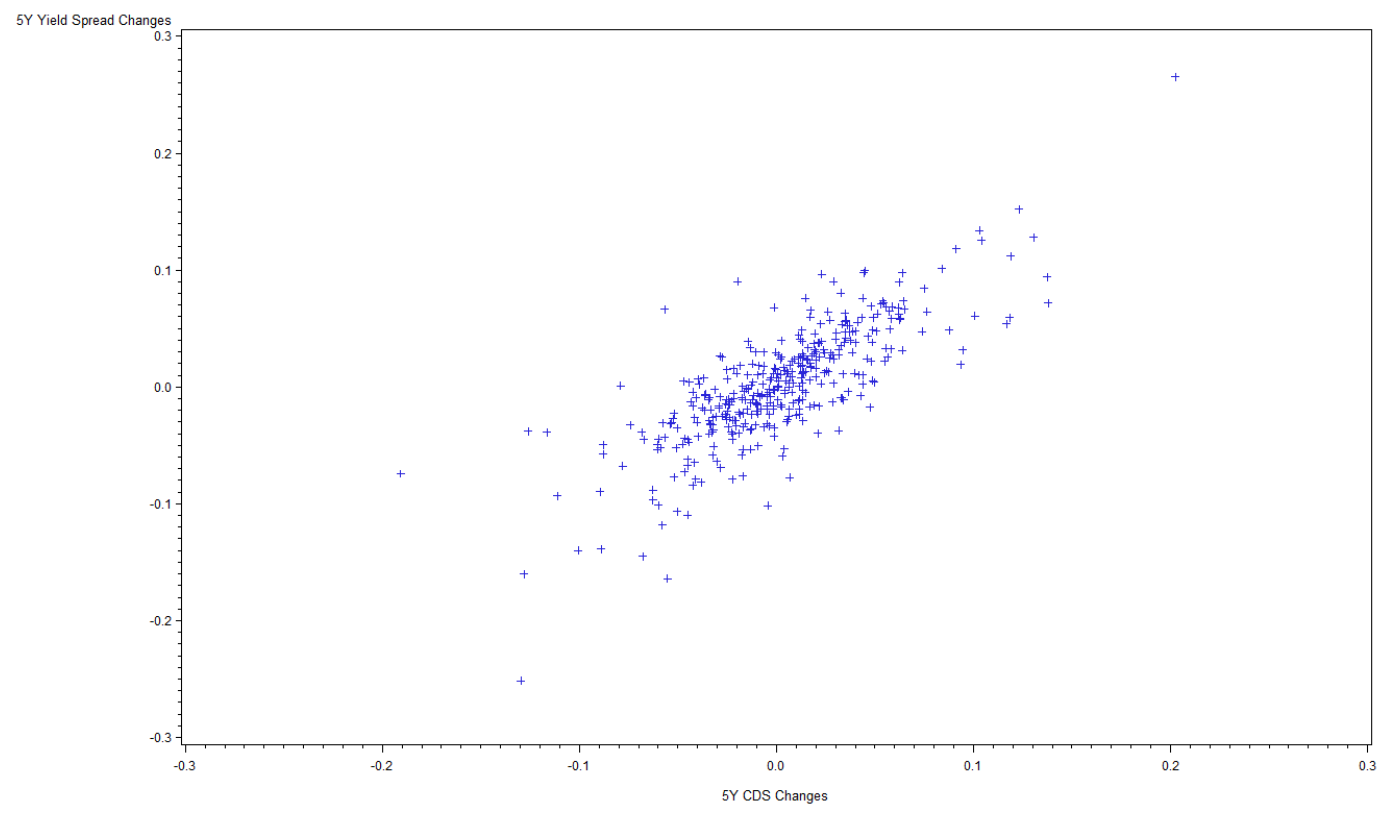

Figure Int.2: The bond yield spread is calculated between the Italian and German bonds with five years to maturity. The CDS Spread is the spread for a five-year US-denominated CDS contract. All data were obtained from Bloomberg and span our data sample, June 1, 2011 to December 31, 2012.

To address the goal of determining the dynamics between the two measures, we perform a VARX $(1,0)$ analysis of the measures $\triangle C D S_{t}$, the change in CDS spread, and $\Delta Y S_{t}$, the change in yield spread to the German bund, augmented with the exogenous variables $\triangle C C B S S_{t}$ and $\triangle U S V I X_{t}$. Table Int.2 shows the results of the analysis: There exists no lead-lag relationship between CDS and yield spread, as the Granger-causality panel shows. The contemporaneous residuals correlation, however, is very high $(74 \%)$, suggesting that, if credit risk is indeed incorporated in one market first and then transmitted to the other, the credit risk transmission takes place within the same day. These results suggest that, when performing an analysis using daily data, the credit risk discovery dynamics should not be a concern, for example when determining the dynamics of credit risk and liquidity as in the case of this study. 
Table Int.1: Results for the Granger-Causality Analysis of Italian CDS Spread and Yield Spread. This table presents the results for the regressions of the day $t$ changes in $C D S$ Spread $\Delta \mathrm{CDS}_{t}$, and the Italian yield spread $\Delta Y S_{t}$, on the lagged terms of both variables. The data have a daily frequency. The significance refers to heteroskedasticityrobust $t$-tests. Heteroskedasticity-robust $F$-test statistics and their significance are reported for the null hypothesis of each variable Grangercausing the other. We also report the contemporaneous correlation in the model residuals. Our dataset consists of 393 days of trading in Italian government bonds, from July 1, 2010 to December 31, 2012. The CDS spread refers to a USD-denominated, five-year CDS spread and the yield spread refers to the spread between the five-year notch of the Italian term structure and its German counterpart. Both variables are obtained from Bloomberg.

\begin{tabular}{l|ll}
\hline Variable & $\Delta C D S_{t}$ & $\Delta Y S_{t}$ \\
\hline Intercept & 0.001 & 0.001 \\
$\Delta C D S_{t-1}$ & 0.088 & -0.030 \\
$\Delta Y S_{t-1}$ & 0.080 & $0.149^{*}$ \\
$\Delta$ CCBSS $_{t}$ & $0.266^{* * *}$ & $0.210^{* * *}$ \\
$\Delta$ USVIX $_{t}$ & $0.152^{* * *}$ & $0.187^{* * *}$ \\
\hline \multicolumn{3}{c}{ Granger-Causality Tests } \\
\hline$Y S \stackrel{G C}{\longrightarrow} C D S$ & 0.892 & $\cdot$ \\
$C D S \stackrel{G C}{\longrightarrow} Y S$ & $\cdot$ & 0.149 \\
\hline \multicolumn{3}{c}{ Residuals Correlation } \\
\hline$\Delta B A_{t}$ & 1.000 & 0.741 \\
$\Delta C D S_{t}$ & 0.741 & 1.000 \\
\hline
\end{tabular}

${ }^{*}$ Significant at a $10 \%$ level. ${ }^{* *}$ Significant at a $5 \%$ level. ${ }^{* * *}$ Significant at a $1 \%$ level. 


\section{Int.III Average Bid-Ask Spread and Bond Heterogeneity}

In this section, we address the usage of the equally weighted average of the quoted bonds' bid-ask spread as a measure of market-wide liquidity. Figure Int.3 (Int.4) reports the evolution of the (log of the) daily median bid-ask spread of each category of bonds throughout our sample period.

Figure Int.3 shows that the magnitude of the bid-ask spread is heterogeneous in the categories. However, Figure Int.4 proves that the time-series dynamics of the median liquidity are the same across different categories.

Finally, comparing Figures Int.3 and 2 shows that the evolution of the market-wide liquidity measure is strikingly similar to those of the median bid-ask spread of each bond category. The relative importance of each bond category does not vary in our time sample, so we conclude that the market-wide average bid-ask spread is a fair representation of the overall market liquidity, despite the heterogeneity in bid-ask spreads across categories.

Evolution of the Median Bid-Ask Spread by Bond Type

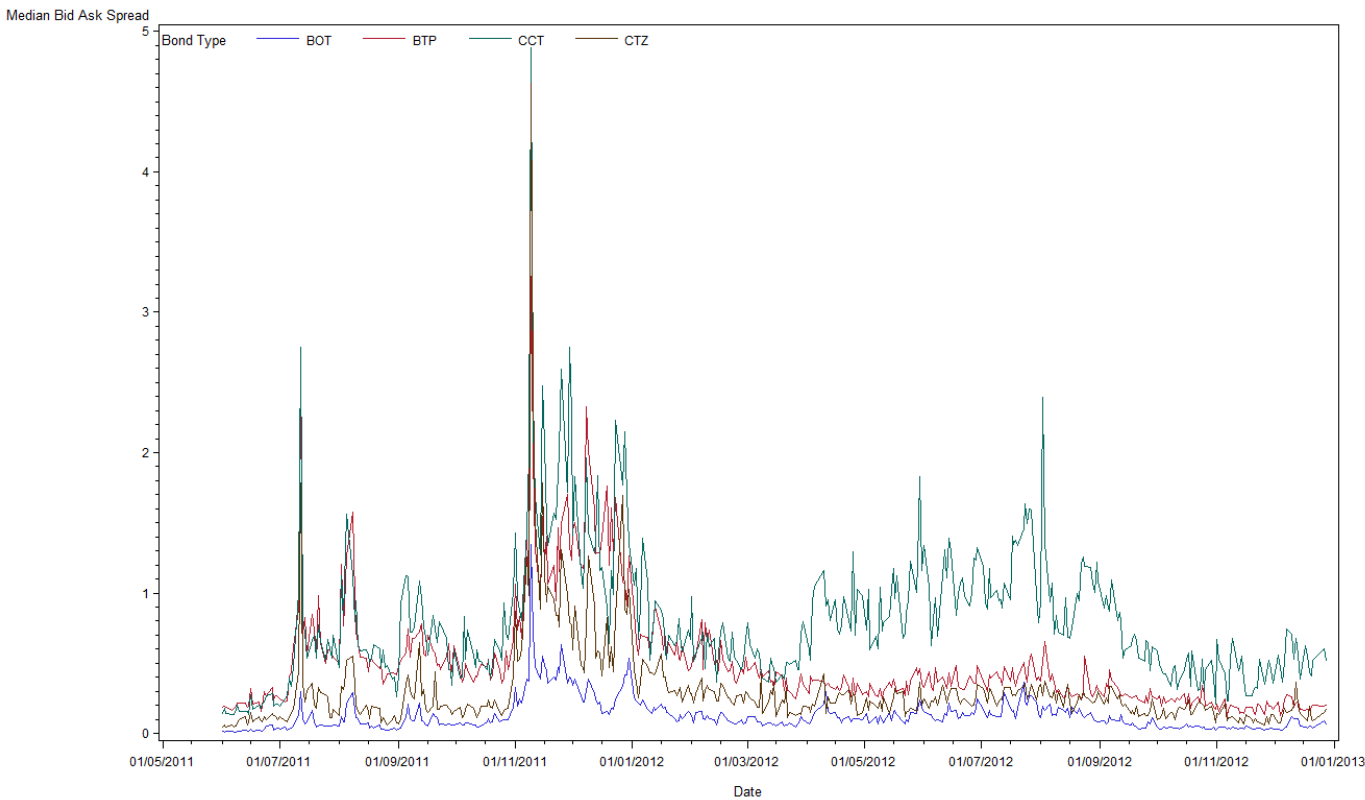

Figure Int.3: The median quoted bid-ask spreads for different bond types is obtained from the MTS data, and spans our sample period of June 1, 2011 to December 31, 2012. 
Evolution of the Log-Median Bid-Ask Spread by Bond Type

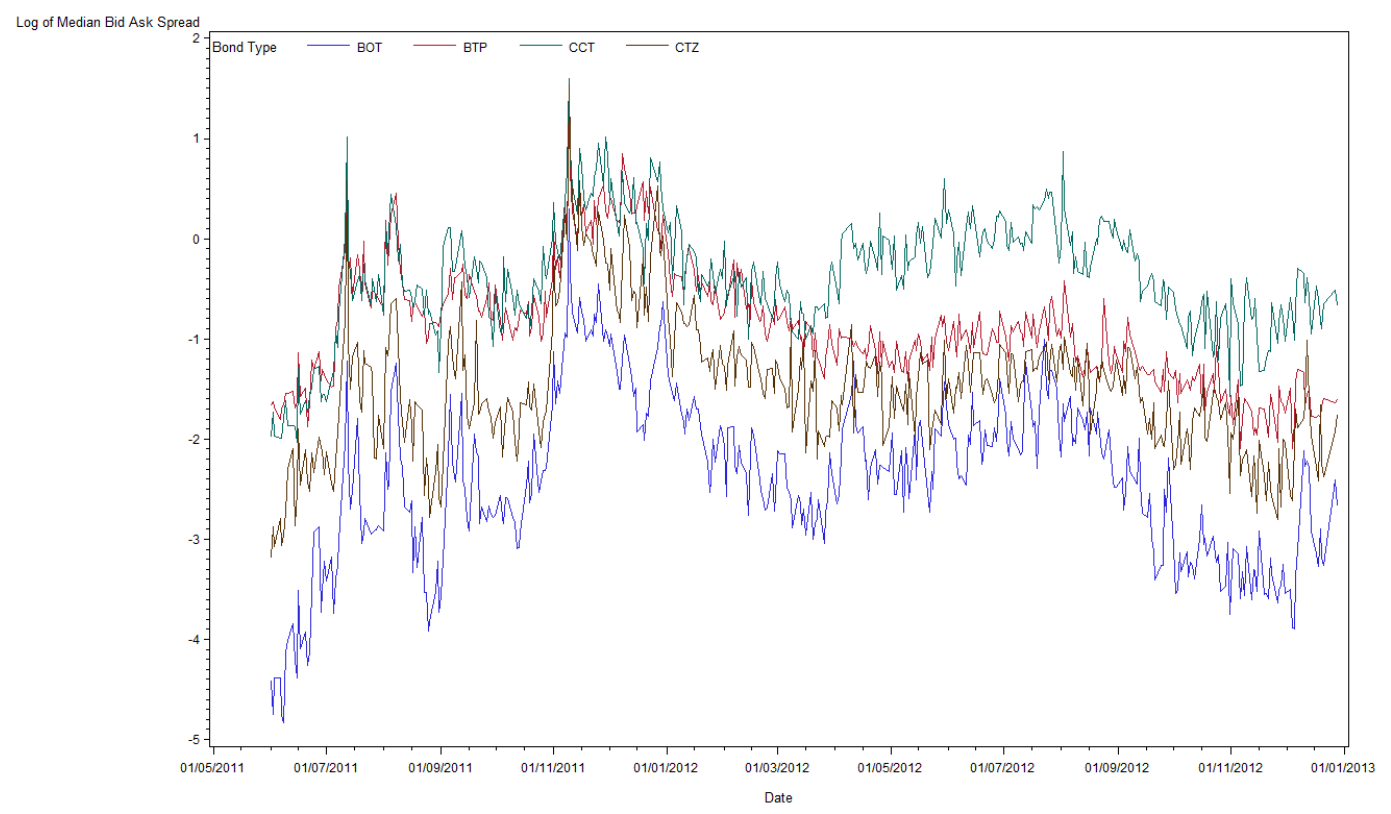

Figure Int.4: The log-median quoted bid-ask spreads for different bond types is obtained from the MTS data, and spans our sample period of June 1, 2011 to December 31, 2012. 


\section{Int.IV Granger-Causality below CDS Threshold}

Table Int.2: Results for the Granger-Causality Analysis of Italian CDS Spread and Bond Liquidity when below the Threshold. This table presents the results for the regressions of the day $t$ changes in $C D S$ Spread $\triangle \mathrm{CDS}_{t}$, and the Italian bond market bid-ask spread $\triangle B A_{t}$, on the lagged terms of both variables. The data have a daily frequency. The significance refers to heteroskedasticity-robust $t$-tests. Heteroskedasticity-robust $F$-test statistics and their significance levels are reported for the null hypothesis of each variable Granger-causing the other. We also report the contemporaneous correlation in the model residuals. Our dataset consists of 307 days of trading in Italian government bonds, between July 1, 2010 and December 31, 2012, when the CDS level is above the threshold found in Section VI.II The CDS spread refers to a USD-denominated, five-year CDS spread and the yield spread refers to the spread between the five-year notch of the Italian term structure and its German counterpart. Both variables were obtained from Bloomberg.

\begin{tabular}{l|ll}
\hline Variable & $\Delta B A_{t}$ & $\Delta C D S_{t}$ \\
\hline Intercept & 0.003 & 0.000 \\
$\Delta C D S_{t-1}$ & $1.311^{* * *}$ & $0.173^{* *}$ \\
$\Delta B A_{t-1}$ & $-0.334^{* * *}$ & -0.009 \\
$\Delta C D S_{t-2}$ & -0.129 & $-0.092^{*}$ \\
$\Delta B A_{t-2}$ & $-0.1540^{* *}$ & -0.001 \\
$\Delta C D S_{t-3}$ & 0.260 & 0.049 \\
$\Delta B A_{t-3}$ & $-0.160^{* *}$ & 0.001 \\
$\Delta$ CBSS $_{t}$ & $0.502^{* *}$ & $0.271^{* * *}$ \\
$\Delta$ USVIX $_{t}$ & 0.243 & $0.143^{* *}$ \\
\hline
\end{tabular}

Granger-Causality Tests

\begin{tabular}{l|cc}
\hline$C D S \stackrel{G C}{\longrightarrow} B A$ & $18.34^{* * *}$ & . \\
$B A \stackrel{G C}{\longrightarrow} C D S$ &. & 0.34 \\
\hline
\end{tabular}

\begin{tabular}{l|ll}
\hline \multicolumn{3}{c}{ Residuals Correlation } \\
\hline$\Delta B A_{t}$ & 1.000 & 0.030 \\
$\Delta C D S_{t}$ & 0.030 & 1.000 \\
\hline
\end{tabular}

${ }^{*}$ Significant at a $10 \%$ level. ${ }^{* *}$ Significant at a $5 \%$ level. ${ }^{* * *}$ Significant at a $1 \%$ level. 


\section{Int.V Using Bloomberg Data}

In this section, we repeat part of the analysis using the bid-ask spread for the 10-year on-the-run (OTR) bond and compare the results obtained when using the bid-ask spread obtained from MTS and from Bloomberg. Figure Int.5 shows the evolution of the bid-ask spread for the 10-year OTR as obtained from Bloomberg (red) and MTS (blue), while Figure Int.6 shows the scatterplot of the daily changes of the two measures. The correlation of the bid-ask spreads from the two sources is $57 \%$ in the level and $0.8 \%$ in the differences.

\section{Evolution of MTS and Bloomberg Bid-Ask Spread for the 10Y OTR Bond}

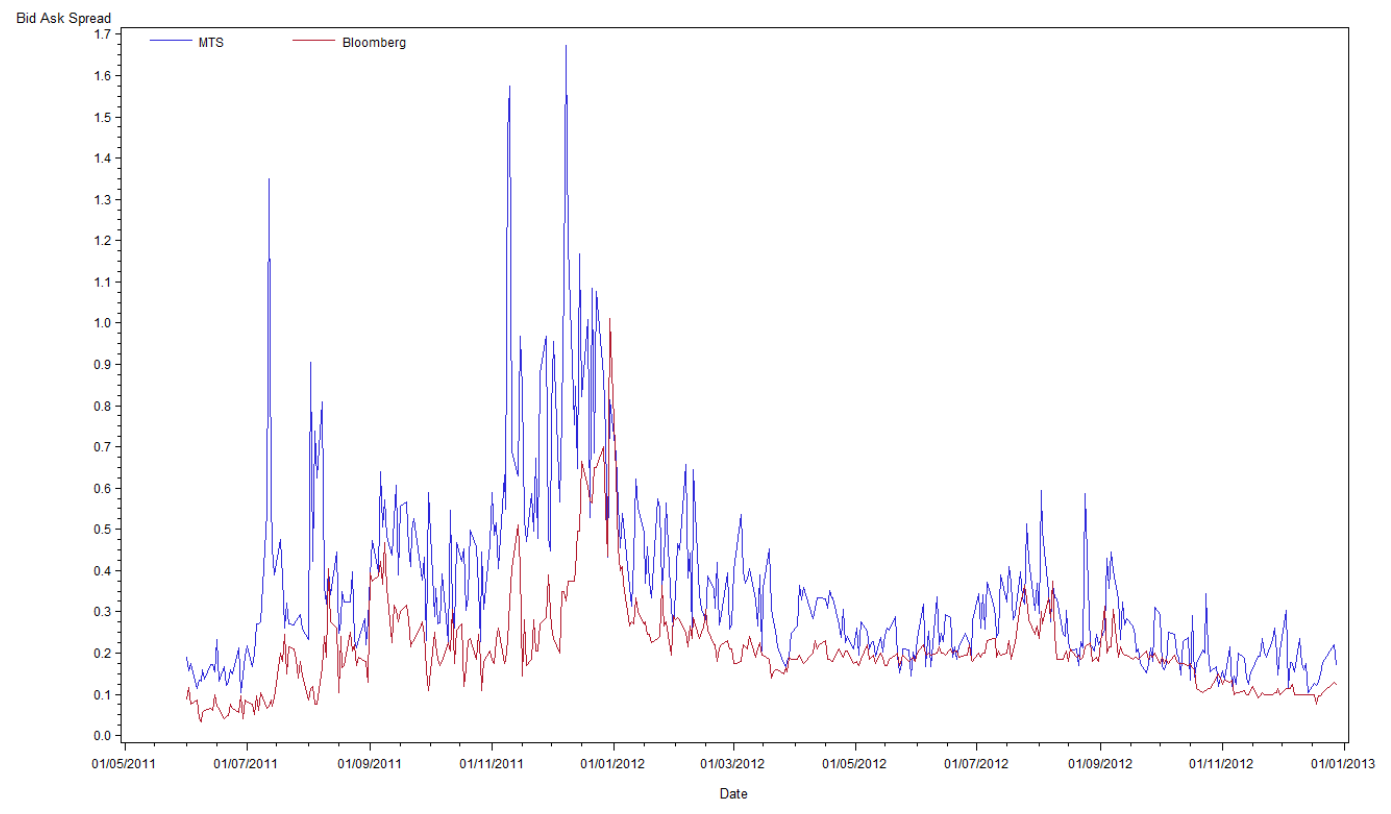

Figure Int.5: The quoted bid-ask spreads for the 10-year on-the-run BTP are obtained from Bloomberg (in red) and MTS (in blue), and span our sample period of June 1, 2011 to December 31, 2012.

The reasons why the two measures differ are as follows: (i) Bloomberg only provides end-of-day measures, while our measure from MTS data reflects the overall daily liquidity. (ii) Bloomberg does not have a minimum quantity to which the quotes they collect need to abide, which, together with the fact that (iii) Bloomberg collects data from all market actors, including e.g. retail investors, means that the quotes represent the liquidity of two different markets, with the MTS being the measure of the liquidity provided to and by market makers. Nonetheless, the null correlation between the changes in the two liquidity measures is remarkable, and potentially worrisome.

In Table Int.3 we report the analysis from Table 5, Panel B, where, instead of the MTS marketwide liquidity measure, we use the 10-year OTR bid-ask spread obtained from Bloomberg (Panel A) and MTS (Panel B). The CDS spread has no power in explaining the bid-ask spread obtained from Bloomberg, while the significance and the magnitude of the effect of a change in CDS spread on the change of the OTR bid-ask spread obtained from MTS are similar to those for the overall market liquidity (cf. Table 5, Panel B). 
Scatterplot of Changes in MTS and Bloomberg Bid-Ask Spread for the 10Y OTR Bond

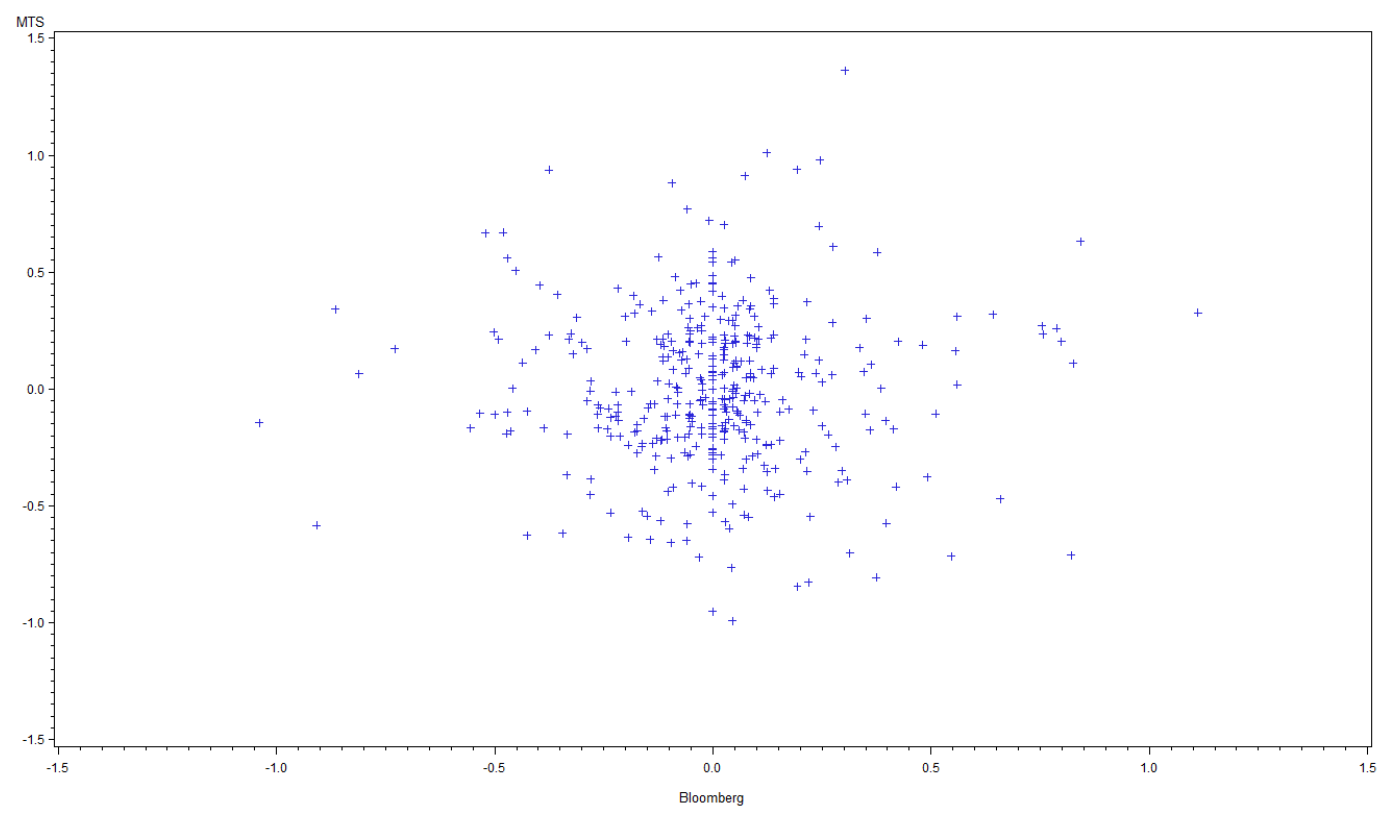

Figure Int.6: This graph shows the scatterplot of changes in quoted bid-ask spread for the 10-year on-the-run BTP obtained from Bloomberg and that obtained from MTS. The sample spans June 1, 2011 to December 31, 2012. 
Table Int.3: Results for the Regression of the Bid-Ask Spread on CDS Spread and Macro Variables. This table presents the results for the regression of the change in the Bid-Ask Spread (the change in the quoted bid-ask spread) on day $t, \Delta \mathrm{BA}_{t}$, on its lagged terms, and on the change in the CDS spread on day $t, \Delta \mathrm{CDS}_{t}$, and its lagged terms and on macro variables, using daily data. The regressions are presented for Equations 2 , 3 , and 4 in Panels A, B, and C, respectively. Parameters multiplying the identity operator $[C D S \leq(>) 500]$ are reported under the $[C D S \leq(>) 500]$ column. The statistical significance refers to heteroskedasticity-robust $t$-tests. The Test columns report the heteroskedasticity-robust test for whether the two parameters above and below the threshold are equal and distributed as chi-square(1). Our dataset consists of 406 days of trading in Italian government bonds, from June 1, 2011 to December 31, 2012, and is obtained from the Mercato dei Titoli di Stato (MTS) Global Market bond trading system. The CDS spread refers to a USD-denominated, five-year CDS spread and the macro variables were obtained from Bloomberg.

\begin{tabular}{l|ll|ll}
\hline \multirow{2}{*}{ Variable } & \multicolumn{2}{|c|}{ Panel A: Bloomberg } & \multicolumn{2}{c}{ Panel B: MTS } \\
& $\mathrm{I}[\mathrm{CDS} \leq 500]$ & $\mathrm{I}[\mathrm{CDS}>500]$ & $\mathrm{I}[\mathrm{CDS} \leq 500]$ & $\mathrm{I}[\mathrm{CDS}>500]$ \\
\hline$\Delta \mathrm{CDS}_{t}$ & 0.084 & 1.241 & -0.253 & $2.646^{* *}$ \\
$\Delta \mathrm{CDS}_{t-1}$ & 0.076 & -0.734 & $0.909^{*}$ & 0.922 \\
& & & & \\
$\Delta \mathrm{BA}_{t-1}$ & $-0.451^{* * *}$ & $-0.311^{*}$ & $-0.571^{* * *}$ & -0.470 \\
$\Delta \mathrm{BA}_{t-2}$ & $-0.197^{* * *}$ & -0.133 & $-0.317^{* * *}$ & $-0.326^{* * *}$ \\
$\Delta \mathrm{BA}_{t-3}$ & -0.135 & 0.044 & $-0.160^{* * *}$ & $-0.218^{* *}$ \\
$\Delta \mathrm{CCBSS}_{t}$ & $0.548^{*}$ & -0.563 & $0.721^{* *}$ & -0.822 \\
$\Delta \mathrm{USVIX}_{t}$ & 0.013 & -0.274 & 0.329 & 0.478 \\
Intercept & -0.001 & 0.016 & 0.002 & -0.018 \\
\hline
\end{tabular}

${ }^{*}$ Significant at a $10 \%$ level. ${ }^{* *}$ Significant at a $5 \%$ level. ${ }^{* * *}$ Significant
at a $1 \%$ level. 


\section{Int.VI CDS Market Liquidity}

In this section, we address the potential issue of a liquidity premium priced in the CDS spread. We replicate the analysis from Section VI.I by adding a third endogenous variable, $\triangle C D S B A_{t}$, the change in the daily bid-ask spread for a CDS contract ${ }^{47}$ We construct this measure by averaging bid-ask spread observations sampled at a five-minute frequency from high-frequency CDS quotes obtained from CMA. Figure Int.7 shows the time-series of CDS liquidity, Table Int.4 shows the Granger-causality results for the $\operatorname{VARX}(5,0)$, and Figure Int.8 shows the IRFs for the system (after standardizing the variables).

While the Granger-causality from the CDS spread to the other two variables is the most significant, the causation from the liquidity of the CDS market to the other two variables is also significant at the $5 \%$ level. However, the IRFs show that the prior finding that a change in the CDS spread significantly affects the bond market bid-ask spread is unchanged. A change in CDS liquidity has only a marginally statistically significant effect on the liquidity of the bond market two days after the shock, and on the level of the CDS spread one day after the shock, both with a negative sign. A shock to the CDS liquidity negatively affect the CDS spread, which is contrary to the intuition of liquidity being priced. The inclusion of the CDS spread in the VAR system does not, thus, affect our conclusion regarding the dynamic relationship between credit risk and market liquidity.

On the other hand, Table Int.4 shows that the residual correlation is high between the liquidity of the bond and CDS markets, and one might be concerned that the CDS level was capturing the CDS liquidity, although the residual correlation of the latter two is low. In Table Int.5 we repeat the analysis of Table 5 Panel B, including the liquidity of the CDS market as one of the explanatory variables. We allow all parameters to depend on the level of CDS, and Figure Int.9 reports the threshold confidence band test of Figure 8 . The threshold selected by the procedure is very close to that selected the first time we performed the analysis (496.31 vs. 496.55), although the confidence band around it is rather large. However, Table Int.5 shows that, as in the main analysis, the threshold effect follows from the different dynamics between the liquidity and the CDS spread and not from the effect of the CDS liquidity, since the parameters for the CDS liquidity when the CDS is above and below the threshold are very close (0.522 and 0.498), and not statistically different. We conclude, thus, that although the liquidity of the CDS market is significantly partially correlated with the liquidity of the bond market (as the literature of commonality in liquidity would suggest) the inclusion of the CDS liquidity does not invalidate any of the results in the main part of the study regarding the relationship between credit risk and market liquidity.

\footnotetext{
${ }^{47}$ The CDS bid-ask spread dataset includes only 391 days that overlap with our original dataset.
} 


\section{CDS Contract Bid-Ask Spread}

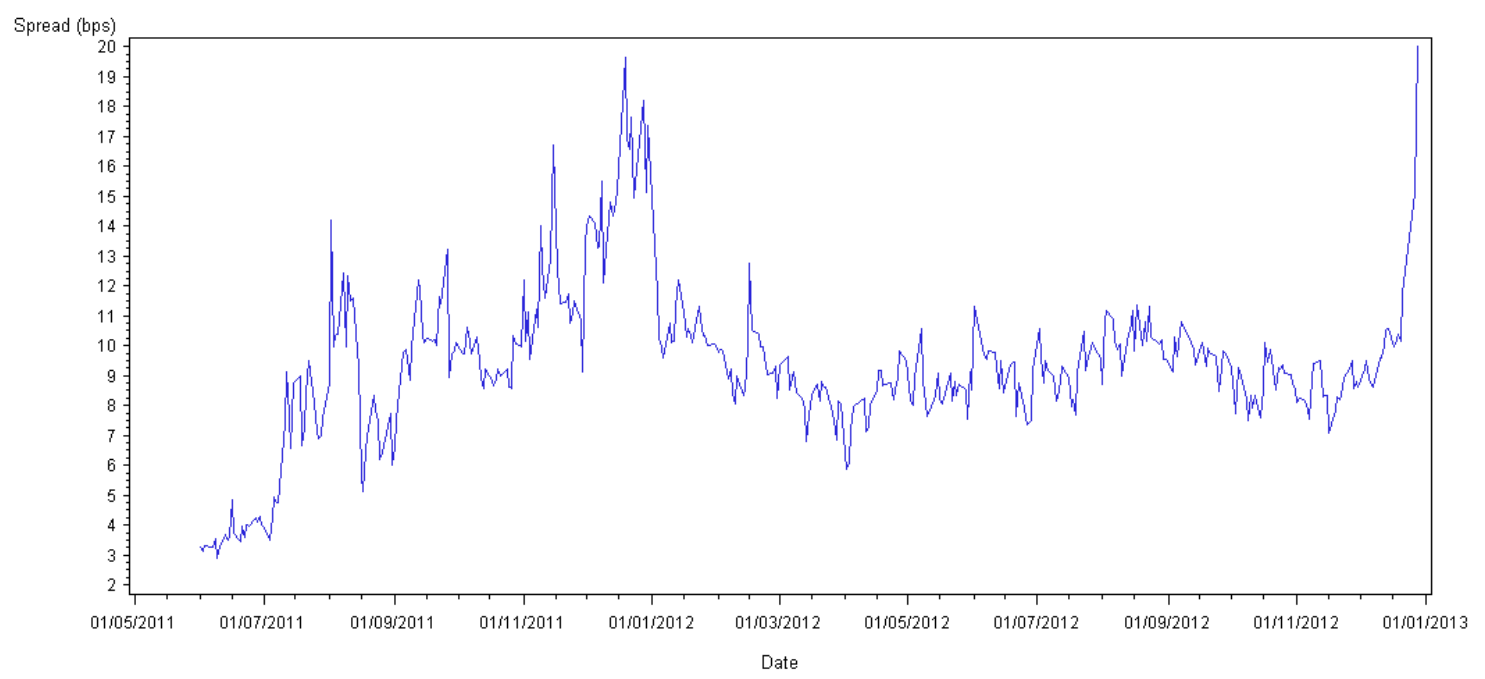

Figure Int.7: The daily average absolute bid-ask spread for the CDS contract was obtained from the CMA data, and spans our sample period of June 1, 2011 to December 31, 2012.

Table Int.4: Results for the Granger-Causality Analysis of Italian CDS Spread, Bond Liquidity, and CDS Liquidity. This table presents the results for the regressions of the day $t$ changes in $C D S$ Spread $\Delta \mathrm{CDS}_{t}$, the Italian bond market bid-ask spread $\Delta B A_{t}$, and the Italian CDS bid-ask spread $\triangle B A C D S_{t}$ on their lagged terms and the contemporaneous changes in CCBSS and USVIX. The data have a daily frequency. Heteroskedasticity-robust $F$-test statistics and their significance levels are reported for the null hypothesis of each variable Granger-causing the others. We also report the contemporaneous correlation in the model residuals. Our dataset consists of 406 days of trading in Italian government bonds, between July 1, 2010 and December 31, 2012. The CDS spread and bid-ask spread refer to a USD-denominated, five-year CDS spread. The CDS spread was obtained from Bloomberg, the CDS bidask spread from CMA, and the bond market bid-ask spread from MTS data.

\begin{tabular}{l|ccc}
\hline \multicolumn{4}{c}{ Granger-Causality Tests } \\
\hline$C D S \stackrel{G C}{\longrightarrow} B A \& B A C D S$ & $2.53^{* * *}$ & $\cdot$ & $\cdot$ \\
$B A \stackrel{G C}{\longrightarrow} C D S \& B A C D S$ & $\cdot$ & 0.90 & $\cdot$ \\
$B A C D S \stackrel{G C}{\longrightarrow} B A \& B A C D S$ &. & $\cdot$ & $2.32^{* *}$ \\
\hline
\end{tabular}

\begin{tabular}{l|lll}
\hline \multicolumn{4}{c}{ Residuals Correlation } \\
\hline & $\Delta C D S_{t}$ & $\Delta B A_{t}$ & $\Delta B A C D S_{t}$ \\
\hline$\triangle C D S_{t}$ & 1.000 & 0.098 & 0.109 \\
$\Delta B A_{t}$ & 0.098 & 1.000 & 0.369 \\
$\triangle B A C D S_{t}$ & 0.109 & 0.369 & 1.000 \\
\hline
\end{tabular}

${ }^{*}$ Significant at a $10 \%$ level. ${ }^{* *}$ Significant at a $5 \%$ level. ${ }^{* * *}$ Significant at a $1 \%$ level. 
Impulse Response from BondBidAskSpread

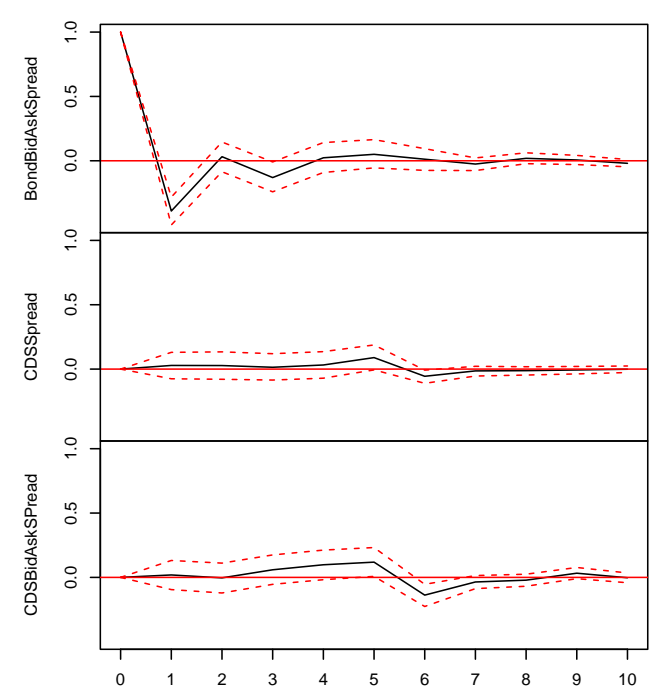

$95 \%$ Bootstrap $\mathrm{Cl}, 5000$ runs
Impulse Response from CDSSpread

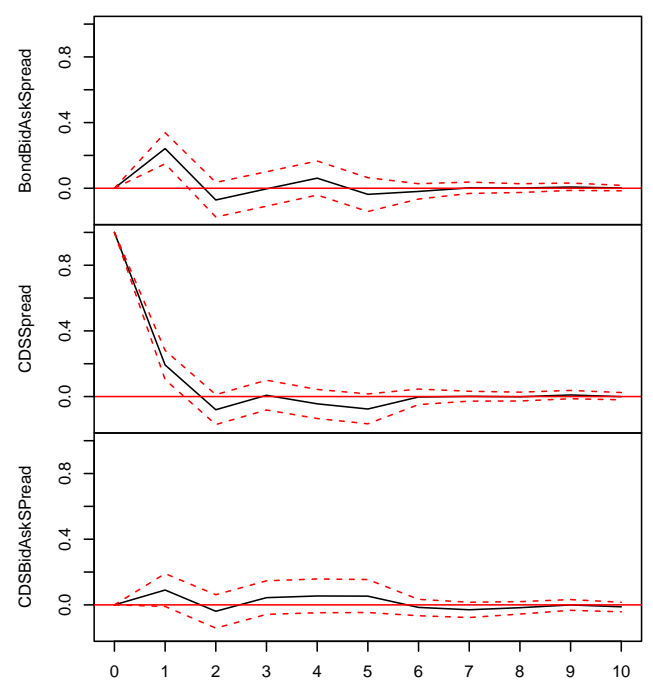

$95 \%$ Bootstrap $\mathrm{Cl}, 5000$ runs

(b) Shock to CDS spread
Impulse Response from CDSBidAskSPread

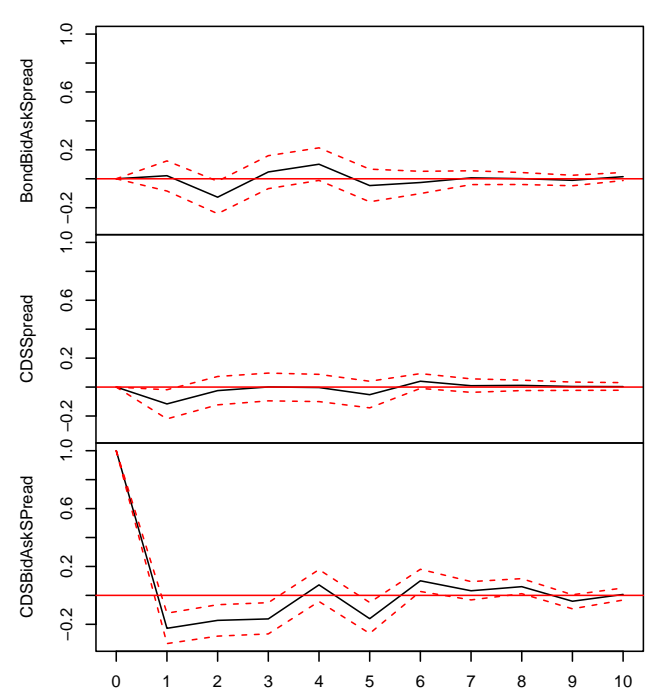

$95 \%$ Bootstrap $\mathrm{Cl}, 5000$ runs

(c) Shock to the CDS market liquidity

Figure Int.8: Impulse Response Functions for the VARX(5,0) System of Section Int.VI. This graph shows the evolution of the impulse response functions to a shock in the bond market liquidity, as measured by the Bid-Ask spread, the CDS spread, and the CDS bid-ask spread, in Panels (a), (b), and (c) respectively. Our dataset consists of transactions, quotes, and orders for all 152 fixed-rate and floating Italian government bonds and quotes for the CDS spread, from June 1, 2011 to December 31, 2012 
Table Int.5: Results for the Regression of the Bid-Ask Spread on CDS spread and Macro variables and CDS Liquidity. This table presents the results for the regression of the change in the Bid-Ask Spread (the change in the quoted bid-ask spread) on day $t, \Delta \mathrm{BA}_{t}$, on its lagged terms, and on the change in the CDS spread on day $t, \Delta \mathrm{CDS}_{t}$, and its lagged terms, using daily data for the Bid-Ask Spread and the CDS spread. The statistical significance refers to heteroskedasticity-robust $t$-tests. The Test columns report the heteroskedasticity-robust test result for whether the two parameters above and below the threshold are equal and distributed as chi-square(1). Our dataset consists of 391 days of trading in Italian government bonds, from June 1, 2011 to December 31, 2012, and was obtained from the Mercato dei Titoli di Stato (MTS) Global Market bond trading system. The CDS spread refers to a USD-denominated, five-year CDS spread and the macro variables were obtained from Bloomberg.

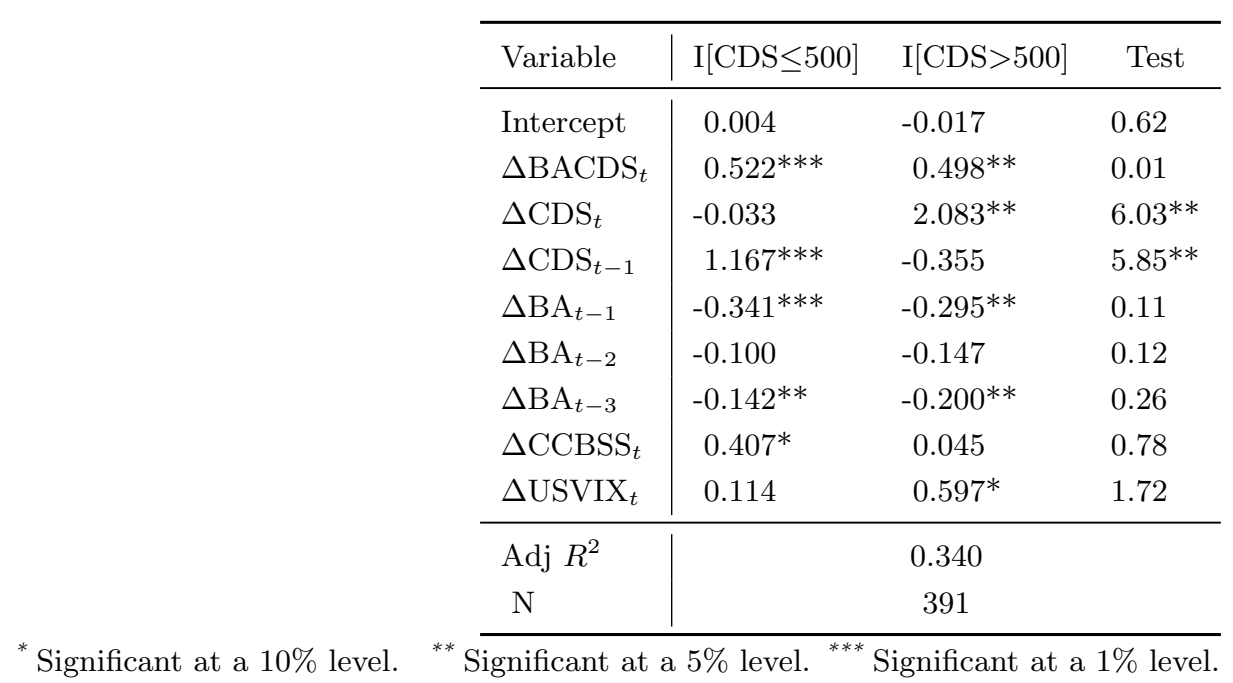

Threshold Confidence Bands. Threshold $=496.3125$

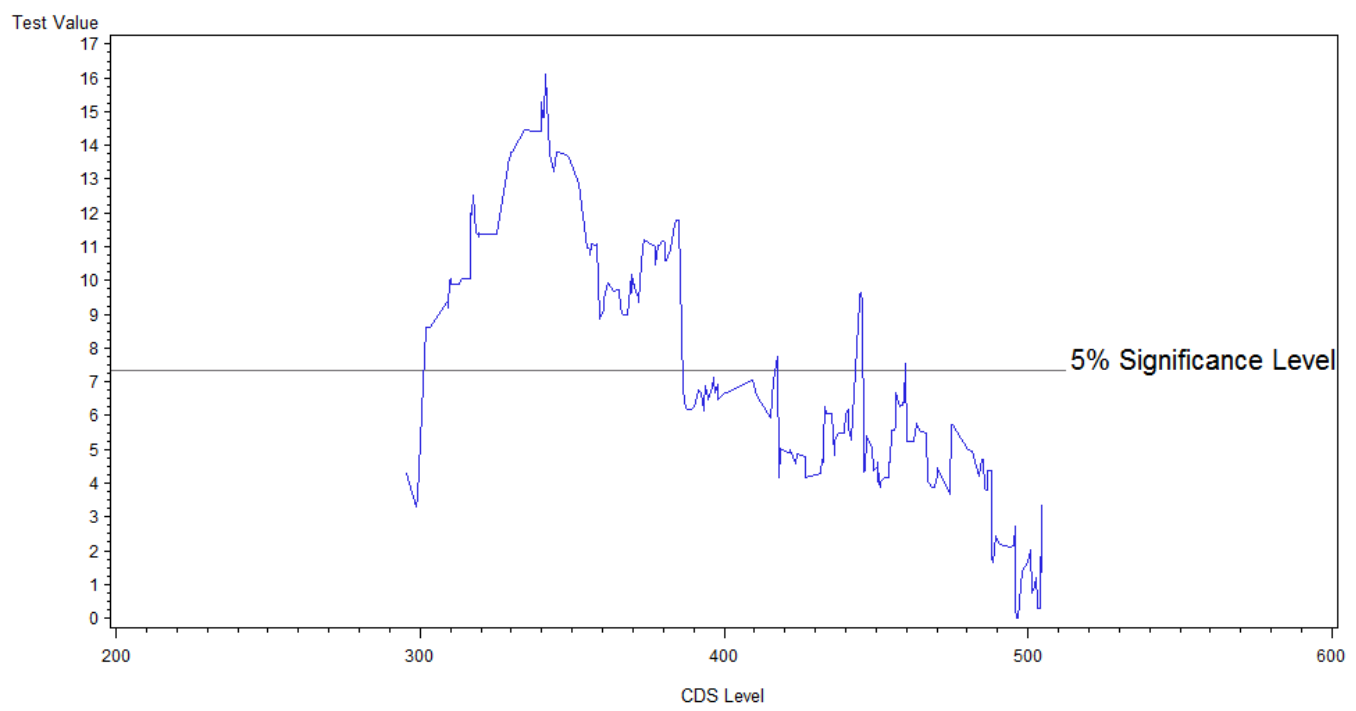

Figure Int.9: Test to Determine Confidence Bands around the CDS Threshold with the Addition of CDS Liquidity. The test statistic described in Appendix C is plotted here for the Equation 3, with the addition of CDS Liquidity. The test statistic is normalized at 0 at the threshold that minimizes the sum of squared residuals. The horizontal line at 7.35 marks the $5 \%$ confidence values for the threshold. Our dataset consists of transactions, quotes, and orders for all 152 fixed-rate and floating Italian government bonds, from June 1, 2011 to December 31, 2012. 


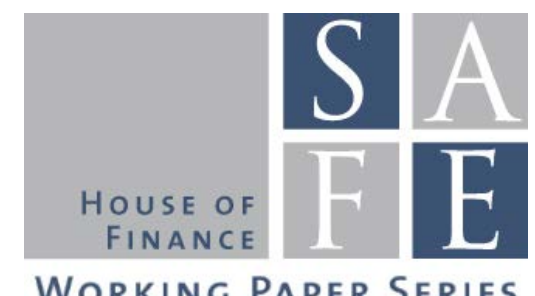

WORKING PAPER SERIES

\section{Recent Issues}

No. 94 Claudia Lambert, Felix Noth, Ulrich Schüwer

No. 93 Shafik Hebous, Tom Zimmermann

No. 92 Christoph Hambel, Holger Kraft, Eduardo S. Schwartz

No.91 Anne-Caroline Hüser

No. $90 \quad$ Pinar Topal

No. 89 Julia Braun, Alfons J. Weichenrieder

No. 88 Ester Faia, Beatrice Weder di Mauro

No. 87 Iñaki Aldasoro, Domenico Delli Gatti, Ester Faia

No. 86 Agar Brugiavini, Danilo Cavapozzi, Mario Padula, Yuri Pettinicchi

No. 85 Holger Kraft, Claus Munk, Sebastian Wagner

No. 84 Raimond Maurer, Olivia S. Mitchell, Ralph Rogalla, Tatjana Schimetschek

No. 83 Patrick Grüning

No. 82 Edgar Vogel, Alexander Ludwig, Axel Börsch-Supan

No. 81 Jens-Hinrich Binder

No. 80 Enrique G. Mendoza, Linda L. Tesar, Jing Zhang
How Do Banks React to Catastrophic Events? Evidence from Hurricane Katrina

Revisiting the Narrative Approach of Estimating Tax Multipliers

Optimal Carbon Abatement in a Stochastic Equilibrium Model with Climate Change

Too Interconnected to Fail: A Survey of the Interbank Networks Literature

Fiscal Stimulus and Labor Market Flexibility

Does Exchange of Information between Tax Authorities Influence Multinationals' Use of Tax Havens?

\section{Cross-Border Resolution of Global Banks}

Bank Networks: Contagion, Systemic Risk and Prudential Policy

Financial education, literacy and investment attitudes

Housing Habits and Their Implications for LifeCycle Consumption and Investment

Will They Take the Money and Work? An Empirical Analysis of People's Willingness to Delay Claiming Social Security Benefits for a Lump Sum

International Endogenous Growth, Macro Anomalies, and Asset Prices

Aging and Pension Reform: Extending the Retirement Age and Human Capital Formation

Resolution Planning and Structural Bank Reform within the Banking Union

Saving Europe?: The Unpleasant Arithmetic of Fiscal Austerity in Integrated Economies 